\title{
The role of climate and bed topography on the evolution of the Tasman Glacier since the Last Glacial Maximum
}

\author{
by \\ Karen Aline McKinnon
}

\begin{abstract}
A thesis submitted to the School of Geography, Environment and Earth Sciences

in partial fulfilment of the requirements for the degree of Master of Science
\end{abstract}

Antarctic Research Centre Victoria University of Wellington

June 2011 



\begin{abstract}
Mountain glaciers respond to climatic changes by advancing or retreating, leaving behind a potentially powerful record of climate through moraine deposition. Estimates of past climate have been made based on the moraine record alone, using geometrical arguments; however, these methods necessarily ignore the effects of glacier dynamics and bed modification. Here, a one-dimensional coupled mass balance-flowline model is used to place constraints on the climate of the Late-glacial (13.5-11.6 kyr ago) and Last Glacial Maximum (LGM, 28 - 17.5 kyr ago) based on the well-mapped and -dated moraines at Tasman Glacier/Lake Pukaki, South Island, New Zealand. Due to the highly-dynamic nature of the system, distinct longitudinal bed profiles are considered for each of the glaciations modelled; the reconstructions show that terminal overdeepenings are likely present in all bed profiles, and hundreds of metres of sediment has been deposited in the glacier valley since the LGM. Using the coupled model and calculated bed topography, a $2.2^{\circ} \mathrm{C}$ temperature depression from the present is necessary to reproduce the Lateglacial ice extent, and $7.0^{\circ} \mathrm{C}$ is required for the early LGM, assuming presentday precipitation. The modelled Late-glacial ice extent is more sensitive to precipitation variability than that during the LGM, but the Tasman Glacier during both periods is primarily driven by temperature changes. While the Tasman Glacier shrank between the early and late LGM, modelling demonstrates that changes in bed topography due to erosion, transport and deposition of sediment are a major driver in reduction of glacier extent; a temperature increase of only $0.1^{\circ} \mathrm{C}$ is required to cause the transition between the two periods, which may be attributable to interannual, zero-trend climate variability. Thus, the consideration of the coupled glacier-sediment system is critical in accurately reconstructing past climate. Future work focusing on modelling this coupled system, such that the bed profile can evolve interactively with glacier flow, will be critical in better resolving transient events such as the early to late LGM transition.
\end{abstract}




\section{Acknowledgements}

I would like to thank a number of people whose assistance and support helped make my thesis experience intellectually fullling and enjoyable

My greatest thanks go to Andrew Mackintosh and Brian Anderson, my

advisers. Together, they could answer questions ranging from computational efficiency to glaciological theory, and helped move this work forward by asking me the right questions.

Members of the glacier modelling group have been extremely helpful during my time at the Antarctic Research Centre. My thanks go to Nick Golledge for being willing to chat about glacier models, help me with my coding, and revise this thesis; Huw Horgan for a variety of interesting discussions about glacier behaviour and for revising this thesis; Alice Doughty for helping me understand the moraine record and other aspects of field geology; and Dan Zwartz for his enthusiastic assistance, no matter what question I brought to his door.

Thanks to David Barrell for providing invaluable maps of and correspondence about the region of study.

I am deeply grateful for the support of Peter Huybers and Eli Tziperman, who made my time at the Antarctic Research Centre possible.

Finally, thank you to my fellow office mates of Cotton 521, who always offered laughs and open ears. 


\section{Contents}

$\begin{array}{ll}\text { Abstract } & \text { i }\end{array}$

Acknowledgements $\quad$ ii

List of Tables $\quad$ v

List of Figures vi vi v v v v

1 Introduction 1

1.1 New Zealand climate reconstructions . . . . . . . . . . . 3

1.1.1 The Last Glacial Maximum . . . . . . . . . . . . 6

1.1 .2 The Late-glacial . . . . . . . . . . . . . . . . 11

1.2 Glaciers as climate indicators . . . . . . . . . . . . . 14

1.3 Aims and methods ................. 16

2 Regional setting 18

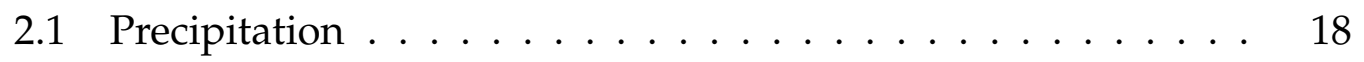

2.2 Temperature .......................... 20

2.3 Geologic setting . . . . . . . . . . . . . . . 22

2.4 Current bed topography ................. 23

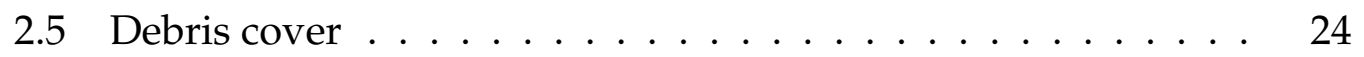

2.6 Proglacial lake ......................... 26

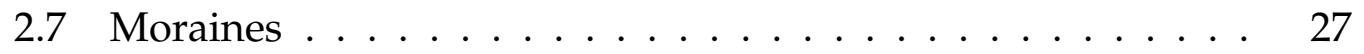


3 Model description $\quad 32$

3.1 In support of simple models . . . . . . . . . . . . . . 32

3.2 Bed profile model . . . . . . . . . . . . . . 33

3.2.1 Model 1: Perfect Plasticity . . . . . . . . . . 34

3.2.2 Model 2: Theoretical erosion ........... 36

3.2.3 Model 3: Mass flux . . . . . . . . . . . . . 36

3.3 Flowline model . . . . . . . . . . . . . 38

3.4 Mass balance model . . . . . . . . . . . . . . . . . 43

3.5 Other methods ...................... 51

4 Reconstructing past glaciations 53

4.1 Constructed bed topography ... . . . . . . . . 53

4.2 Last Glacial Maximum . . . . . . . . . . . . . . . . . . . . . . 54

4.3 Transition from early to late LGM . . . . . . . . . . . . 58

4.4 Late-glacial . . . . . . . . . . . . . . . . 60

4.5 Erosional influence .................. 61

5 Discussion and conclusions $\quad 64$

5.1 Climates of the past . . . . . . . . . . . . 64

5.1.1 The early Last Glacial Maximum . . . . . . . . . . . 65

5.1.2 The late Last Glacial Maximum . . . . . . . . . . . . . . 68

5.1 .3 The Late-glacial . . . . . . . . . . . . . 70

5.1 .4 Precipitation effects . . . . . . . . . . . 72

5.1 .5 Mass balance sensitivity ............ 73

5.2 Glacier valley profiles . . . . . . . . . . . . . . 74

5.3 Future work ...................... 77

5.4 Concluding thoughts .................. 78 


\section{List of Tables}

3.1 Values for the constants used in the mass balance model. . . . 48

4.1 The range of temperature depressions for the early LGM. . . . 58

5.1 Temperature depressions for the LGM in New Zealand found in this and other studies. . . . . . . . . . . . . . . 66

5.2 Temperature depressions for the Late-glacial in New Zealand from this and other studies. . . . . . . . . . . . . . . . . 71 


\section{List of Figures}

1.1 The Tasman Glacier today, looking upglacier. . . . . . . . . . 2

1.2 Eight continuous climate proxy records and the disparate glacial sequence record. . . . . . . . . . . . . . . . 5

1.3 A schematic of the modern-day and LGM currents. . . . . . 9

1.4 A schematic of glacier flow, illustrating the accumulation and ablation areas. . . . . . . . . . . . . . . . . 15

2.1 The South Island, New Zealand, and the region of study. . . . 19

2.2 The Tasman Glacier and surrounding valleys today. . . . . . 20

2.3 Present day annual precipitation. . . . . . . . . . . . . . . 21

2.4 The location of the seismic lines from the two surveys and the interpolated bedrock elevation along the flowline). . . . . . . 23

2.5 The current bed of the Tasman Glacier, based on the gravity surveys. . . . . . . . . . . . . . . . . . . . . . 24

2.6 An ice pinnacle under a boulder, an example of the insulating effects of debris. . . . . . . . . . . . . . . . . 25

2.7 The mapped moraines along the Tasman Valley and around Lake Pukaki. . . . . . . . . . . . . . . . . . . . . . . . . . . . . . 29

2.8 The current elevation of the sediment surface along the flowline and the location and height of mapped moraines for both the early and late LGM. . . . . . . . . . . . . . . . 30

2.9 The elevation of the right and left lateral early LGM moraines around Lake Pukaki. . . . . . . . . . . . . . . . . . . . 30 
3.1 The approximation of the current bed of the Tasman Glacier based on the perfect plasticity model. . . . . . . . . . . . 35

3.2 The main and three tributary flowlines chosen for the model domain. . . . . . . . . . . . . . . . . . 39

3.3 The trapezoidal geometry used in the flowline model. . . . . . 40

3.4 The modelled present-day mass balance profile for the Tasman Glacier using the PDD model, and available mass balance data. 44

3.5 The modelled seasonal cycle in temperature compared to that measured at the Hermitage, Mt. Cook. . . . . . . . . . . . . . .

3.6 The RMSE (cost) between the modelled mass balance profile and the available data . . . . . . . . . . . . . . . .

3.7 The spread of mass balance profiles calculated by varying each of the five tuning variables within its reasonable range. . . .

4.1 The reconstructed bed of the LGM Tasman Glacier based on three models: perfect plasticity, theoretical erosion and mass flux. . . . . . . . . . . . . . . . . . . . .

4.2 The equilibrium extent of the Tasman glacier, matching the early LGM moraine record, due to a temperature depression

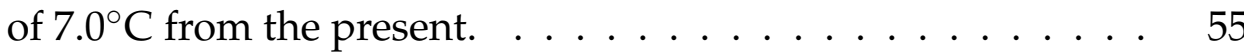

4.3 Modelled glacier profile elevation versus moraine ridge heights along the flowline for the early LGM. . . . . . . . . . . . 56

4.4 The response of the model to changes in temperature and precipitation. . . . . . . . . . . . . . .

4.5 The equilibrium profile of the late LGM Tasman glacier, compared to lateral moraine heights. . . . . . . . . . . . .

4.6 Modelled glacier profile elevation versus moraine ridge heights along the flowline for the late LGM. . . . . . . . . . . 
4.7 The equilibrium extent of the Tasman glacier, best matching the Late-glacial moraine record, due to a temperature depression of $2.2^{\circ} \mathrm{C}$ from the present. . . . . . . . . . . . . . . 60

4.8 As in Figures 4.4(a) and 4.4(b), but for the Late-glacial recon-

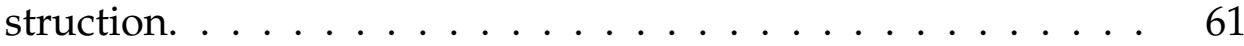

4.9 Glacier retreat due to change in temperature and reduction in bed elevation due to erosion. . . . . . . . . . . . . . . . . 62

5.1 An illustrative example of the effect of a low-pass filter on white noise. . . . . . . . . . . . . . . . . . . . . . 69

5.2 The bed profiles from the present-day, Late-glacial, early and late LGM. . . . . . . . . . . . . . . . . . . . . . . . . . . . . . . 75 


\section{Chapter 1}

\section{Introduction}

Throughout geologic time, the global climate has varied between cold and warm periods, leaving in its wake glacial deposits at the tropical paleolatitudes and evidence of ice-free polar regions. The landscape that we live in today can be read as a palimpsest, with the traces of past climate states still present but requiring careful reading. There are many different pens that record evidence of past climates on the landscape, and each must be interpreted differently. In this work, the geologic record left by previous positions of the Tasman Glacier, South Island, New Zealand (Figure 1.1) is used as a constraint on past climate. Three periods of different ice extents are considered: the Late-glacial (13.5-11.6 kyr ago), and two during the Last Glacial Maximum (LGM, 28 - 17.5 kyr ago).

As a mountain glacier retreats, it may leave a record of its steady-state extent through terminal (end of glacier) and lateral (side of glacier) moraine deposition. In classical glaciological theory, these moraines are thought to record the extent of the glacier at that steady-state position, and to have been located at the margin of the glacier until it retreated from this position. The latter assumption allows for the moraine record, if sufficiently preserved, to be precisely dated using in situ cosmogenic exposure age dating, as has been done for the Tasman Glacier (Schaefer et al., 2006). The combination of geologic mapping and these dating techniques can therefore provide an outline 


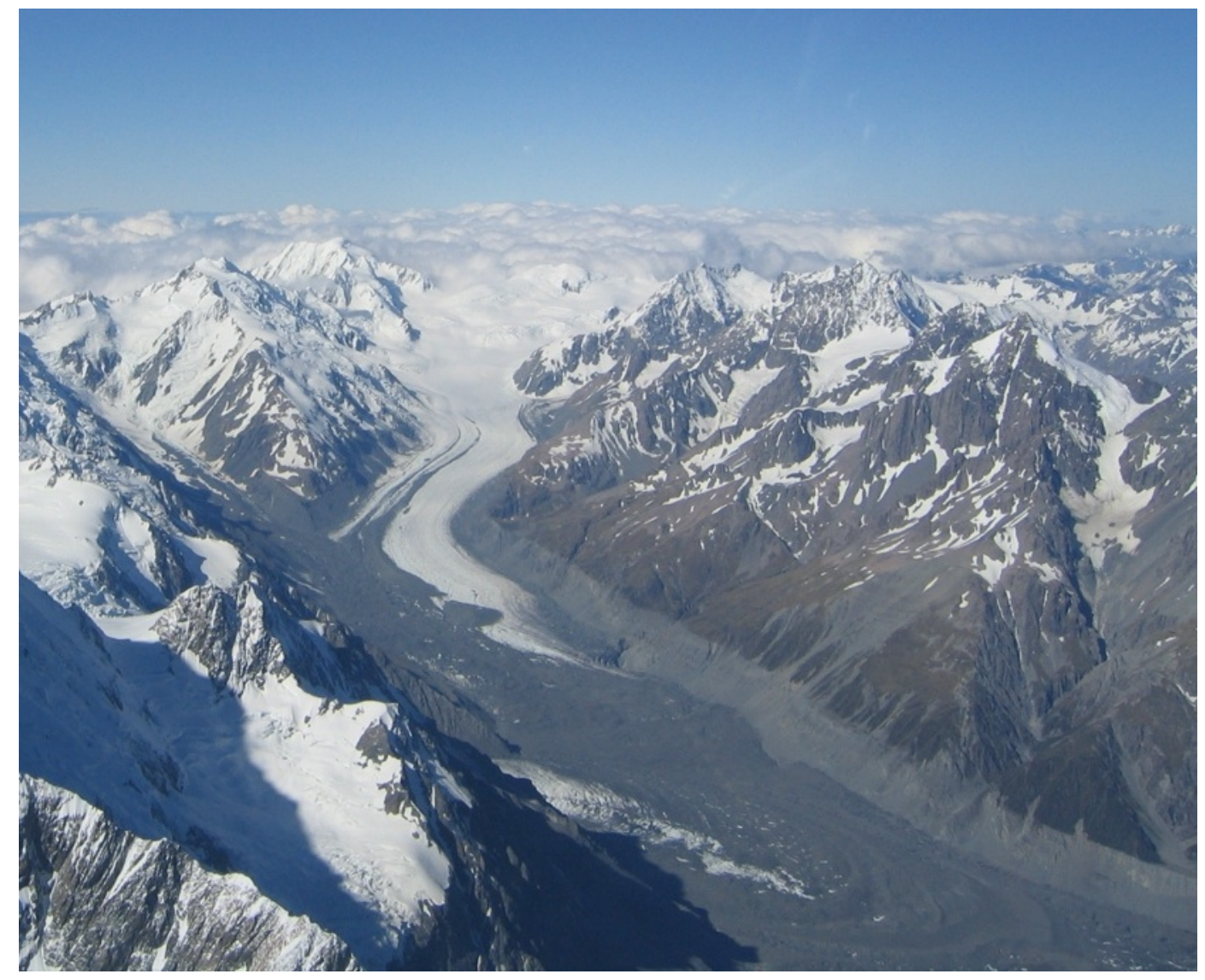

Figure 1.1: The Tasman Glacier today, looking upglacier. Photo courtesy of Andrew Mackintosh.

of past glacier extent, and place a time-stamp on that outline. This alone is a powerful combination for understanding of the climates of the past: in general, larger glaciers are caused by colder and/or wetter climate regimes.

Yet is it possible to go farther, to try to get more information out of these snapshots of past glacier states? With regard to interpreting climate change over time, the desired information is not only glacier extent but also the driving climatic factors. Models, inasmuch as they are repositories of known information about the drivers and responses of a physical system, can assist in bridging the gap between the moraine record and the desired climatic information. Due to the substantial work that has been done mapping and dating the New Zealand moraine record (e.g. Porter, 1975; Schaefer et al., 2006; Ka- 
plan et al., 2010; Putnam et al., 2010; Barrell et al., 2011) ${ }^{1}$, glacier modelling has the potential to provide land-based climatic constraints throughout the most recent glacial cycle. This can aid the comprehension of Southern Hemisphere mid-latitude climate change and its role in global change.

Understanding the manner in which our climate has changed over time is not only of scientific interest but is also critically important in the current regime of climate change. Past climate reveals the magnitude of variability that the earth system can accommodate. Placing constraints on sensitivity, or the magnitude of change in a system due to a given change in temperature, is beneficial as we forecast possible scenarios for future climate.

\subsection{New Zealand climate reconstructions}

The climate of the Southern Hemisphere plays a critical role in understanding the last glacial cycle. It remains uncertain whether the recent (last 30,000 years) glacial initiations and terminations were synchronous (e.g. IvyOchs et al., 1999; Schaefer et al., 2006) or asynchronous (e.g. Turney et al., 2003; Shulmeister et al., 2010) across hemispheres, a debate which will reveal the nature of inter-hemispheric climatic connections. While Antarctica provides a wealth of data in its ice cores, there is a comparative lack of climate data in the Southern Hemisphere mid-latitudes, in part because of the oceanic dominance in the hemisphere. Climate proxies in New Zealand can help fill this void, providing information about the timing and magnitude of climatic changes. Of particular interest is the four thousand years preceding the onset of the Holocene, during which both Antarctic and Greenland ice cores show a period of anomalous cooling, although the Antarctic cooling (termed the Antarctic Cold Reversal, 14.5 - 12.9 kry ago, Jouzel et al. 2001; Barbante et al. 2006) precedes the Greenland cooling (Younger Dryas, 12.9 - 11.7 kyr ago,

\footnotetext{
${ }^{1}$ A large body of yet unpublished work has also been done dating the LGM moraines of the Tasman Glacier, but is not available for reference in this thesis.
} 
Broecker et al. 2010). The comparison of New Zealand data with that from Antarctica and the Northern Hemisphere will answer questions about spatial and temporal patterns of change. Finally, New Zealand is located within the mid-latitude storm tracks, so may provide information about the changes in this westerly wind belt over time.

Due to these reasons and more, significant work has been done to reconstruct the climate in New Zealand, with a focus on the last 30,000 years. Much of this work has been compiled as part of the NZ-INTIMATE (INTegration of Ice-core, MArine and TErrestrial records) project (Alloway et al., 2007). A primary result of the project is six different continuous climate proxy records (Auckland maars, Kaipo wetland, Otamangakau wetland, marine core MD97-2121, Okarito wetland and northwest South Island speleothems), which are shown in Figure 1.2, juxtaposed against temperature proxy records from the EPICA Dome C and GISP2 ice cores, and the discontinuous New Zealand glacier moraine record. The continuous records are chronologically connected through 21 different tephra deposits, and collectively paint a relatively consistent picture of past climate. The authors infer that the LGM in New Zealand lasted from 28 to $18 \mathrm{kyr}$ ago, although it was not consistently cold, especially between 27 and $21 \mathrm{kyr}$ ago. Warming began $18 \mathrm{kyr}$ ago, interrupted by the Late-glacial reversal (cooling) from 13.5 to $11.6 \mathrm{kyr}$ ago. ${ }^{2}$ Whereas the work compiled in Alloway et al. (2007) provides an understanding of temperature trends in New Zealand during the LGM and Late-glacial, it does not provide quantitative constraints. Further studies on the LGM and Late-glacial climate in and around New Zealand are discussed below.

\footnotetext{
${ }^{2}$ All ages can be viewed as approximate, following Alloway et al. (2007)
} 

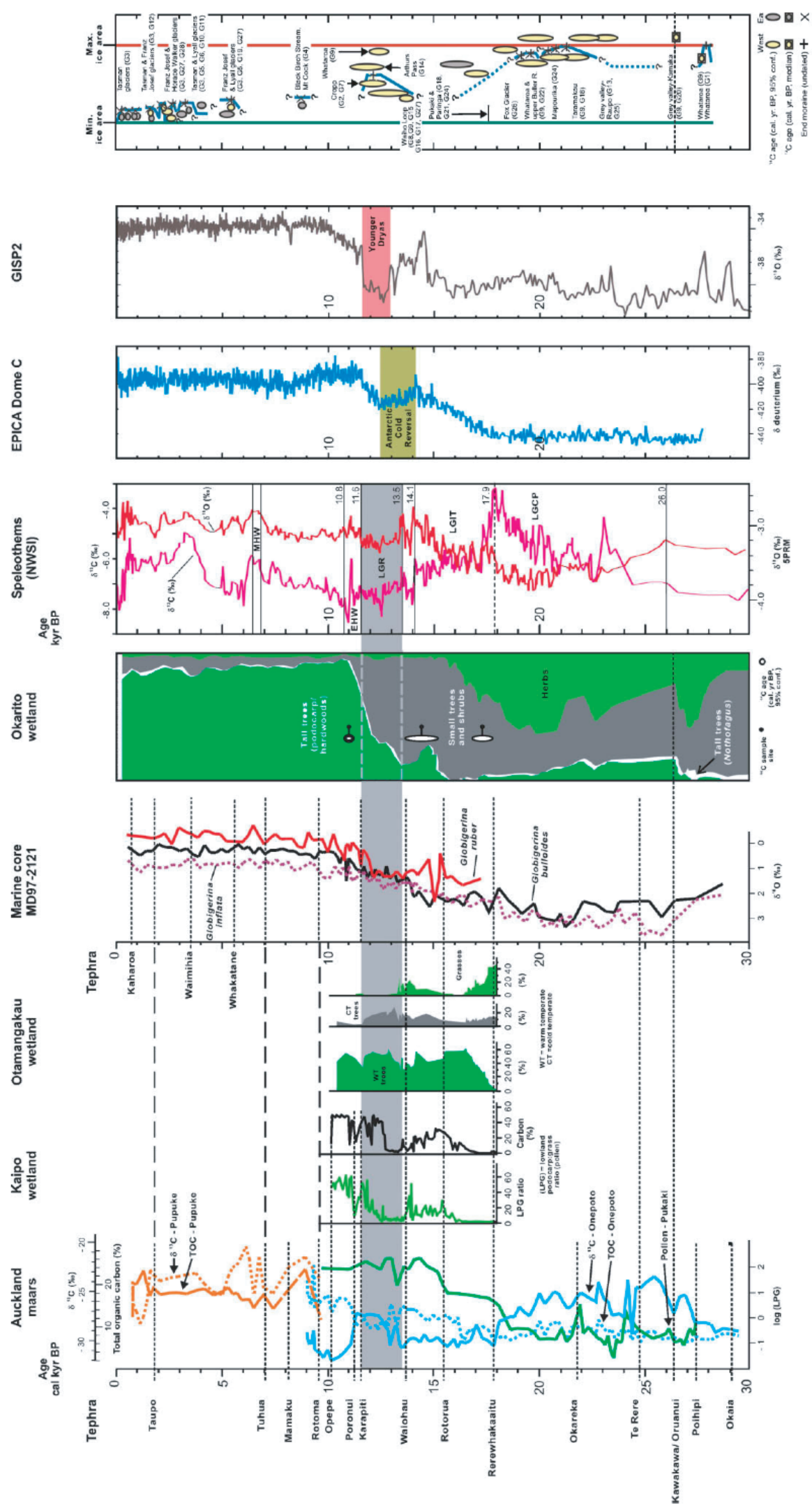

Figure 1.2: Eight continuous climate proxy records and the disparate glacial sequence record (rightmost), modified from Alloway et al. (2007). The mountain glacier signal seems to be consistent with other climate proxies, and can be tied to a temperature signal through modelling. 


\subsubsection{The Last Glacial Maximum}

The climate of the LGM has been studied extensively in New Zealand, and is evident through a number of proxies; the non-glacial proxies are discussed in this section. Estimates of the magnitude of LGM temperature depression, however, vary across studies. This variability may in part be due to the spatial heterogeneity of the reconstructions, which should not be expected to provide identical LGM temperatures. Deviating slightly from the definition offered by Alloway et al. (2007), the New Zealand LGM is considered to end $17.4 \mathrm{kyr}$ ago, in line with the mean moraine ages for the Tasman Glacier presented in Schaefer et al. (2006).

\section{Pollen}

Pollen records provide information about past climate on the basis of changing species dominance, since the presence of a species indicates a climate amenable to its growth. A sediment core taken from the Lake Poukawa Basin, Hawke's Bay, North Island, shows evidence of tussock grasslands during the LGM, which occur above treeline (Shulmeister et al., 2001). As the basin is currently at 20 metres above sea level (m.a.s.l.) and the contemporary treeline is at 1300 m.a.s.l., it is assumed that at a 1300 metre depression of treeline is necessary to explain the record. Based on an atmospheric lapse rate between -5 and $-6^{\circ} \mathrm{C} / \mathrm{km}$, this corresponds to a mean annual temperature 6.5 $-7.8^{\circ} \mathrm{C}$ colder than present. A more sophisticated statistical model connecting climatic variables to the pollen record on the basis of pre-deforestation pollen assemblages was used by Wilmshurst et al. (2007) to find an LGM temperature depression. Because most of New Zealand was tree-less during the LGM, only the northernmost of the seven pollen sites considered, Maratoto, Waikato, North Island, could provide a robust estimate of $5.3^{\circ} \mathrm{C}$ cooler than present. A pollen record from Auckland, North Island, showed the presence of grassland and shrubland forested with beech trees and some 
conifers (Sandiford et al., 2003). The authors concluded that the presence of beech trees indicates that the temperature was at least $4^{\circ} \mathrm{C}$ cooler than present. The climate of the LGM was not uniformly cold, however. Transitions between dominance of grasses (colder climate) and limited expansion of forest (warmer climate) are evident in a pollen record from the Okarito Pakihi Bog, Westland, New Zealand (Newnham et al., 2007b), with a warm period bracketing $26.5 \mathrm{kyr}$ ago, near the beginning of the LGM. Wilmshurst et al. (2007), Sandiford et al. (2003) and Vandergoes and Fitzsimons (2003) all found that the LGM terminated $\sim 18 \mathrm{kyr}$ ago, as temperatures began to rise in the approach to the Holocene.

\section{Speleothems}

Speleothems are secondary calcite deposits that can record past climate information through their isotopic ratios. Trends in $\delta^{18} \mathrm{O}$ and $\delta^{13} \mathrm{C}$ are usually considered. The former is interpreted as being influenced by temperature and precipitation source, and the latter is interpreted as being negatively related to the magnitude of water surplus in the cave environment, increases in biological activity, and atmospheric carbon dioxide concentrations (Alloway et al., 2007). A 30,000 year, continuous speleothem record from Nettlebed Cave, Northwest Nelson, South Island, New Zealand, exhibits seven local minima in $\delta^{18} \mathrm{O}$, which Hellstrom et al. (1998) attributes to northward movement of the Subtropical Front, leading to a change in precipitation source region. While the authors do not argue that the change in $\delta^{18} \mathrm{O}$ reflects a temperature signal, they do note that the northward movement of the front is itself related to colder temperatures in New Zealand. Hellstrom et al. (1998) correlates each minimum with different glacier advances across New Zealand, but many of the advances were not well-dated during the time of the study. Two of the excursions coincide with the late LGM and Late-glacial as they are considered here; one may coincide with the early LGM, although the correspondence is less clear. Williams et al. (2005) obtained eight differ- 
ent speleothem records from two different locations in the northwest South Island to create a composite record of isotope changes from $23 \mathrm{kyr}$ ago to the present. After adjusting for ice volume effects, the $\delta^{18} \mathrm{O}$ record shows low values from the beginning of the record to $18.2 \mathrm{kyr}$ ago, coinciding with the pollen-based estimates of the termination of the LGM. A warm period, between 20.4 and $19.7 \mathrm{kyr}$ ago is also present in the record. This study was extended by Williams et al. (2010) to include 15 different speleothem records in both the northwest South Island and the central-west North Island. The updated time series spans the entire LGM, showing an initiation at $28 \mathrm{kyr}$ ago, an interstadial between 23 and $21.7 \mathrm{kyr}$ ago, and termination beginning 18.1 kyr ago. Unfortunately no modelling work has been done to obtain quantitative temperature constraints from the speleothem proxy record.

\section{Marine cores}

Stable isotope records from foraminifera in marine sediment cores provide an estimate of sea surface temperature (SST) in the past. The $\delta^{18} \mathrm{O}$ record can be used as a proxy for SSTs, with planktic species reflecting surface temperatures and benthic species reflecting deep ocean temperatures. $\delta^{18} \mathrm{O}$ values are also influenced by global ice volume, however, so the record must be adjusted to take these effects into account. Marine sediment cores can place quantitative constraints on SSTs through well-established methods (Urey, 1948; McCrea, 1950); however, the temperatures found are SSTs rather than land-based temperatures. While there may be a close correspondence between the two in a maritime climate like New Zealand's, equality should not be assumed (Barrows and Juggins, 2005).

Weaver et al. (1998) analysed seven marine sediment cores drilled on the eastern side of New Zealand, spanning $35^{\circ} \mathrm{S}$ to $50^{\circ} \mathrm{S}$, in order to determine the latitudinal gradient in SSTs. They found that temperatures during the LGM were $8^{\circ} \mathrm{C}$ cooler than present south of the Chatham Rise, but only $4-6^{\circ} \mathrm{C}$ cooler north of the Rise, leading to the conclusion that the thermal gradient 

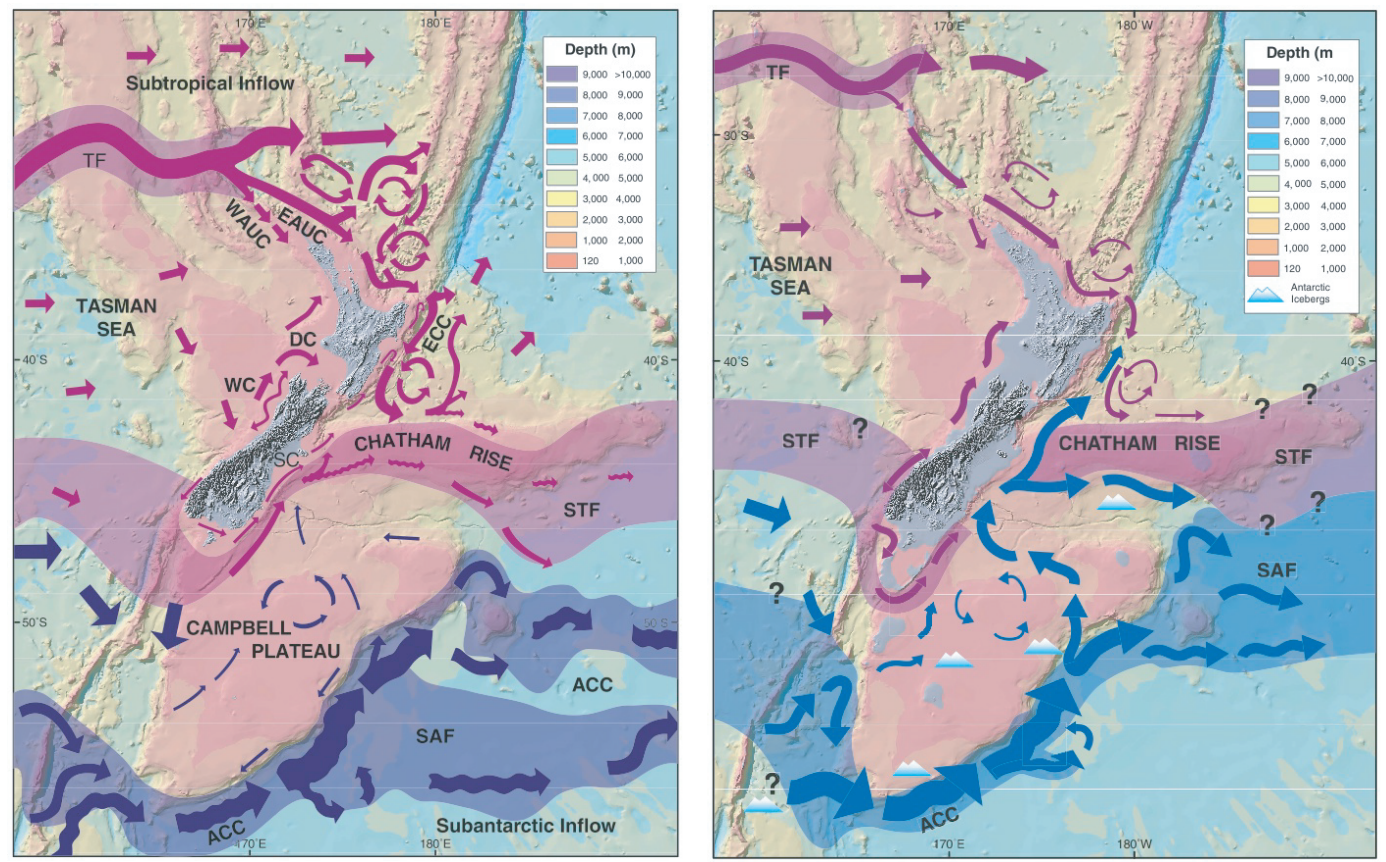

Figure 1.3: A schematic of the modern-day (left) and LGM (right) currents as interpreted by Carter (2001). The northward movement of the Antarctic Circumpolar Current (ACC) may have led to anomalously cold SSTs on the southeast side of New Zealand.

was enhanced during the LGM to $\sim 3^{\circ} \mathrm{C}$ per degree latitude. A similar pattern was found by Sikes et al. (2002) using the foraminifera from four sediment cores on the east coast of New Zealand: subtropical waters were $4^{\circ} \mathrm{C}$ cooler than the present, while subpolar waters were $8^{\circ} \mathrm{C}$ cooler. An explanation for this enhanced gradient may be the northward migration of the Subtropical Front (warm) and the acceleration of the Antarctic Circumpolar Current (cold), which conspired to bring an increased amount of cold water along the south-eastern coast of New Zealand (see Figure 1.3, Carter 2001). Sikes et al. (2002) also reconstructed LGM temperature using alkenones, which exhibit an increase in the degree of unsaturation with a decrease in temperature (Brasseil et al., 1986). Interestingly, this reconstruction does not show the enhanced latitudinal gradient, but rather indicates a $4^{\circ} \mathrm{C}$ temperature depression in both subpolar and subtropical waters. A latitudinal tempera- 
ture gradient is also evident in the LGM temperatures found by Barrows and Juggins (2005). Temperature depressions between 1 and $5^{\circ} \mathrm{C}$ were found on both the east and west side of the northern two-thirds of New Zealand, while larger depressions between 7 and $9^{\circ} \mathrm{C}$ were found on the east side of southern New Zealand. Temperature estimates are not available for the ocean directly west of southern New Zealand. The smallest temperature change near New Zealand is in the Bay of Plenty (Barrows and Juggins, 2005), consistent with the work of Samson et al. (2005), who found foram-based SST depressions during the LGM of $0.9^{\circ} \mathrm{C}$ in the winter and $1.5^{\circ} \mathrm{C}$ in the summer.

\section{Beetle fossils}

Fossil beetle data from Lyndon Stream, Canterbury, South Island may provide an estimate of LGM temperatures during warmer periods. Marra et al. (2006) interpreted beetle assemblages to show summer temperatures between $0.5^{\circ} \mathrm{C}$ warmer and $1.9^{\circ} \mathrm{C}$ cooler, and winter temperatures between $1.0^{\circ} \mathrm{C}$ warmer and $2.2^{\circ} \mathrm{C}$ cooler than present. While these temperature reconstructions are not fit for comparison with those for a mean LGM climate, they do reveal the magnitude of variability that may have occurred during the long New Zealand LGM.

\section{Climate models}

Climate models are not a proxy record, but do provide an alternative way of gaining insight into past climate, especially when constrained by available proxy records. A very basic snow-mass balance model, unconstrained by data, demonstrated that a $1-4^{\circ} \mathrm{C}$ temperature depression could lead to the LGM glacier extent (Rother and Shulmeister, 2006). The temperature change would cause the precipitation across large swaths of low-gradient glacierised terrain to switch from rain-dominated to snow-dominated, leading to large increases in net mass balance and subsequent glacier advance. The model was likely too simple for the system, however, as it used a single elevation, 
was not tuned to mass balance measurements, modelled a generic rather than specific domain, and did not consider the effects of feedbacks.

The climate of New Zealand during the LGM was also examined using a more complex atmospheric general circulation model and its regional counterpart (HadAM3H and HadRM3H) within the Paleoclimate Modelling Intercomparison Projection (PMIP,Braconnot et al. 2000). Because the model was forced by prescribed SSTs, it has potential to reveal the similarities and/or differences between SST changes and land-based temperature changes, although the absolute results are highly dependent on the assumed SSTs. Across all of New Zealand, an average temperature depression of $4.6^{\circ} \mathrm{C}$ was found (Drost et al., 2007). Unfortunately, the temperature changes in the Southern Alps, of interest to this study, were primarily driven by prescribed LGM orography, which is unknown and was up to 1000 metres above the present surface, leading to questions about its validity.

\subsubsection{The Late-glacial}

The Late-glacial period, as used here, refers to a short interval of stable or depressed temperatures, which were a departure from the upward temperature trend between the LGM termination and the onset of the Holocene. The period can be said to span 13.5-11.6 kyr ago, following Alloway et al. (2007), but its duration varies between studies. Furthermore, some temperature reconstructions do not exhibit this period of stable or decreasing temperatures. The climate reconstructions for this period are discussed by proxy.

\section{Pollen}

Pollen stratigraphy from Kaipo Bog in the eastern North Island shows a drop in the ratio of podocarp to grassland pollen between $\sim 13.6$ and $\sim 12.6$ kyr ago, aligning with the Late-glacial period (Newnham and Lowe, 2000). The period of maximum cooling appears to match the timing of the Antarc- 
tic Cold Reversal and to precede the Younger Dryas by $\sim 600{ }^{14} \mathrm{C}$ years. A later study of a pollen record from Okarito Pakihi Bog, south Westland, New Zealand also found a period of cooling, indicated by an increase in grass pollen, although its time period could not be constrained beyond 14 to $11 \mathrm{kyr}$ ago, which spans both the Antarctic Cold Reversal and the Younger Dryas (Newnham et al., 2007b). Wilmshurst et al. (2007) employed a mathematical model connecting the pollen record and climatic variables, with a focus on mean annual temperature. In line with both of the above studies, the authors found that the warming trend that began after the LGM slowed and reversed between 15 and $14 \mathrm{kyr}$ ago, and did not begin again until $12.5 \mathrm{kyr}$ ago, a record that aligns with the Antarctic Cold Reversal. None of these pollen records have been tied to quantitative measures of temperature, although McGlone and Topping (1977) intuited that the period between 14 and $10 \mathrm{kyr}$ ago could not have been more than $2^{\circ} \mathrm{C}$ cooler than present based on sections in the Tongariro region, based on the dominance of podocarp forest. In contrast, a sediment core taken from Auckland, North Island, did not show evidence of a Late-glacial cooling (Sandiford et al., 2003), and Vandergoes and Fitzsimons (2003) interpreted the changes in pollen in a peat core from Westland, South Island, to be attributable to an increase in precipitation and enhanced westerly circulation rather than cooling between 14.3 and 11.4 kry before present.

\section{Speleothems}

A Late-glacial temperature depression related to the northward migration of the Subtropical Front is evident in the speleothem record analysed by Hellstrom et al. (1998), as discussed with reference to the LGM. A temperature depression, bounded by two climatic optima, is evident between 13.5 and $11.1 \mathrm{kyr}$ ago in the Williams et al. (2005) record. This period lags the beginning of the Antarctic Cold Reversal, but extends into the Younger Dryas, possibly implying that Antarctica led New Zealand in temperature change 
(Williams et al., 2010).

\section{Marine cores}

The presence of the Late-glacial cooling signal is inconsistent across marine cores, based on the four cores presented by Barrows et al. (2007a): DSDP 594, MD97-2120, and SO136-GC3. The SO136-GC3 SST stack, calculated from the faunal-based and $\mathrm{U}_{37}^{K^{\prime}} \mathrm{SST}$ estimates, shows a moderate $\left(\sim 0.5^{\circ} \mathrm{C}\right)$ cooling during the Antarctic Cold Reversal, but its lowest value is not significantly different from the present. A Southern Ocean SST stack, produced through averaging the MD97-2120 and MD88-770 SST records together, shows a tem-

perature depression of $\sim 0.5^{\circ} \mathrm{C}$ from the present. The latter core, however, is west of Australia, so the stack may not be representative of a signal registered in New Zealand. A Late-glacial cooling does not appear to be present in DSDP 594. The presence or lack thereof of a Late-glacial cooling in the marine sediment core record may also be be a function of core resolution.

\section{Chironomids}

As was shown by Dieffenbacher-Krall et al. (2007), an analysis of fossil chironomid head types can serve as a proxy for summer temperature in New Zealand. The chironomid record in the Boundary Stream Tarn on the western edge of Lake Pukaki was examined by Vandergoes et al. (2008). The record begins $17.5 \mathrm{kyr}$ ago with the warming trend from the LGM, and shows evidence of a cooling between 14.2 and $13.2 \mathrm{kyr}$ ago, reaching temperatures $2-3^{\circ} \mathrm{C}$ lower than present. Temperatures warmed during the Younger Dryas (12.9 to $11.5 \mathrm{kyr}$ ago) to slightly cooler than present, indicating asynchrony between the hemispheres. By comparing the chironomid record with a pollen record, which reflects minimum winter temperatures or winter duration, Vandergoes et al. (2008) also find that seasonality was enhanced during the Late-glacial. 


\subsection{Glaciers as climate indicators}

Glacier modelling offers an additional method with which to obtain quantitative paleotemperature estimates in New Zealand, although this field is nascent. Geologists have recognised for at least 150 years that New Zealand was more heavily glaciated in the past (Gage and Suggate, 1958), and the existence of a relationship between glaciers and climate has long been known. Gage and Suggate (1958) compiled the first record of New Zealand glaciations throughout the Pleistocene, noting that each change in the moraine record was indicative of a climate signal. Since then, more-detailed regional records of glacier advance and retreat have been produced, although the challenge of connecting these extents to a climate signal remains present.

One measure of climate is the equilibrium line altitude (ELA), which divides the area of the glacier dominated by accumulation from that dominated by ablation (Figure 1.4). A colder and/or wetter climate causes a depression of the ELA, while a warmer and/or drier climate causes an elevation of the ELA. Changes in ELA do not directly translate into changes in temperature and/or precipitation, but reasonable estimates can be made as a function of lapse rate. For instance, if the ELA was found to be depressed by 500 metres in a colder period, and the regional lapse rate was assumed to be $-5^{\circ} \mathrm{C} / \mathrm{km}$, it would be reasonable to calculate a temperature depression of $2.5^{\circ} \mathrm{C}$ from the present if precipitation did not change.

The first comprehensive reconstruction of ELAs in the Southern Alps was done by Porter (1975), based on an outline of past glacier extent and an accumulation area ratio (AAR), the ratio of the accumulation area and the full area of the glacier. Using a typical AAR of $0.6 \pm 0.05$ and mapped moraines in the region of the Tasman Glacier, Porter (1975) found ELA depressions of 500 metres during the Late-glacial (Birch Hill), 750 metres during the late LGM (Tekapo) and 875 metres during the early LGM (Mt. John). Using a lapse rate of $-7.2^{\circ} \mathrm{C} / \mathrm{km}$ as suggested by Ruddell (1995) and assuming no changes 


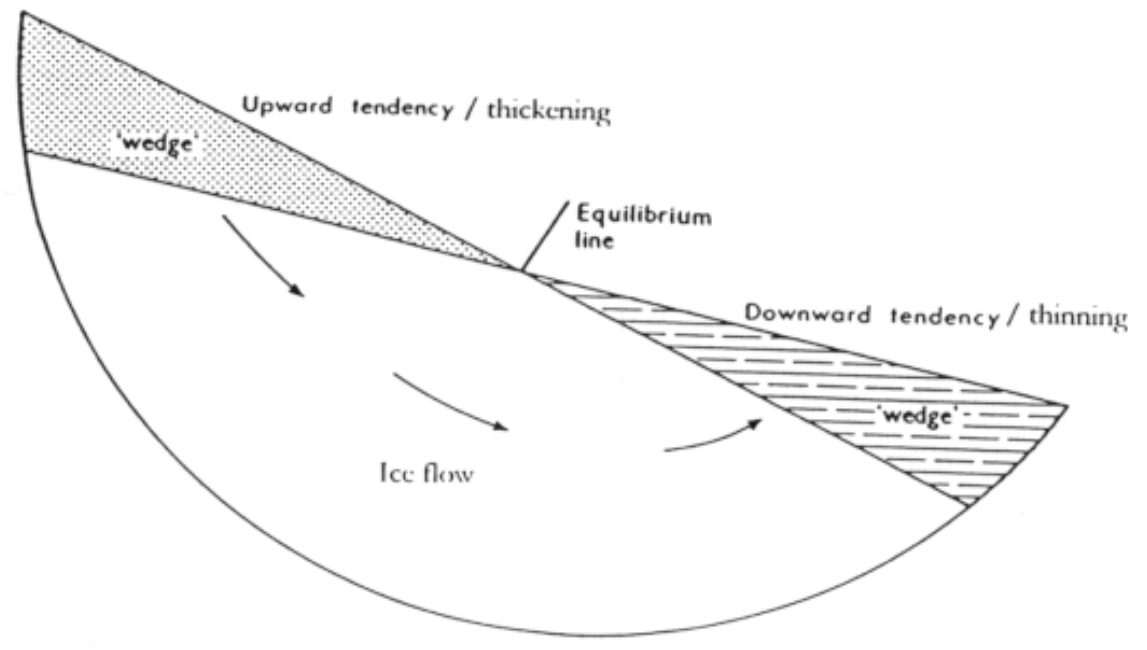

Figure 1.4: A schematic of glacier flow. Mass is added to the glacier above the equilibrium line altitude (ELA) by snow accumulation, and removed by ablation (melt) below it; in equilibrium, the net mass balance is zero, illustrated by the equal areas of the accumulation and ablation wedges. Glacier movement allows for the transfer of mass from above the ELA to below it. A colder and/or wetter climate leads to a depression of the ELA. Figure from Sugden and John (1985).

in precipitation, these depressions translate into temperature depressions of $3.6^{\circ} \mathrm{C}, 5.4^{\circ} \mathrm{C}$ and $6.3^{\circ} \mathrm{C}$, respectively.

Similar work was undertaken in the Inland Kaikoura Range and at Boulder Lake, although neither of these areas is significantly glacierised today. ELA depressions of 740 metres for the early LGM (late Otiran), 575 metres for the late LGM (final Otiran) and 450 metres for the Late-glacial were found in the Inland Kaikoura Range (Bacon et al., 2001). Compared to the estimates made by Porter (1975), these are notable because there is a smaller change between the present and the LGM, but a larger one between the present and the Late-glacial, possibly indicating a smaller climatic change in the transition from the LGM to the Late-glacial. Work at Boulder Lake found an ELA 
depression of 965 metres for the early LGM (MIS 2) and between 965 and 735 metres during the late LGM (MIS 2 retracted phase, McCarthy et al. 2008). Using their $-6.5^{\circ} \mathrm{C} / \mathrm{km}$ lapse rate, these depressions indicate a temperature decrease of $6.3^{\circ} \mathrm{C}$ during the early LGM, and $4.8^{\circ} \mathrm{C}$ by the late LGM. Taking into account variations in precipitation, the authors suggest a likely range of temperatures $5-7^{\circ} \mathrm{C}$ cooler than present during the LGM as a whole.

ELA-based climate reconstructions are good first estimates, but have multiple drawbacks. First, they require an assignment of AAR because they do not include flow dynamics. This is of concern because AARs are known to vary between 0.5 and 0.8 , and directly affect the reconstructed ELA (Meier and Post, 1962; Hawkins, 1985). This effect will be especially large on a thin and steep glacier like the Tasman, because a small change in AAR will correspond with a large change in the ELA. Second, they cannot be used to examine the balance between temperature and precipitation in influencing glacier extent. Third, in deglacierised regions, it is necessary to estimate both the current and past ELA, potentially introducing more error.

Using a simple coupled mass balance-flowline model allows for the inclusion of dynamics as well as the determination of the relative influences of temperature and precipitation on the glacier system. Anderson and Mackintosh (2006) have taken this approach. Using Franz Josef Glacier, West Coast, South Island, they found a temperature depression of $3-4^{\circ} \mathrm{C}$ from the present for the Late-glacial, and determined that temperature, rather than precipitation, change is the dominant driver of glacier fluctuations.

\subsection{Aims and methods}

New Zealand has some of the most beautifully-preserved moraine sequences in the world. The Late-glacial and LGM moraines in the Tasman valley system have been the subject of numerous studies, through which they have been both mapped and dated (Schaefer et al., 2006; Kaplan et al., 2010; 
Barrell et al., 2011). This works aims to use this moraine record to (1) determine the climate state(s) that allow for a reproduction of the glacier extent during the Late-glacial and early and late LGM, (2) diagnose the relative influences of temperature and precipitation on glacier extent and longitudinal profile, and (3) deduce the role of changing bed topography in influencing glacier advance and retreat.

A two-step method is employed to reach these aims. First, an equilibrium model is used to produce bed profiles for each glaciation modelled. The model employs equations from the flowline model (used in step two), an estimate of the surface profile of the glacier, and field-based constraints on bed topography to calculate the beds. Second, these beds are used as a spatial boundary condition for a one-dimensional coupled mass balance-flowline model, which is numerically-integrated to find time-dependent glacier extent as a function of prescribed climatic variables.

These methods will allow for climate information to be extracted from the moraine record for comparison with other climate proxies in New Zealand. Collectively, these will help better determine the climate of the Southern Hemisphere mid-latitudes during the last glacial cycle. 


\section{Chapter 2}

\section{Regional setting}

The region of study is the Tasman Glacier/Pukaki Valley system, South Island. The Tasman Glacier originates in the Southern Alps (Figure 2.1) at $43.30^{\circ} \mathrm{S}, 170.18^{\circ} \mathrm{E}$ at an elevation of approximately 2550 metres above sea level (m.a.s.l.). The glacier flows southwest from its highest point, turning towards the south-southwest as it descends, and terminates at approximately 730 m.a.s.l. The glacier is fed by the Hochstetter Ice Fall and a number of tributary glaciers; however, none of the Murchison, Hooker or Mueller glaciers currently provides an ice flux to the Tasman. The Jollie Catchment has only minor glacierisation today (Figure 2.2).

\subsection{Precipitation}

Precipitation patterns on the South Island are strongly affected by the Southern Alps, which run northeast-southwest along the western edge of the island (Henderson and Thompson, 1999). The prevailing westerlies bring moist air masses over the Tasman Sea; the steep Southern Alps are the first major topographic barrier they encounter. As the air masses rise above the mountains, condensates form and drop out, leading to a band of high precipitation along the north-western slopes of the Alps (Figure 2.3, Stuart 2011).

Precipitation varies on decadal timescales as a function of specific modes 


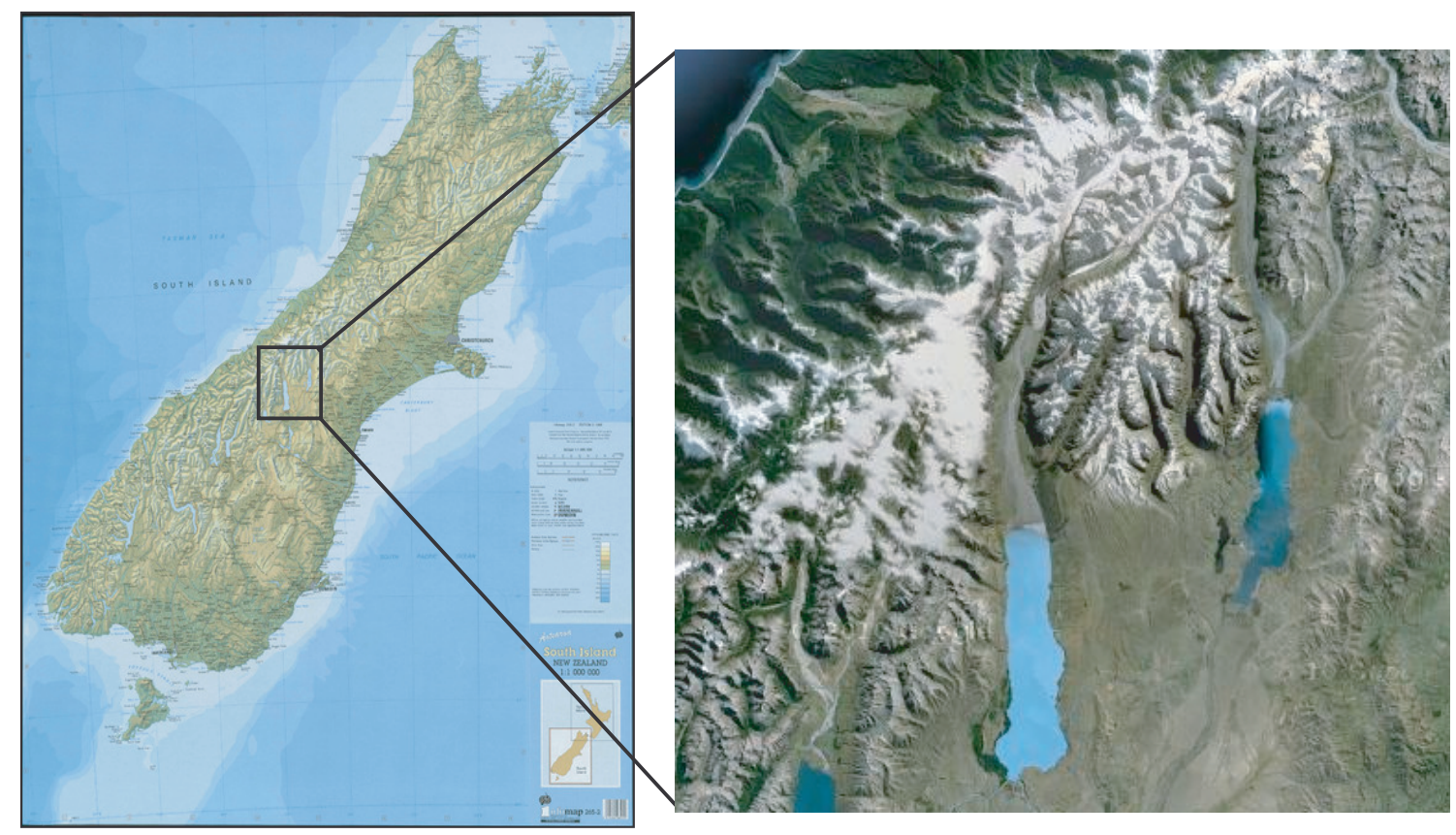

Figure 2.1: The South Island, New Zealand (left), and the region of study (right). The Tasman Glacier and its deglacierised valley, presently terminating in Lake Pukaki, is the middle valley system in the right-hand image. Satellite image courtesy of Google.

of atmosphere-ocean variability. Strong westerly circulation leading to greater precipitation over the Southern Alps is correlated with El Niño conditions and a negative Southern Oscillation index, while the converse is associated with La Niña and a positive Southern Oscillation Index (Mullan, 1996; Fitzharris et al., 1997). These inter-decadal variations appear to be large enough to induce a response in glacier extent (Fitzharris et al., 2007).

Precipitation patterns may have changed since the LGM. There is some evidence that the westerlies migrated during the LGM, but the evidence is inconclusive (Rojas et al., 2009). Thus, the simplest assumption of persistence of current precipitation is used, although the glacier response to a scaling of the whole precipitation surface is examined with respect to the relative influences of temperature and precipitation changes. 


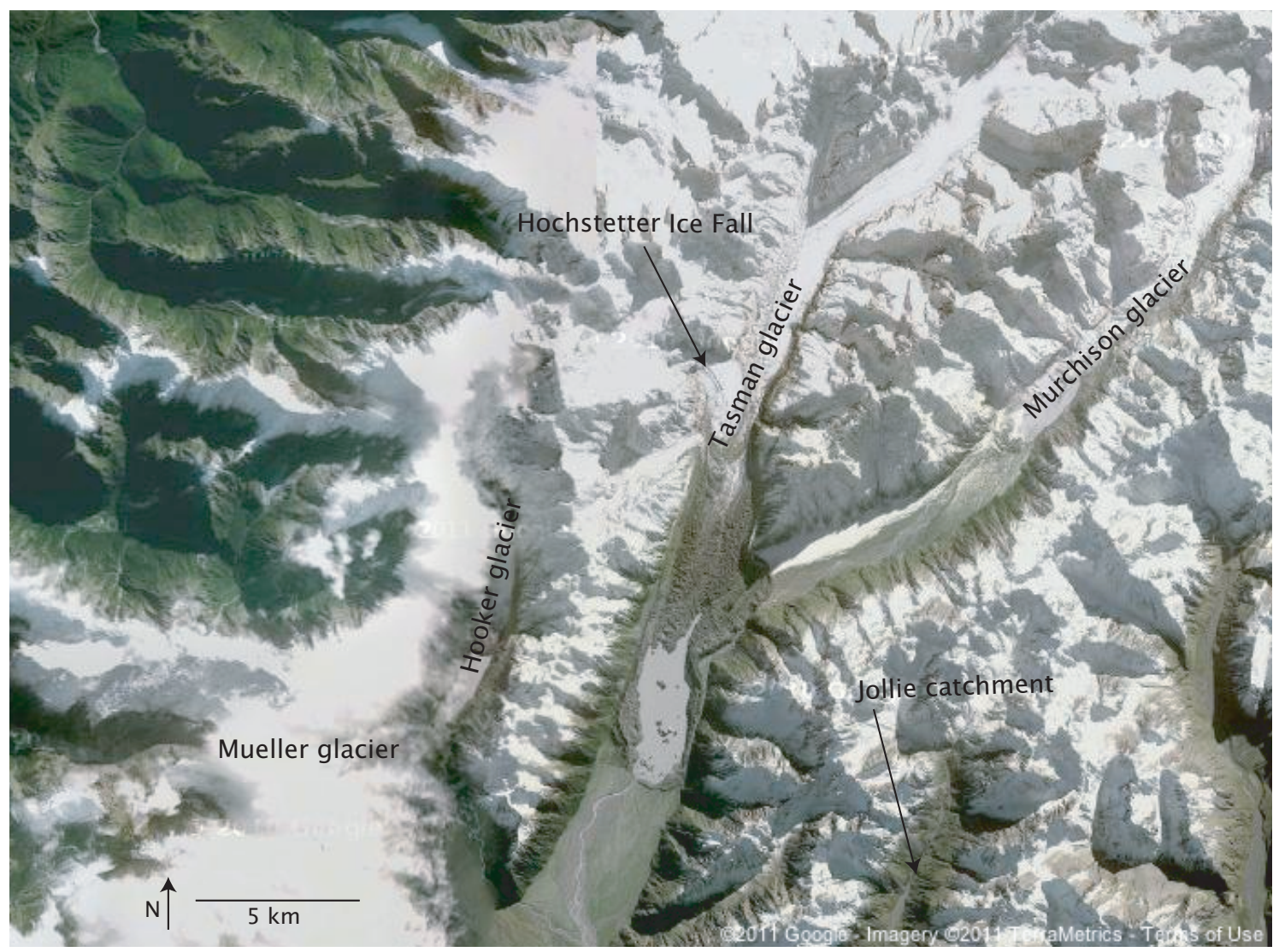

Figure 2.2: The Tasman Glacier and surrounding valleys today. The Murchison, Hooker and Mueller glaciers, and Jollie catchment, all fed into the Tasman Glacier during the LGM. The present-day Tasman Glacier terminates in a proglacial lake. Satellite image courtesy of Google.

\subsection{Temperature}

The National Institute of Water and Atmospheric research (NIWA) maintains the Mt. Cook Hermitage climate station in the Tasman Glacier valley, at an elevation of 765 m.a.s.l. ${ }^{1}$ Based on a 1930-1999 climatology, the mean annual temperature here is $8.5^{\circ} \mathrm{C}$, and the amplitude of the climatological seasonal cycle is $6.1^{\circ} \mathrm{C}$. The standard deviation in temperature from the climatological seasonal cycle over this period is $1.3^{\circ} \mathrm{C}$, and the standard deviation in annual mean temperatures over the same period is $4.3^{\circ} \mathrm{C}$. The record

\footnotetext{
${ }^{1}$ Climate data can be found in the National Climate Database: http:/ / cliflo.niwa.co.nz/
} 


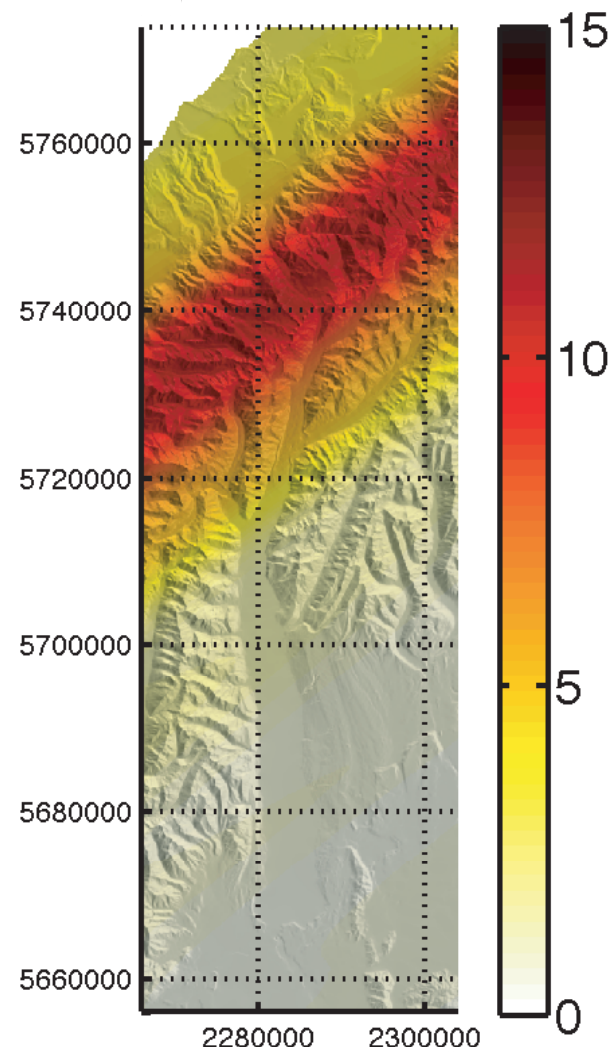

Figure 2.3: Present day annual precipitation (metres), produced from rain gauge measurements using spline interpolation (Stuart, 2011), and superimposed over present-day topography. Note the strong precipitation gradient down the Tasman Glacier, which is located between 5720000 and 5760000 northing and 2280000 and 230000 easting (New Zealand Map Grid).

indicates an upward trend of $0.67^{\circ} \mathrm{C}$ per 100 years (85\% significance level).

The atmospheric lapse rate dictates the rate at which temperature decreases with elevation. While many studies in New Zealand use lapse rates between -5 and $-6^{\circ} \mathrm{C} / \mathrm{km}$, Ruddell (1995) found an annual mean lapse rate of $-7.2^{\circ} \mathrm{C} / \mathrm{km}$ in the Tasman valley by comparing temperatures between $\mathrm{Mt}$. Cook Village climate station (765 m.a.s.l.) and a temporary climate station located at Tasman Saddle (2340 m.a.s.l.). The lapse rate ranged between $8.0^{\circ} \mathrm{C} / \mathrm{km}$ in October and $-6.4^{\circ} \mathrm{C} / \mathrm{km}$ in February, but does not exhibit a clear 
seasonal cycle. The lower relative humidity on the east side of the Southern Alps may account for the higher-than-average lapse rate for the region of study (Ruddell, 1995).

\subsection{Geologic setting}

The Tasman Glacier is in the Southern Alps, a tectonically-active region at the oblique collision of the Australian and Pacific plates (Hales and Roering, 2009). The lithology of the region is dominated by greywackes and argillites, which have been densely faulted and jointed in response to orogenic processes (Cox and Findlay, 1995). These joints have the effects of reducing rock strength and allowing for greater penetration of water into the rock, which increases mechanical and chemical weathering. Thus, weak-tomoderate strength rock dominates the region, and rockfall above the firn line is the dominant debris supplier for the present-day Tasman Glacier. Subglacial erosion has been estimated to be as high as $10 \mathrm{~mm} \mathrm{yr}^{-1}$ (Kirkbride, 1989). The combination of aggressive erosion and deposition has led to an overdeepened basin at the LGM terminus of the Tasman Glacier that has been subsequently filled in with up to 500 metres of sediment (Shulmeister et al., 2010).

Two seismic surveys have been performed in the Lake Pukaki area (Kleffmann et al., 1998; Long et al., 2003), with portions of the seismic lines parallel to the flowline used in this study (Figure 2.4). Both surveys reveal large sediment deposits as well as the location of bedrock, which indicates the magnitude of erosion and deposition that has occurred in the Pukaki Valley system. ${ }^{2}$

\footnotetext{
${ }^{2}$ The profiles are interpolated into the flowline using a 'nearest neighbour' approach. The elevations are adjusted slightly based on differences in surface height along the seismic line and along the flowline to take into account the higher glacier erosion along the centerline than the edges.
} 

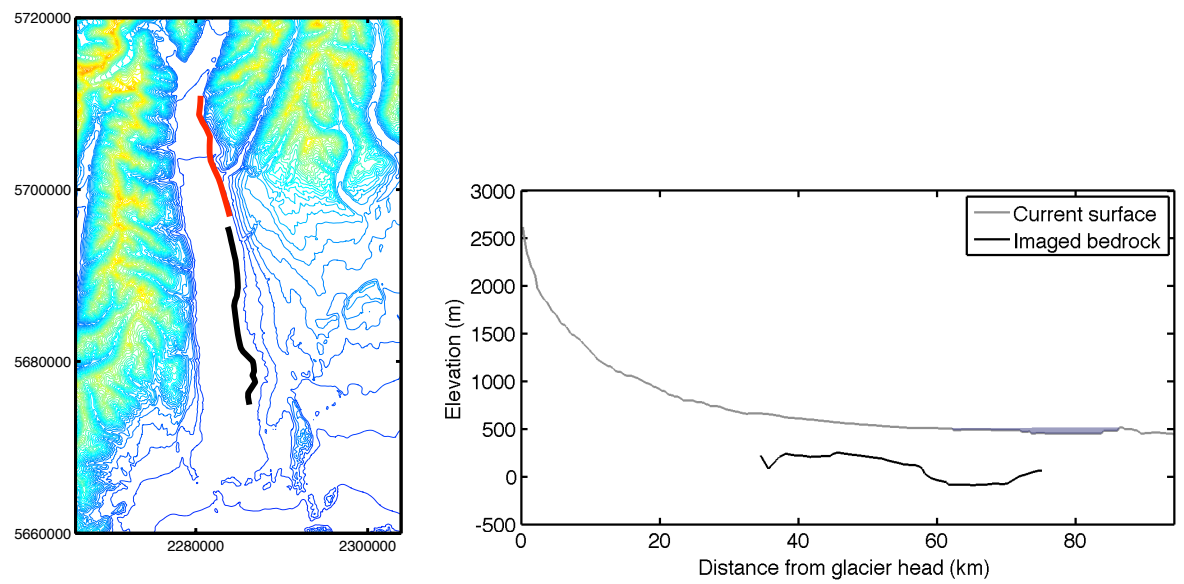

Figure 2.4: The location of the seismic lines (left) from the two surveys (red: Long et al. 2003, black: Kleffmann et al. 1998) and the interpolated bedrock elevation along the flowline (right). Present-day Lake Pukaki is shaded in blue. Location is specified by New Zealand Map Grid northing and easting values.

\subsection{Current bed topography}

The bed of the Tasman Glacier has not been fully imaged, but two cross sections from seismic (Anderton et al., 1975) and gravity (Watson, 1995) surveys provide valuable information. Anderton et al. (1975) additionally provided an estimate of ice thickness across the entire glacier; however, the Tasman Glacier has downwasted significantly in recent decades (Hochstein et al., 1995; Dykes et al., 2011), which leads to an underestimation of bed elevation when calculated with reference to a more recent surface. ${ }^{3}$ The elevation of the ice/sediment and sediment/bedrock interfaces is therefore estimated based on the work of Watson (1995), and is shown in Figure 2.5.

Geological evidence indicates that the length of the Tasman Glacier has remained largely unchanged throughout the Holocene, retreating less than half a kilometre prior to the onset of lake calving (Schaefer et al., 2009; Barrell et al., 2011), during which the glacier eroded the bed to its current state. Al-

\footnotetext{
${ }^{3}$ All surface elevation data is based on a 1986 digital elevation model produced by Land Information New Zealand.
} 


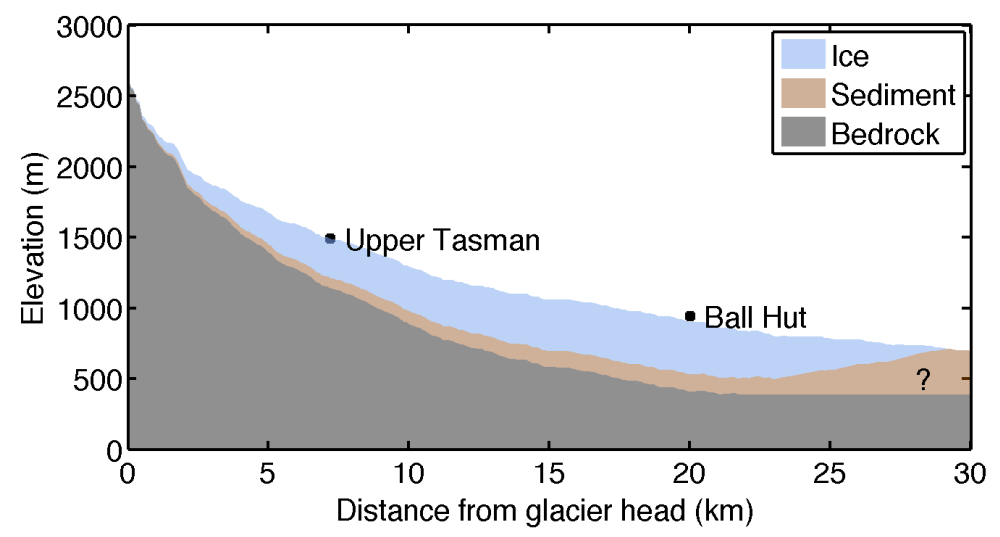

Figure 2.5: The current bed of the Tasman Glacier, based on the gravity surveys performed by Watson (1995). The bed is interpolated between two cross sections, indicated by the dots on the figure. The bed is significantly overdeepened, and the glacier is resting on thick sediment layers. Note that the bedrock elevation is extrapolated at a constant value out from its minimum value downglacier of Ball Hut, but this elevation is unconstrained. The present day proglacial lake is not shown.

ley et al. (2003) have suggested that, for a highly-erosive glacier such as the Tasman, bed overdeepening can be a stabilising erosive process. The mechanism they propose, glaciohydraulic supercooling, will lead to a bed profile that is of a reverse slope to and $20-70 \%$ steeper than the ice-air interface. This model is consistent with the interpolated bed of the present-day Tasman Glacier (Figure 2.5). Furthermore, given that the Tasman Glacier in the past was at least as erosive as it is today, due to a larger ice flux, it is likely that the bed of the Tasman Glacier in its previous steady-state positions also exhibited overdeepenings. Indeed, modelling of the bed, discussed in Section 3.2, indicates that terminal overdeepenings were present during the Late-glacial and the LGM.

\subsection{Debris cover}

A large debris mantle dominates the lower Tasman Glacier today, as can be seen in Figure 2.2. Debris thickness generally increases downglacier, and 
has been estimated to be over two metres at the terminus; however, measurements of debris thickness are sparse. Significant debris cover has been a feature of the glacier since the earliest observations in 1863, although it has increased in areal cover over time (Kirkbride and Warren, 1999). The dominant effect for a very thin and/or sparse debris layer is to decrease the albedo of the ice surface, leading to more ablation. For a thicker, uniform debris cover, insulation of the glacier surface is dominant, leading to reduced ablation (Figure 2.6) as well as a lag in response to climatic changes. The transition between the two states occurs when debris is $0.5-1.0 \mathrm{~cm}$ thick (Benn and Evans, 2010). Estimates for the lower 9 kilometres of the Tasman Glacier indicate a debris layer that is at least $5 \mathrm{~cm}$ thick; therefore, the large-scale effects of debris on the Tasman are insulating.

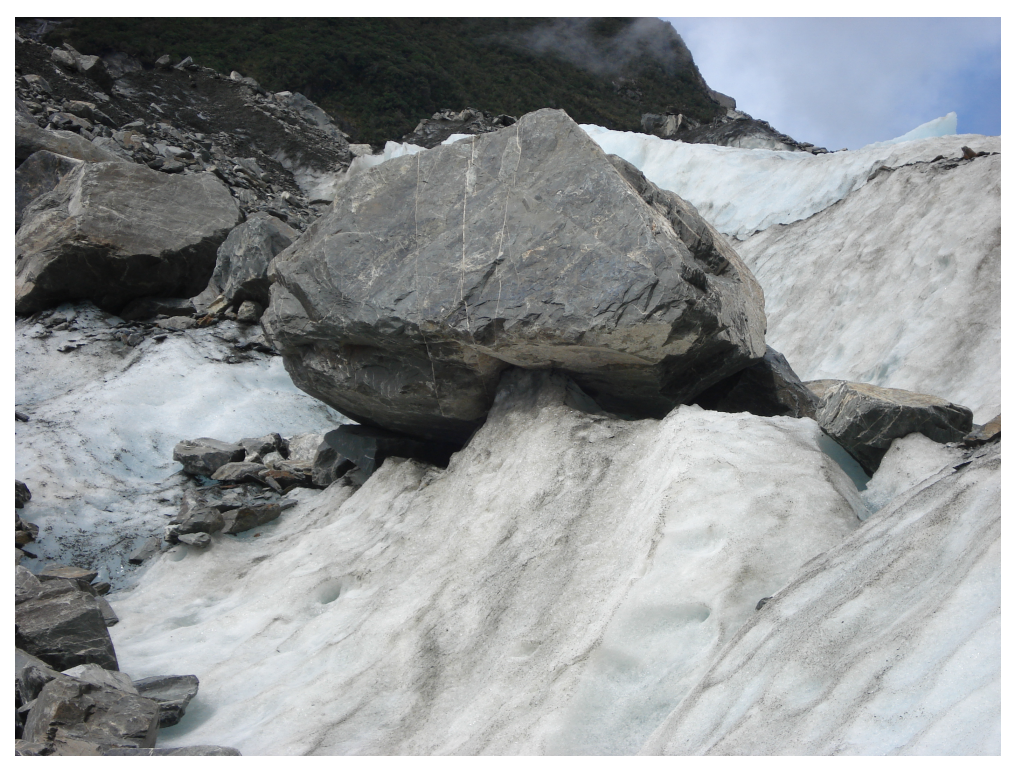

Figure 2.6: An ice pinnacle under a boulder, an example of the insulating effects of debris. Franz Josef Glacier, March 2011, photo by the author.

The recent dynamics of the Tasman Glacier have been heavily influenced by debris cover. While glaciers around the world are retreating in response to a warming climate (Oerlemans, 2005), the Tasman terminus has remained close to its "Little Ice Age" position. Instead of retreating, the glacier has ex- 
hibited downwasting and the formation of a proglacial lake, finally retreating through lake calving (Purdie and Fitzharris, 1999). As such, modelling the present-day Tasman Glacier requires a careful consideration of the effects of debris cover on mass balance. Conversely, although Kirkbride and Warren (1999) argue that "debris cover is the normal glaciological state regardless of historical mass-balance change," it is unlikely that debris cover played a dominant role during the Late-glacial and LGM equilibrium states modelled in this work for the following reasons. First, the extraglacial sources of debris are dominated by rockfalls from the steep valley walls (Kirkbride, 1989); a thicker glacier with greater areal cover would reduce the magnitude of this source. Second, the overall concentration of debris will decrease as glacier size increases, even holding the magnitude of the source constant. Third, warmer climates may be associated with weaker rock slopes due to degradation of permafrost and reduction in ice-bonded rock strength (e.g. Allen et al., 2009). Fourth, the downwasting process, induced by a warming climate, concentrates debris at the terminal surface, leading to a positive feedback cycle with increasing debris concentrations as downwasting continues. This transient behaviour will be less applicable when modelling a steady-state glacier, as is done here. Hence, the effects of debris cover are not modelled in this study.

\subsection{Proglacial lake}

In part due to the in situ downwasting induced by thick debris cover, a large proglacial lake has formed at the terminus of the Tasman Glacier, leading to retreat due to calving at rates ranging from 54 to $144 \mathrm{~m} \mathrm{yr}^{-1}$, and a maximum retreat of $3.7 \mathrm{~km}$ between 2000 and 2008 (Dykes et al., 2011). The presence of the lake, in addition to the debris cover, indicates that, for the present-day, the transient behaviour of the Tasman Glacier cannot be directly tied to a climate signal. Rather, the debris cover has slowed the response to a 
warming climate, and the formation of the lake has served as a tipping point for rapid retreat.

Lake calving and thick debris cover are likely to become important processes for modelling under similar circumstances, namely the transient retreat of the glacier in response to warming. A physically-meaningful model for lake calving may be necessary to understand transitions from the early LGM to late LGM to Late-glacial states of the Tasman Glacier (Hart, 1996; Mager and Fitzsimons, 2007; Shulmeister et al., 2010). These factors are less important, however, when studying distinct equilibrium states, as is done here.

\subsection{Moraines}

Measurements and observations from the present-day Tasman Glacier can assist in an understanding of the processes and environment influencing the glacier. The moraines deposited by the glacier throughout geologic time, however, are the key for modelling past glacier extent. The Late-glacial is well-preserved in the moraine record (Putnam et al., 2010), as are multiple glacier positions from the LGM. Barrell et al. (2011) have grouped these into two different major glacier extents during the LGM, as can be seen in Figure 2.7. These groupings are used throughout this work. The mean age of the late LGM moraines is $17.4 \mathrm{kyr}$ ago (Schaefer et al., 2006). While work on dating the older LGM moraines is in progress, it is not available for reference in this work. Thus, it is assumed that the oldest moraines correspond with the beginning of the LGM at $28 \mathrm{kyr}$ ago (Alloway et al., 2007).

The terminal moraines place constraints on glacier length, while the lateral moraines dictate both glacier profile and glacier width. For the Tasman system, the lateral moraines provide two other pieces of information. First, the LGM moraine elevation is consistently higher on the true right (looking downglacier) of the glacier, against the Ben Ohau Range, than on the true 
left (Figure 2.9). Rather than a symmetric profile, the LGM Tasman Glacier appears to have 


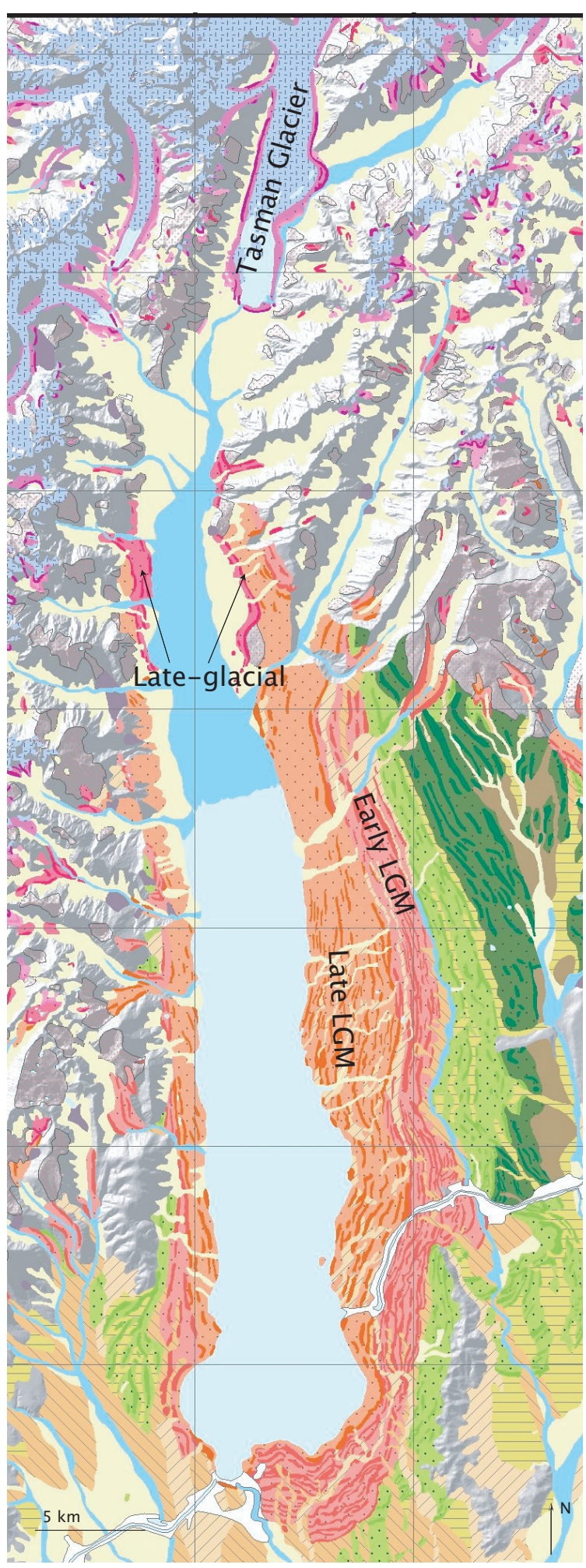

Figure 2.7: The mapped moraines along the Tasman Valley and around Lake Pukaki, adapted from Barrell et al. (2011). The three glacier extents studied here, Late-glacial, early LGM, and late LGM, are labelled. The present-day glacier is also labelled. Individual moraine ridges are marked in bold colour. The moraine outlines provide the geometric constraints for modelling. 


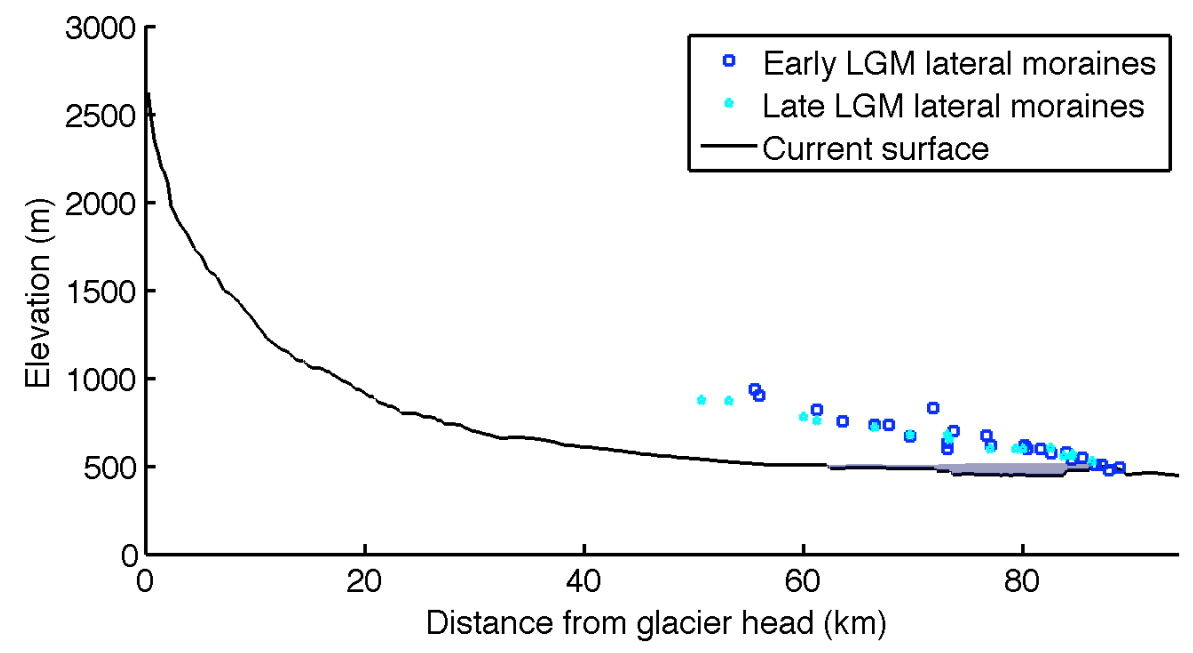

Figure 2.8: The current elevation of the sediment surface along the flowline and the location and height of mapped moraines for both the early and late LGM. Lake Pukaki shown in shaded blue. The low profile of the lateral moraines with respect to the current bed is one indicator that the LGM bed was likely at a lower elevation.

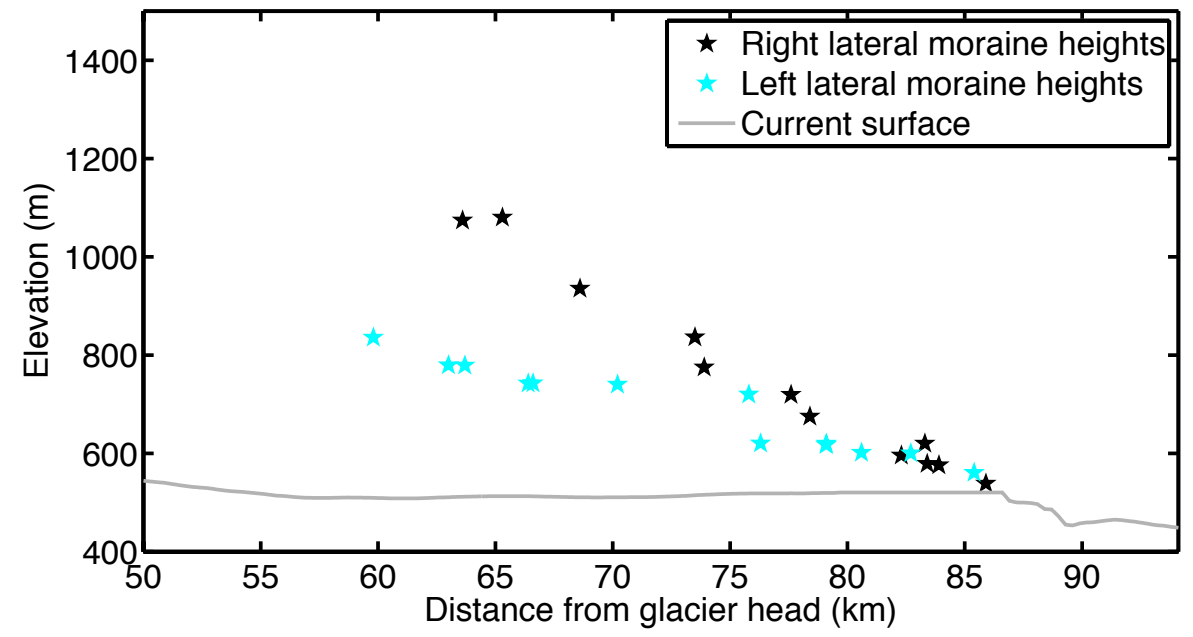

Figure 2.9: The elevation of the right and left lateral early LGM moraines around Lake Pukaki. The right lateral moraines are higher than the left, indicating an asymmetric cross-sectional profile and transverse flow. 
been sloped toward the true left due to mass influx from the glaciers of the Ben Ohau Range. This crosswise flow, however, cannot be considered in the one-dimensional model used here. Second, the lateral moraine elevations offer an indication that the Tasman Glacier bed during the LGM was significantly different from than the present. As can be seen in Figure 2.8, both the early and late LGM lateral moraine elevations (Barrell et al., 2011) have a low surface profile that terminates with minimal curvature into the present bed. The model used in this study does not support equilibrium profiles with this curvature. This discourages the use of the null hypothesis that the best estimate of past bed topography is present bed topography. Rather, the lateral moraine locations and heights encourage interpretation of an overdeepened bed below the LGM terminus. 


\section{Chapter 3}

\section{Model description}

The Tasman Glacier is modelled using a simple one-dimensional coupled mass balance-flowline model. Bed topography is not considered constant throughout time, and is statically modelled. Each of these aspects is discussed below.

\subsection{In support of simple models}

An important principle for modelling studies can be encapsulated in Einstein's statement, to "make things as simple as possible, but no simpler." More complex models can capture more processes influencing a system, but also require a greater amount of data for tuning to ensure that they are not under-constrained, and a more careful interpretation due to the interplay of a large number of variables. Given the paleoclimate focus of this work, models of low to intermediate complexity are utilised to allow for the inclusion of processes deemed most important with a relatively small number of tuning parameters.

Glacier dynamics are included via a one-dimensional flowline model based on advection-diffusion mathematics. The model includes the geometric effects of changing valley width and side wall slope, and has two tuning parameters (Oerlemans, 1986). The parameters, which affect sliding and defor- 
mation velocities, are physically-meaningful, so adjustment of their values reflects the physical system being modelled. The model is computationallyefficient, allowing for sensitivity studies that could not be performed on a reasonable timescale with more complex models. Finally, unknowns such as bed topography can be more easily addressed in a model with fewer spatial dimensions.

Bed profiles are modelled using the same equations as those that govern the flowline model (Anderson et al., 2004), and are constrained by the available seismic data for the region (Kleffmann et al., 1998; Long et al., 2003).

There are several different mass balance models of varying complexity that can be used in glacier modelling (Hock, 2005). Models of greater complexity allow for the inclusion of a larger number of environmental variables to better reproduce the physical system, but this comes with the cost of a greater variance in model output, which leads to large uncertainties in model results. Conversely, simple models necessarily ignore and/or simplify certain processes, leading to a biased but more predictable result, i.e. the biasvariance trade-off (Spall, 2003). Due to the uncertainties inherent in studying past climates, this work uses a relatively simple positive degree day (PDD) model.

\subsection{Bed profile model}

Glacier modelling requires bed topography as a boundary condition; besides climatic factors, bed topography (and composition) offers a second major control on glacier behaviour. The reasons for its influence are threefold: the sensitivity of glacier length to climate changes depends on bed slope (Oerlemans, 1989), the elevation of the bed controls the temperature at each point along the flowline, due to the atmospheric lapse rate (Oerlemans, 2002), and properties of the substrate affect the dynamics of glacier flow (e.g. Truffer et al., 2001) and the resulting glacier surface longitudinal profile (Boul- 
ton and Jones, 1979). Placing constraints on the bed topography of the Tasman Glacier during and since the LGM is nontrivial because the valley has evolved through time. Through a succession of glacial and interglacial periods, the advancing and retreating Tasman Glacier and the flow of its associated rivers have eroded the bed and deposited sediment, leading to a valley presently occupied by hundreds of metres of sediment (Kleffmann et al., 1998).

While the relationship between glacier motion and erosion has been examined using models (e.g. Oerlemans, 1984; Boulton and Hindmarsh, 1987; Boulton, 1996), the relationship between the two is primarily studied with respect to a glacier advancing and retreating over bedrock rather than thick layers of sediment (Boulton, 1978; Pelletier, 2008; Koppes and Montgomery, 2009; Thomson et al., 2010). The mid-latitude, low-elevation and high-precipitation (up to 11 metres per year, Stuart 2011) environment of the Tasman Glacier allows for the presence of large amount of water in the glacier system, increasing erosive, transport, and deposition capacity (Boulton, 1978; Hallet et al., 1996). The presence of heavily-deformed sediment bodies around the present-day Lake Pukaki encourages this interpretation (Hart, 1996, although there is some disagreement over this interpretation, see Mager and Fitzsimons 2007). Field data illustrate that quickly moving glaciers atop sediment bodies can erode 10-100 $\mathrm{mm} \mathrm{yr}^{-1}$ (Hallet et al., 1996; Björnsson, 1996), making these processes significant on timescales as short as thousands of years. Three models are considered as methods for reconstructing steadystate glacier profiles, and are discussed in turn below.

\subsubsection{Model 1: Perfect Plasticity}

Previously used by Oerlemans and Van der Veen (1984), the assumption of perfect plasticity in ice can be used to calculate bed topography (b) from surface height $(h)$ and yield stress $\left(\tau_{y}\right.$, a value of $2 \times 10^{5}$ is use based on Oerle- 
mans 1997), as

$$
b=h-\frac{\tau_{y}}{\rho g \frac{d h}{d x}} .
$$

The density of ice, $\rho$, is assumed constant, and $\mathrm{g}$ is the acceleration due to gravity. The assumption of perfect plasticity is known to be incorrect - it is the extreme case when Glen's flow constant goes to infinity (Oerlemans, 2001) - but this does not preclude its usefulness. In order to test this model's ability to predict bed topography, it is applied to the contemporary Tasman Glacier, and the results are compared to the limited data available (Figure 3.1).

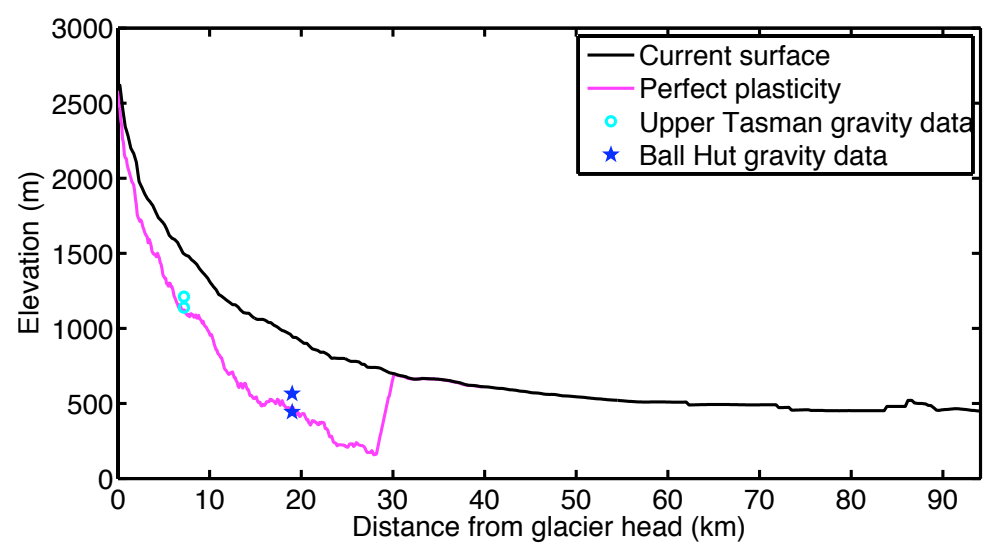

Figure 3.1: The approximation of the current bed of the Tasman Glacier based on the perfect plasticity model. For each set of gravity data points, the upper point is the estimated ice/sediment interface, while the lower point is the estimated sediment/bedrock interface. The model struggles to produce a reasonable bed when the surface slope is minimal.

While the model does relatively well in fitting the data for the upper regions of the glacier, it fails when the surface slope diminishes at the terminus, and cannot produce the decreases in ice thickness that are required there. This is a major concern for the reproduction of the LGM bed, as both the current bed and the LGM glacier shallow significantly in slope as they spread across the lower plain towards the shores of present-day Lake Pukaki. Secondary concerns with this model are the dependence on surface height, 
which is known only approximately in the LGM, and the need to prescribe a yield stress, which has not been experimentally obtained for a glacier like the Tasman. The former concern, however, cannot be avoided in most bed topography models, and LGM surface height will remain as a necessary approximation.

\subsubsection{Model 2: Theoretical erosion}

A second model for placing constraints on glacier beds was proposed by Anderson et al. (2006), and depends on the proposed proportionality of mass flux and erosion. They note that, in steady state, a basic one-dimensional flowline model can be written as

$$
\frac{d Q}{d x}=b W
$$

since the time dependent component is equal to zero. $\mathrm{Q}$ is mass flux, $\mathrm{b}$ is mass balance, and $\mathrm{W}$ is width. This formulation allows for mass flux to be determined as a function of mass balance and width:

$$
Q(x)=\int_{0}^{x_{\text {term }}} W b d x \text {. }
$$

With a variable width, the erosion rate is argued to vary more directly with ice discharge per unit width, $Q / W$, recognising the additional forces exerted in a narrower valley over a broad one by a glacier with the same mass flux. The total magnitude of erosion is calculated as $\kappa \mathrm{Q} / \mathrm{W}$, where $\kappa$ is a function of the time available for erosive processes in the steady state and the structural integrity of the bed material. A bed composed of sediment, like that of the Tasman, will evolve more quickly and easily due to glacial processes than a bedrock one. The choice of $\kappa$ is discussed below.

\subsubsection{Model 3: Mass flux}

While the third model also depends on the calculation of mass flux, it takes a different approach. Anderson et al. (2004) note that equations 3.4-3.6 
allow one to solve for ice thickness as a function of mass flux using iterative methods. Armed with an estimate for mass flux and a surface profile, this approach provides bed topography.

$$
\begin{aligned}
& Q=U S \\
& U=f_{d} H \tau^{n}+f_{s} \frac{\tau^{n}}{H} \\
& S=H(w+H \tan \theta)
\end{aligned}
$$

$\mathrm{Q}$ is mass flux, $\mathrm{U}$ is velocity, $\mathrm{S}$ is cross-sectional surface area, $f_{d}$ and $f_{s}$ are the tuning parameters controlling deformation and sliding velocities, respectively, $\mathrm{H}$ is ice thickness, $\theta$ is the side wall slope (see Figure 3.3), and $\mathrm{w}$ is width. $\tau$ is the driving stress, depending on surface slope and ice thickness. Glacier surface and extent reconstructions from Porter (1975) are used to provide an initial surface profile. Examination of more recent glacier extent reconstructions (Barrell et al., 2011) reveals that the Porter (1975) Mt. John glaciation reconstruction corresponds with the early LGM glaciation, while the Tekapo reconstruction corresponds with the late LGM.

The two-dimensional map of surface elevation is fed into the PDD model discussed in Section 3.4. A glacier in steady-state must have a mass flux profile that peaks at its ELA and diminishes to zero at its terminus; using this constraint, an equilibrium mass flux profile and a corresponding temperature and ELA are calculated for input into the bed topography model.

As noted by Anderson et al. (2004), the bed topography is more sensitive to the flow parameters, $f_{d}$ and $f_{s}$, than it is to the mass flux profile. Large flow parameters correspond with an easily flowing ice body with a smaller ice thickness (and higher elevation bed for a given surface profile), with the converse being true about small flow parameters. Since measurements cannot constrain the value of these flow parameters, an alternative method must be used. Since the glacier bed at any point during the past cannot have been below the current bedrock surface, the elevation of the bedrock, discussed in 
Section 2.3, provides a lower limit for the calculated bed where data is available. Thus, the location of the bed topography is solved for iteratively, with changing magnitudes of the flow parameters, until none of the calculated bed is at a lower elevation than the seismically imaged bedrock.

The oft-used set of flow parameters from Budd et al. (1979) was calculated for an ice/rock interface, distinctly different from the ice/sediment interface that was likely present for much of the LGM Tasman Glacier. Enhanced sliding will occur when the water pressure in the sediment is at or exceeds the ice pressure from above (Boulton and Hindmarsh, 1987). Ice deformation is unaffected by hydrostatic pressure (Glen, 1958), but is controlled by the composition of the glacier, i.e. ice, water, and sediment, and its temperature (Paterson, 1994). While it is not obvious that the Tasman Glacier should deform more readily than a glacier atop bedrock, the mass flux model demands an elevated deformation parameter in order to accommodate the LGM mass flux with a bed profile that does not fall below the bedrock surface. This is because the model is more sensitive to the deformation parameter than the sliding parameter. The high value of the deformation parameter may reflect a real effect, or may indicate the shortcomings of the simplified flowline model, upon which the mass flux bed profile model is based. The simplifying assumptions of the model will be discussed in the next section.

\subsection{Flowline model}

Whereas the Tasman Glacier exists in three-dimensional space, the spatial complexity can be reduced for the purpose of a simple model. Glacier flow is calculated along a flowline through the middle of the glacier (for existing glaciers) or glacial basin (for deglaciated regions). Here, the Tasman is mod-

elled as a primary flowline with three incoming tributaries, as can be seen in Figure 3.2.

The model is based upon that of Oerlemans (1986); the relevant geomet- 


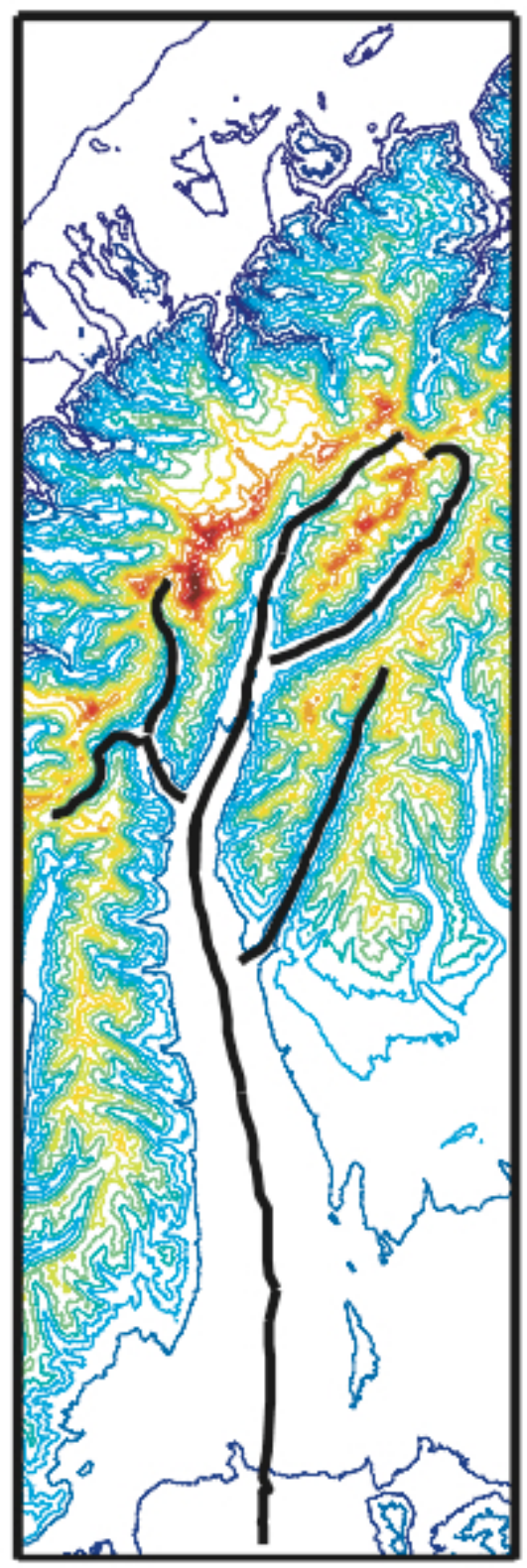

Figure 3.2: The main and three tributary flowlines chosen for the model domain.

ric and dynamic details are discussed here. A trapezoidal geometry is used for the cross-section of the glacier (Figure 3.3). As opposed to the more conventional method of defining the trapezoid by the width of the base (e.g. Oerlemans, 1986), it is defined by the width of the glacier surface $\left(\mathrm{w}_{S}\right)$ at a given thickness, and the slope of the valley walls $(\theta)$. The surface width, $\mathrm{w}_{S}$, can be found from the mapped moraines, the thickness is based upon the re- 
constructions of Porter (1975), and $\theta$ can be calculated from the present valley geometry. Both $\mathrm{w}_{s}$ and $\theta$ can vary along the flowline. The thickness of the glacier, $\mathrm{H}$, is calculated at the centreline.

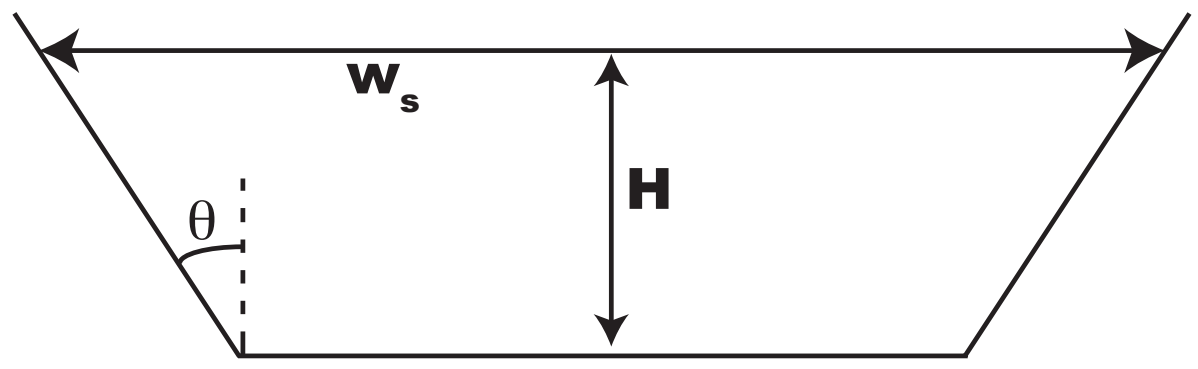

Figure 3.3: The trapezoidal geometry used in the flowline model. Note that the surface width of the glacier changes as a function of ice thickness.

Glacier movement along the flowline is governed by a nonlinear differential equation, which can be derived from conservation of mass principles. The change in the cross-sectional area (S), illustrated in Figure 3.3, is driven by the net flux through the cross-section and the mass balance. Mathematically,

$$
\frac{d S}{d t}=-\frac{\partial(U S)}{\partial x}+w M
$$

where $U$ is velocity $(\mathrm{m} / \mathrm{s}), \mathrm{w}$ is the width of the glacier at its surface $(\mathrm{m})$, and $\mathrm{M}$ is the mass balance (m.w.e./s).

A flow law must be implemented to calculate velocity as a function of stress and, perhaps, temperature and other ice properties. As is common practice, Glen's flow law (Glen, 1955) is implemented here, which states that strain rate scales with stress raised to the power $n$ :

$$
\dot{\epsilon}=A \sigma^{n} .
$$

The flow law assumes randomly-oriented polycrystalline ice, so it can be modelled as an isotropic material Glen (1958), and has been developed 
through theoretical, laboratory and field research. As discussed by Alley (1992), each of these approaches has drawbacks. Theoretical work often relies on poorly-constrained physical parameters, laboratory work allows for control of variables but considers relatively short time scales, while field research uses the timescales of the glacier itself but relevant boundary conditions and stresses are poorly constrained. It is therefore difficult to consider all the appropriate time and space scales in a rigourous framework, preventing full verification of the model (Van der Veen, 1999).

Alley (1992) summarises the work that has been done to determine the value of $n$, and finds that the commonly-used value of three is acceptable for systems with high driving stresses ( $\sigma>1$ bar), such as steep mountainous environments.

The value of A depends on temperature and pressure, although the latter can be incorporated through an adjustment of the former (Weertman, 1973; Van der Veen, 1999). The simplification of a constant scaling parameter, independent of temperature, is employed in this study. Physically, this assumption is acceptable because the Tasman is a temperate glacier that can be considered to be at its melting point throughout (e.g. Harrison, 1972). Logistically, this assumption is necessary because the model is vertically-integrated, so temperature is not calculated at depth.

The driving stress is calculated using the shallow ice approximation, which approximates stress as the first term in the infinite expansion that fully describes stress (Hutter, 1983). The first term is the local driving stress $(\tau)$, which is assumed to exactly balance the local basal shear stress (Hutter, 1983) and is expressed as

$$
\tau=-\rho g H \frac{\partial h}{\partial x} .
$$

This approximation, however, was originally developed to model the interior of ice sheets, and depends on the assumption that $[\mathrm{H}] /[\mathrm{L}] \ll 1$ ( $<$ $10^{-2}$ ), where $\mathrm{H}$ is the characteristic length scale of ice thickness and $\mathrm{L}$ is the 
characteristic length scale of horizontal variations in ice thickness and velocity, and bed topography (Baral et al., 2001). This assumption is clearly violated in mountain glacier systems, where ice can be thin and steep and/or uneven topography reduces the length scale of horizontal variations. Higher order stresses have been included in other modelling studies, primarily in the form of longitudinal (also known as membrane) stresses (Glen, 1958; Kamb and Echelmeyer, 1986; Le Meur et al., 2004; Hindmarsh, 2006). The inclusion of these stresses addresses the short horizontal length scale of topographic variation, but do not address the effects of steep topography (Baral et al., 2001). Recent work has led to the development of a model that includes the first three terms of the series (Egholm et al., 2011), but this model requires an iterative approach that leads to computation times 5 to 15 times greater than the shallow ice approximation. Furthermore, the authors note that the inherently large value of $[\mathrm{H}] /[\mathrm{L}]$ in steep mountain glacier systems to some extent invalidates the shallow ice approximation as a whole, since the perturbative framework itself depends on small values of the ratio.

Despite these limitations, the shallow ice approximation has been used with some success in modelling contemporary glacier advance and retreat in response to mass balance changes (e.g. Oerlemans et al., 1998). As such, the shallow ice approximation is employed due to its computational-efficiency, which is valuable for long integrations and sensitivity studies, both of which are part of this study.

The derivation of velocity, based on the shallow ice approximation and the Weertman (1964) sliding law, can be found in Oerlemans (1997). It is expressed as:

$$
\frac{d H}{d t}=\frac{-1}{w_{s}-2 H \tan \theta} \frac{\partial}{\partial x}\left(D \frac{\partial h}{\partial x}\right)+M
$$

where $h$ is the elevation of the ice surface (i.e. $h=H+b$, where $b$ is the bed elevation) and $\mathrm{D}$ is the diffusivity, calculated as 


$$
D=\left(w_{s}-H \tan \theta\right)\left(f_{d} \gamma H^{n+2}\left(\frac{\partial h}{\partial x}\right)^{n-1}+f_{s} \gamma H^{n}\left(\frac{\partial H}{\partial x}\right)^{n-1}\right), \gamma=(\rho g)^{n}
$$

The diffusivity depends on the parameters $f_{s}$ and $f_{d}$, which control sliding velocity and deformation, respectively. As discussed in Section 3.2.3, their value is determined indirectly by demanding that the calculated LGM and Late-glacial beds do not fall below the seismically-imaged bedrock surface (Section 2.3). Since both water (Boulton and Hindmarsh, 1987) and sediment (Boulton et al., 2001) contribute to increased glacier motion and will accumulate more readily in basins, the flow parameters are considered to vary with the reciprocal of bed slope, generally increasing downglacier.

The space step of the model is set at 300 metres for a balance of resolution and computational efficiency. The timestep is adaptive to allow for both computational efficiency and numerical stability, and is calculated as (Hindmarsh, 2001)

$$
\Delta t=\frac{\Delta x^{2}}{2 n \times \max (\operatorname{abs}(-U H /(d h / d x)))}, \Delta t_{\text {max }}=20 \text { days. }
$$

Some care must be taken when calculating the ice exchange between the three incoming tributaries and the main trunk to ensure conservation of mass. The mass flux out of the tributary glaciers is calculated at the last gridpoint of the tributary and, for stability, the removed mass is divided between the last two gridpoints. The flux into the main tributary is divided evenly among the three closest gridpoints.

\subsection{Mass balance model}

The flowline model is coupled to a modified PDD, which fundamentally controls glacier behaviour. The most basic PDD models are based on an empirically-derived relationship between melting and positive degree days, 


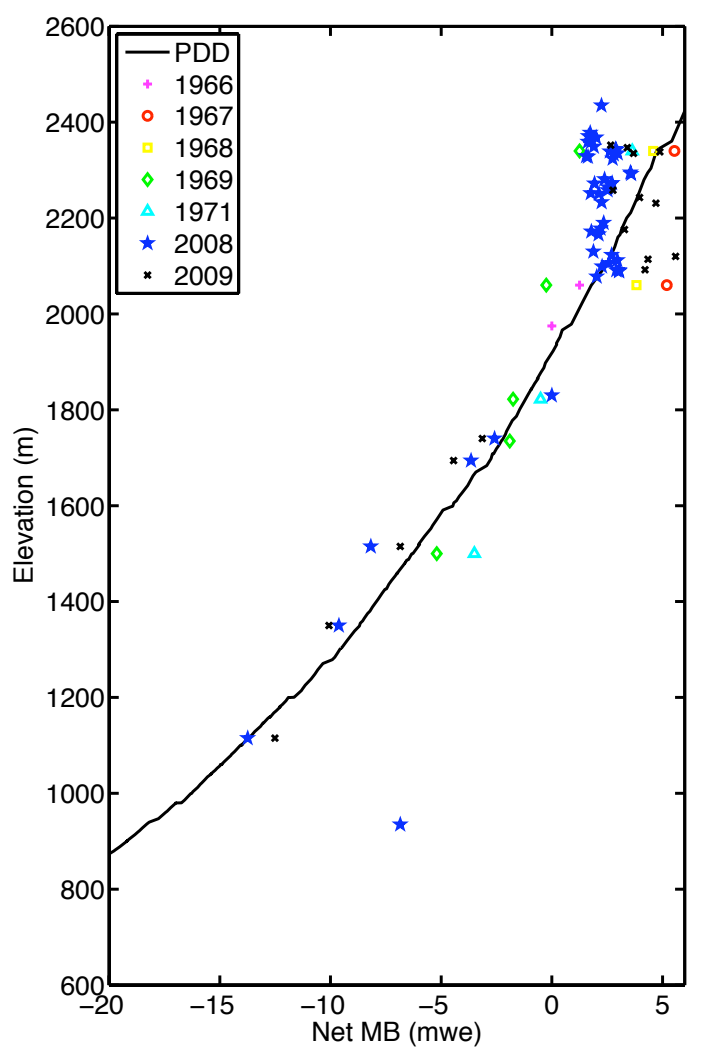

Figure 3.4: The modelled present-day mass balance profile for the Tasman Glacier using the PDD model, and available mass balance data. The mass balance curve is calculated statically, i.e. without being coupled to the flowline model. The PDD model does not include the effects of debris cover, which reduces ablation, accounting for the lowest-elevation data point.

defined as the sum over time of the number of degrees above $0^{\circ} \mathrm{C}$ for each day (e.g. Braithwaite, 1995; Hock, 2003). Air temperature is a strong predictor of melt because of the dominance of longwave radiation in the melt energy budget (Ohmura, 2001). The energy available for melt from longwave radiation is directly dependent on the air temperature at the emission level, which is most heavily influenced by 2 metre air temperature. The second most important environmental variable contributing to melt is shortwave radiation, which is also intimately tied to 2 metre air temperature, but is considered as a separate term here because it can be quantified with reasonable accuracy (Berger and Loutre, 1991). 


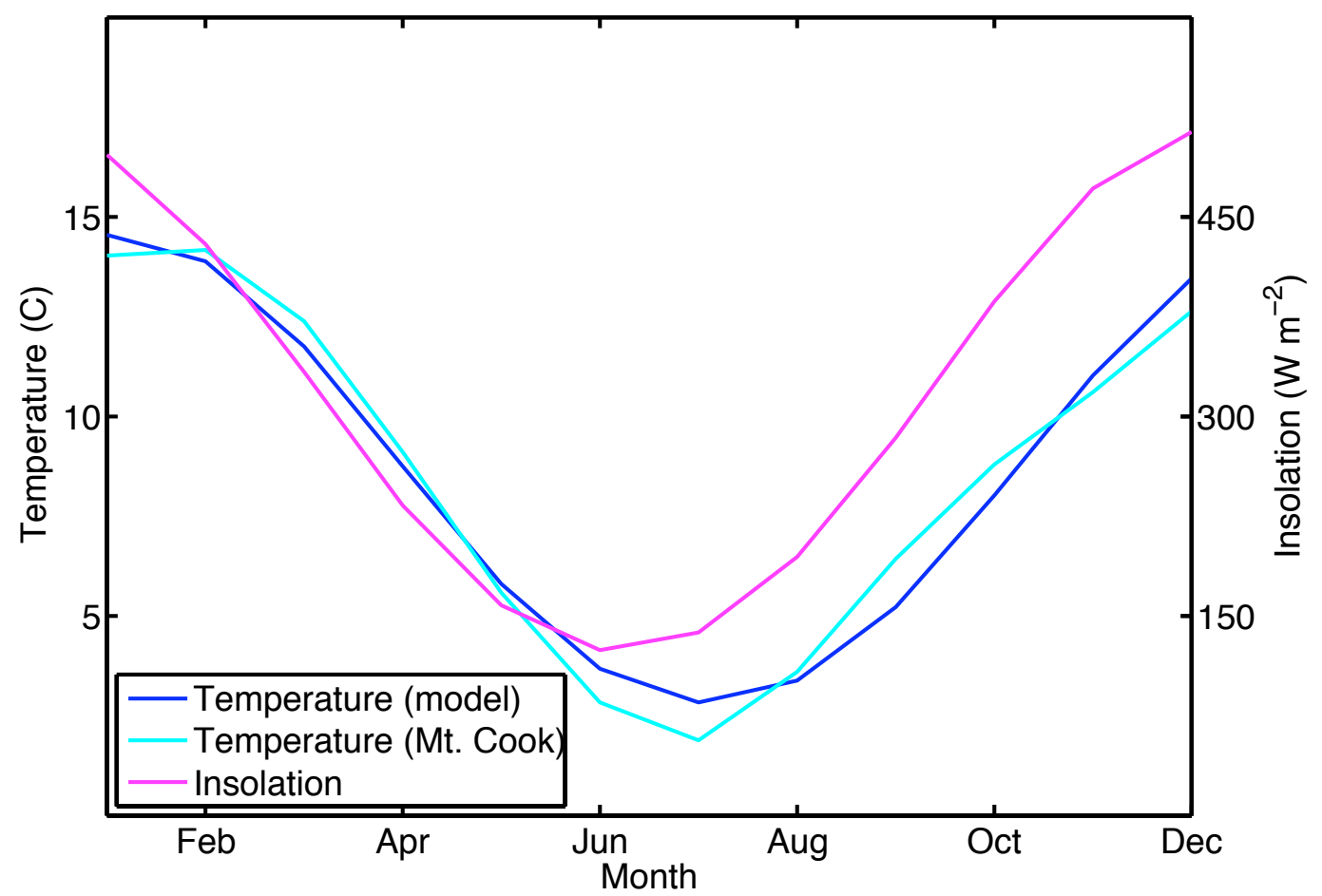

Figure 3.5: The modelled seasonal cycle in temperature compared to that measured at the Hermitage, Mt. Cook (left axis). The modelled temperature is based on a scaling and shifting of the seasonal cycle in insolation (right axis).

The scaling factor between the number of PDDs and the magnitude of melt is defined as the degree day factor (DDF, in units of meters-of-waterequivalent (mwe) day ${ }^{-1 \circ} \mathrm{C}^{-1}$ ). While the number of PDDs can, in theory, be calculated over any time period, longer time intervals are better since accuracy decreases with increasing temporal resolution (Hock, 2003). In this basic model, melt is calculated as

$$
\begin{aligned}
P D D & =\sum_{\text {day }=i}^{j} T_{\text {day }}^{+} \\
\text {melt } & =D D F \times P D D,
\end{aligned}
$$

where the number of PDDs are calculated between (and including) the $i^{\text {th }}$ and $j^{\text {th }}$ day of the year, and $\mathrm{T}_{d a y}^{+}$is the temperature, in Celsius, above $0^{\circ} \mathrm{C}$.

In this work, the basic model is modified in two ways. First, two different DDFs are used, $\mathrm{DDF}_{\text {snow }}$ and $\mathrm{DDF}_{\text {ice, }}$ which reflects the different melt rates 
for snow and ice due to their differing material properties, including albedo and the role of re-freezing. This requires calculating PDD values on shorter than annual timescales in order to take into account the seasonal cycle in snow accumulation; here, the calculation is done by calendar month. Second, a term scaling melt with incoming solar radiation is included; the inclusion of this term has been shown to better represent the climate sensitivity of a glacier (Oerlemans, 2001), critical for a study on past climates. The modified model can be written as

$$
\text { melt }(x)=J \sum_{\text {day }=1}^{365} \frac{I^{+} \times d t_{\text {year }}}{L_{f} \times \rho}+\sum_{\text {month }=1}^{12} P D D_{\text {month }} \times D D F(x),
$$

where $\operatorname{DDF}(x)$ is a function of space, so equation (3.15) is applied at each point along the flowline. Points are considered to be snow-covered if there has been snow accumulation for at least half of the month, and they are considered to be ice-covered otherwise. Following Huybers (2006), insolation contributes to melt only on days during which the daily mean is greater than $225 \mathrm{~W} \mathrm{~m}^{-2}\left(I^{+}\right)$; for the latitude of the Tasman Glacier, this correlates with days above freezing. $L_{f}$ is the latent heat of melting for water, $\rho$ is the density of water, and $d t_{\text {year }}$ is the number of seconds in a year. $J$ is in units of mwe $\mathrm{J}^{-1}$.

Improved methods have been developed for calculating the number of PDDs from the climatological annual temperature cycle. Here the solution introduced by Calov and Greve (2005), which offers benefits in computational efficiency and accuracy, is employed. In this method, PDDs are calculated as

$$
P D D=\int_{t 1}^{t 2} d t\left[\frac{\sigma}{\sqrt{2 \pi}} \exp \left(-\frac{T^{2}}{2 \sigma^{2}}\right)+\frac{T}{2} \operatorname{erf}\left(-\frac{T}{\sqrt{2} \sigma}\right)\right]
$$

where $[\mathrm{t} 1, \mathrm{t} 2]$ is the time period over which the PDDs are calculated, $\sigma$ is the standard deviation of the temperature from that cycle, taking into account the diurnal cycle and stochastic temperature variations, and $\mathrm{T}$ is the annual cycle in temperature. 
While the annual cycle in temperature is often modelled as a sinusoid, an investigation into paleoclimate encourages a connection between insolation and temperature. Seasonality (S) allows for this link between the temperature $(\mathcal{T})$ and insolation $(\mathcal{I})$ quasi-sinusoids, shown in Figure 3.5 and expressed as follows:

$$
\mathcal{T}=S \mathcal{I}-\mathcal{L}
$$

The lag, $\mathcal{L}$, between the insolation and temperature sinusoid is based upon their present-day relationship; simple energy balance modelling demonstrates that decreases in temperature and decreases in heat capacity (due to larger distances from the ocean) that may have occurred during the LGM are not sufficiently large to cause a change in the lag from present-day.

Insolation is calculated as a function of latitude, day, and years before present according to astronomical geometry (Berger and Loutre, 1991). ${ }^{1}$

Accumulation is calculated using a snow/rain threshold, below which precipitation is assumed to fall as snow. Annual cumulative precipitation is assumed to fall across the glacier surface and throughout the year at a uniform rate; however, only snow contributes to the positive mass balance.

The mass balance model is tuned to best match available mass balance measurements (Chinn, 1994; Kirkbride, 1995; Purdie et al., 2010), which span the time period 1966 to 2009 . The mass balance measurements are generally sparse for a given year (with the exception of 2008), which requires the assumption that they collectively represent a reasonable climatology. This conclusion is encouraged by the fact that the suite of measurements does present a consistent picture of mass balance that can be modelled using a single set of model parameters, but it is possible that the present-day model is biased due to lack of measurements.

In total, there are eight parameters that control the mass balance model. Mean annual temperature, cumulative annual precipitation, and strength of

\footnotetext{
${ }^{1}$ Code available at http:/ /www.ncdc.noaa.gov/paleo/pubs/huybers2006b/huybers2006b.html
} 
Table 3.1: Values for the constants used in the mass balance model. The latter two are physical constants; all others are calculated or taken from measurements.

\begin{tabular}{lll} 
Constant name & Value & Units \\
\hline \hline $\mathrm{DDF}_{\text {snow }}$ & $3.4 \times 10^{-3}$ & $\mathrm{~m} \mathrm{day}^{-1}{ }^{\circ} \mathrm{C}^{-1}$ \\
$\mathrm{DDF}_{\text {ice }}$ & $7.4 \times 10^{-3}$ & $\mathrm{~m} \mathrm{day}^{-1}{ }^{\circ} \mathrm{C}^{-1}$ \\
$\mathrm{~J}$ & $9.6 \times 10^{-5}$ & \\
$\mathrm{~T}_{\text {snow }}$ & 2 & ${ }^{\circ} \mathrm{C}$ \\
$\sigma$ & 4 & ${ }^{\circ} \mathrm{C}$ \\
Seasonality & 0.03 & \\
Lag & 26 & days \\
$\mathrm{L}_{f}$ & $3.34 \times 10^{5}$ & $\mathrm{~J} \mathrm{~kg}^{-1}$ \\
$\rho$ & $1 \times 10^{3}$ & $\mathrm{~kg} \mathrm{~m}^{-3}$
\end{tabular}

the seasonal cycle are set at present-day levels (Chapter 2) for model tuning. Lapse rate, the rain/snow threshold, $\mathrm{DDF}_{\text {snow }}, \mathrm{DDF}_{\text {ice, }}$ and $\mathrm{J}$ can be adjusted to match measurements. The five parameters, however, can compensate for each other in creating a mass balance curve, such that determining all of their values using a simple root-mean-square-error (RMSE) approach is not possible. To address this, three parameters are set to values determined from previous work. The lapse rate is set to $-7.2^{\circ} \mathrm{C} / \mathrm{km}$ (Ruddell, 1995) and $\mathrm{DDF}_{\text {snow }}$ is set to $3.4 \mathrm{~mm} \mathrm{day}^{-1{ }^{\circ}} \mathrm{C}^{-1}$, from the value measured by Cutler and Fitzharris (2005) that is also within the range of other mid-latitude glaciers (Hock, 2003). The snow / rain threshold $\left(\mathrm{T}_{\text {snow }}\right)$ is set to $2^{\circ} \mathrm{C}$, a value that falls between the range of estimates made for New Zealand (Barringer, 1989; Kerr, 2005) and provides a better fit to the available data. $\mathrm{J}$ and $\mathrm{DDF}_{\text {ice }}$ are then adjusted independently to reduce the RMSE between the model and observations. The value of these parameters and all others discussed in this chapter are shown in Table 3.1.

The sensitivity of the model to the five tuning parameters is examined. 

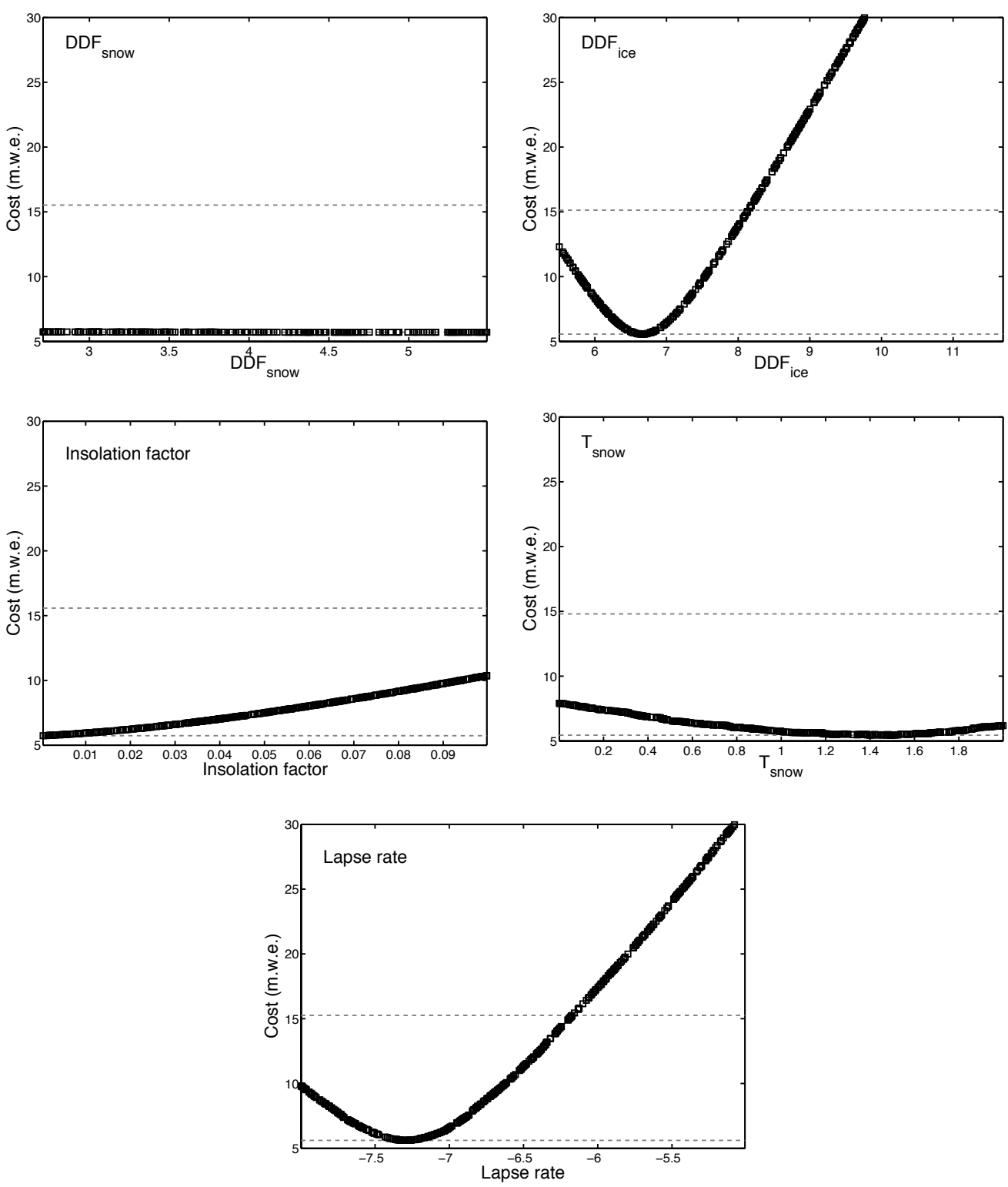

Figure 3.6: The RMSE (cost) between the modelled mass balance profile and the available data. For each sensitivity test, one variable is changed and the other four are kept at the values in Table 3.1. 

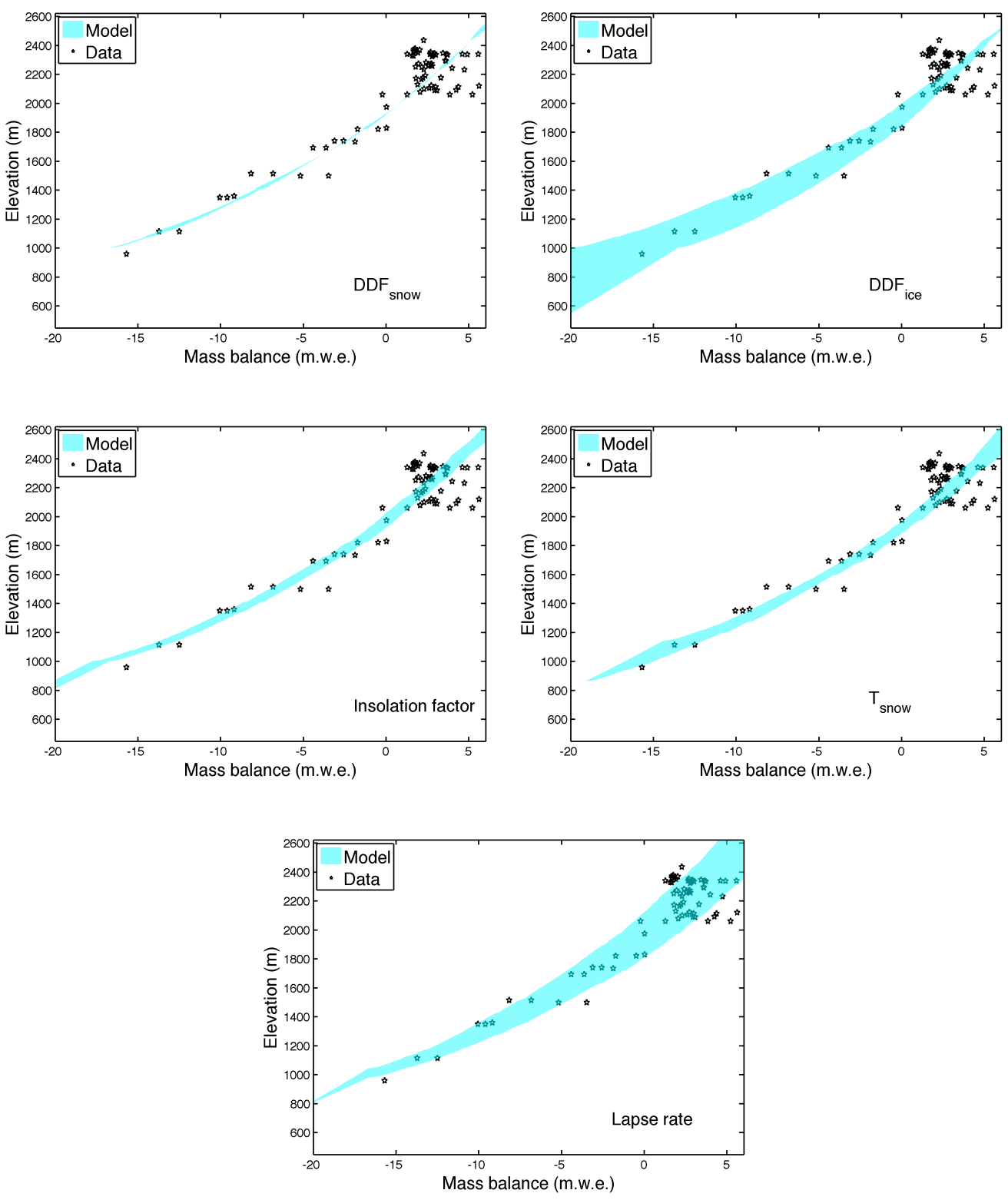

Figure 3.7: The spread of mass balance profiles calculated by varying each of the five tuning variables within its reasonable range (see text). For each sensitivity test, one variable is changed and the other four are kept at the values in Table 3.1. 
While holding the other four constant, each parameter is varied within a range consistent with that seen in the literature, and the RMSE between the model and the measurements is calculated (Figure 3.6). The interval of reasonable values for each parameter is considered as one e-folding length on either side of the minimum RMSE. If all RMSE values for the interval considered are less than the e-folding length cut-off, then the full original range from the literature is retained. The range of reasonable mass balance curves for each tuning variable are shown in Figure 3.7. The model is most sensitive to $\mathrm{DDF}_{\text {ice, }}$, because most ablation occurs in regions not dominated by accumulation, and the lapse rate, because the Tasman Glacier spans almost 2 kilometres in elevation.

The five tuned parameters constraining the model based on present-day data are assumed to be constant across time. This assumption is reasonable for all three degree-day factors: it is unlikely that the relationship between heat and melt has changed over time. Lapse rate, however, is dependent on relative humidity, which has likely changed between the LGM and today (e.g. Rojas et al., 2009). The snow/rain threshold may also be sensitive to humidity (Kienzle, 2008) and temperature (Yang et al., 1997). The sensitivity of the temperature reconstructions to all five variables within the reasonable ranges discussed above will be discussed in Chapter 4 .

\subsection{Other methods}

The fit of the full model to the moraine data is evaluated in two ways. First, the location of the glacier terminus is compared against the location of the terminal moraine furthest downvalley (LGM) or the inferred terminal moraine location (Late-glacial, since no terminal moraines are preserved on the outwash plain, see Figure 2.7). Second, fit to the full suite of moraines (terminal and lateral) is performed through a cost minimisation approach. 
Cost $\left(\mathrm{m}^{2}\right)$ is defined as $\sum_{x_{\text {moraine }}}\left(h_{\text {data }}-h_{\text {model }}\right)^{2}$.

All model code was written and simulations were performed in MATLAB. 


\section{Chapter 4}

\section{Reconstructing past glaciations}

\subsection{Constructed bed topography}

The three models discussed in Section 3.2 are used to construct LGM bed topography; despite their differences, the resultant bed profiles have a surprising number of similarities, as can be seen in Figure 4.1. All beds show an overdeepened trough of similar shape. Each model has a tuning parameter that allows control over the magnitude of the deepening ( $\tau_{y}$ for perfect plasticity, $\kappa$ for theoretical erosion, and $f_{d}$ and $f_{s}$ for mass flux); the latter two have been tuned so that no part of the bed goes below the sediment/bedrock interface, while perfect plasticity bed has been constrained less exactly due to its undulating nature. The non-physical oscillations in that bed reconstruction are due to the amplification of oscillations in the surface profile, as can be seen in equation 3.1 .

The similarity between the models encourages confidence in the largescale structure of the reconstructed bed. The bed produced from the mass flux model is used for all future analysis, due to its calculation from the same one-dimensional flowline model used for all other analysis, which allows the tuning parameters $\left(f_{d}\right.$ and $\left.f_{s}\right)$ to control model dynamics for the experiments on climate and glacier extent. The terminal overdeepening of the profile is consistent with field observations (Alley et al., 2003). 


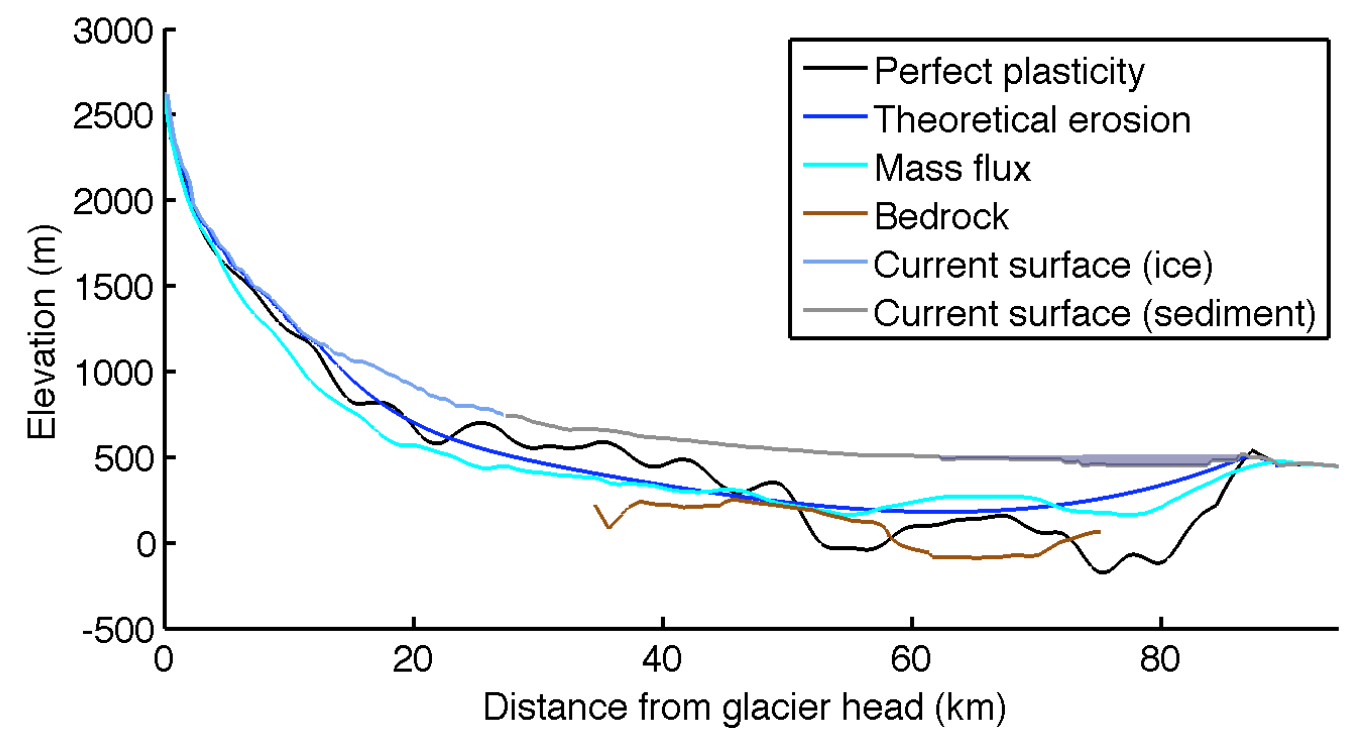

Figure 4.1: The reconstructed bed of the LGM Tasman Glacier based on three models: perfect plasticity, theoretical erosion and mass flux. While each has their drawbacks, they all reproduce a large overdeepened trough of similar shape.

\subsection{Last Glacial Maximum}

Implementing the coupled mass balance-flowline model atop the calculated bed profile allows for a reconstruction of the early LGM Tasman Glacier. The model indicates that LGM temperatures $7.0^{\circ} \mathrm{C}$ colder than present, combined with present-day precipitation, are necessary to best match the moraine record. The modelled Tasman Glacier is shown in Figure 4.2. The profile and extent match the lateral and terminal moraines.

The elevation of the lateral moraines is compared to the corresponding elevation of the modelled glacier profile in Figure 4.3. The model appears to be biased towards a slightly higher elevation profile than the moraines indicate, although the opposite relationship is true for both the lowest and highest elevation moraines. Model elevations reflect the surface profile along the centreline of the glacier, while lateral moraines indicate the elevation of the glacier edge. As such, higher model elevations are consistent with a convex glacier profile, typical of the lower reaches of valley glaciers. 


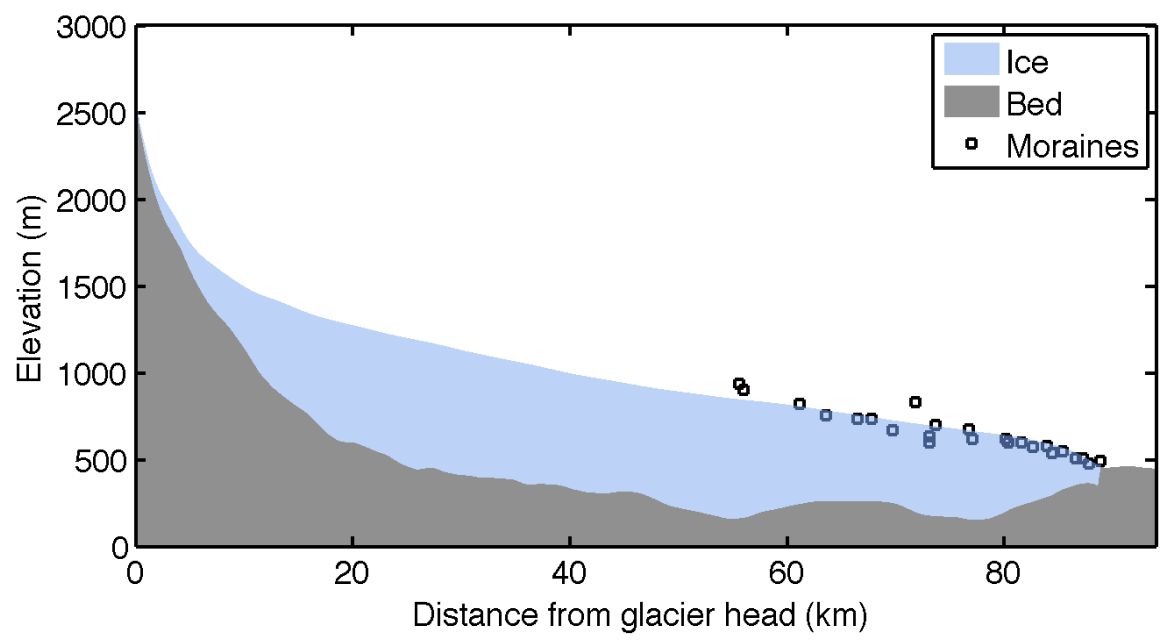

Figure 4.2: The equilibrium extent of the Tasman glacier, matching the early LGM moraine record, due to a temperature depression of $7.0^{\circ} \mathrm{C}$ from the present. Moraine heights are from the outermost true left lateral moraine ridges, based on Barrell et al. (2011).

Increases in precipitation and temperature have competing effects, and are able to compensate for each other. Perturbing precipitation from present levels around the aforementioned equilibrium solution shows that an increase (decrease) in precipitation of $10 \%$ can compensate for an increase (decrease) in temperature of $0.1^{\circ} \mathrm{C}$. Figures $4.4(\mathrm{a})$ and $4.4(\mathrm{~b})$ show that this relationship is not linear: smaller temperature depressions are compensated by larger precipitation increases.

Uncertainty in the reconstruction due to the mass balance model and the calculated bed profile is addressed. The reasonable range of values for the five tuning parameters in the PDD model are used as a basis for determining uncertainty due to mass balance. The temperature depression required to reproduce the LGM glacier extent is re-calculcated for the two extremes of each tuning parameter, leading to 10 additional parameter sets in total.

The model is most sensitive to the insolation scaling factor, J, which spans the largest range and is the least constrained by the literature. Excluding the end member using the higher value of $\mathrm{J}$, the reconstructions span the range 


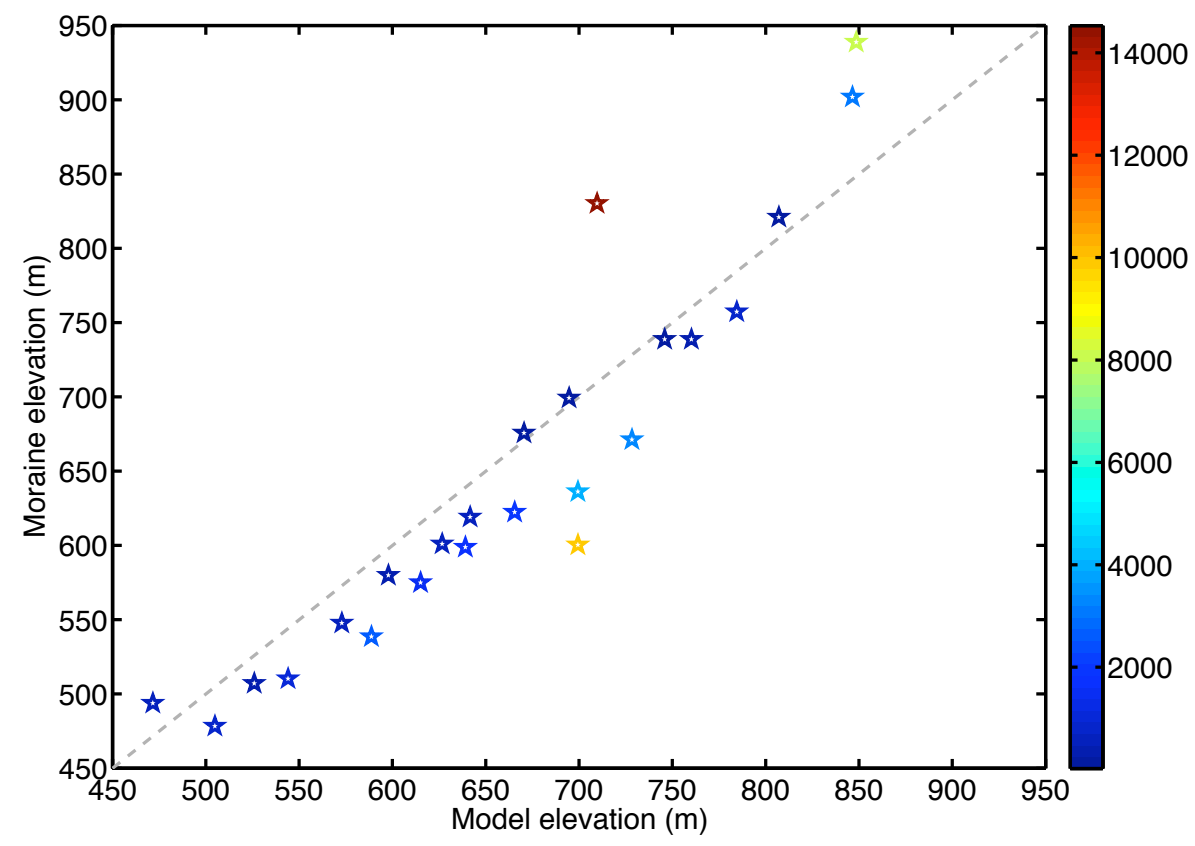

Figure 4.3: Modelled glacier profile elevation versus moraine ridge heights along the flowline for the early LGM. Moraine heights are from the outermost true left lateral moraine ridges, based on Barrell et al. (2011). Colour indicates cost. The dotted grey line indicates a one-to-one relationship.

$6.5-9.0^{\circ} \mathrm{C}$ cooler than present. Interestingly, this range is skewed towards larger temperature depressions than the value of $7.0^{\circ} \mathrm{C}$ cooler than present found using the set of parameters considered to best represent the system (see Table 3.1 and Section 3.4). Furthermore, the reconstructions from the two end member values of $\mathrm{DDF}_{\text {snow }}$ and $\mathrm{T}_{\text {snow }}$ bracket a range that does not overlap with the original $7.0^{\circ} \mathrm{C}$ temperature depression. This may indicate that there are non-linearities in the model; additional model simulations with parameters between the end members are necessary.

The bed profile is constrained by the imaged bedrock surface, which is used as a lower bound on the calculated bed, as discussed in Section 4.1. The elevation of this surface is, however, uncertain because (1) it is projected from the edge of Lake Pukaki to its centre, and (2) its depth depends on correct velocity modelling. The bed is recalculated by moving the bedrock surface up and down in elevation 200 metres. Because the bed profile model involves 

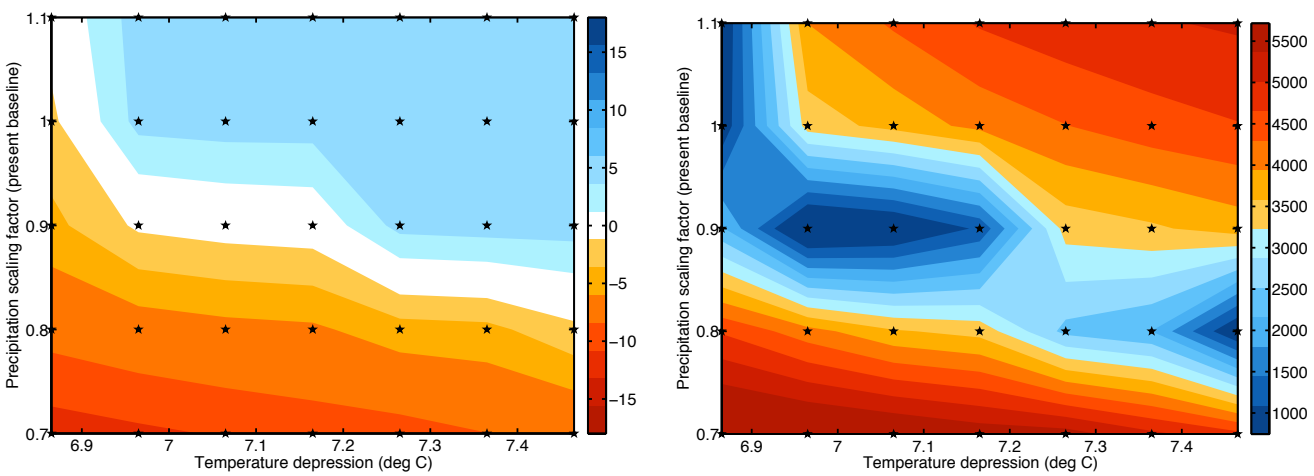

Figure 4.4: The response of the model to changes in temperature and precipitation. Left: The difference in distance along the flowline between the modelled terminus location and the location of the terminal moraine, measured in kilometres. Right: The value of the cost function. There are three minima in cost where the glacier model bests fits the moraine record. The negligible difference in cost between all three minima indicates that, in this case, the moraine record cannot provide information about the relative roles of temperature and precipitation in past climates. On both plots, black stars indicate model simulations from which the contours are based.

adjustment of the flow parameters, both $f_{d}$ and $f_{s}$ change with the calculated bed. Lowering the bedrock surface by 200 metres also yields a temperature reconstruction of $7.0^{\circ} \mathrm{C}$ colder than present. While this may seem surprising, the flow parameters provide a link between the bed profile and the flowline model, which apparently allows for different bed profiles to lead to the same temperature reconstruction. The effect is slightly asymmetric: increasing the elevation of the bedrock constraint leads to a temperature reconstruction of $6.7^{\circ} \mathrm{C}$ colder than present. Nevertheless, the effect remains smaller than the sensitivity to any of the mass balance terms due to the compensating effect of changing the flow parameters.

The sensitivity of the model to seasonality, or the amplitude of the annual temperature cycle, is briefly examined. Increased seasonality for a constant mean temperature leads to decreased glacier extent. To compensate for an increase in the amplitude of the seasonal cycle of $1^{\circ} \mathrm{C}$ during the LGM, an 
Table 4.1: The range of temperature depressions for the early LGM calculated from changing the five parameters in the model from their base values, shown in Table 3.1.

\begin{tabular}{llll} 
Constant name & Range $($ values $)$ & Units & Range $\left(\Delta \mathrm{T},{ }^{\circ} \mathrm{C}\right)$ \\
\hline \hline $\mathrm{DDF}_{\text {snow }}$ & $2.7-5.5 \times 10^{-3}$ & m day $^{-1}{ }^{\circ} \mathrm{C}^{-1}$ & $7.7-7.8$ \\
$\mathrm{DDF}_{\text {ice }}$ & $5.5-8.1 \times 10^{-3}$ & $\mathrm{~m} \mathrm{day}^{-1}{ }^{\circ} \mathrm{C}^{-1}$ & $6.5-8.1$ \\
$\mathrm{~J}$ & $9.6 \times 10^{-5}-0.1$ & & $7.0-11.4$ \\
$\mathrm{~T}_{\text {snow }}$ & $0-2.5$ & ${ }^{\circ} \mathrm{C}$ & $8.6-7.6$ \\
Lapse rate & $-8--6.2$ & ${ }^{\circ} \mathrm{C} \mathrm{km}^{-1}$ & $6.9-9.0$
\end{tabular}

additional $0.5^{\circ} \mathrm{C}$ temperature depression is required.

\subsection{Transition from early to late LGM}

The moraine record around Lake Pukaki has been interpreted by Barrell et al. (2011), following Porter (1975), to represent two distinct glaciations during the LGM: the larger early LGM and slightly smaller late LGM. While the difference between the two is difficult to distinguish along the true right of the glacier due to the steep topography of the Ben Ohau Range, the early LGM moraines outline a longer, wider glacier than the late LGM glacier. Is a different mean climate necessary to produce these two states?

Due to the highly-dynamic nature of the Tasman system, the assumption of a constant bed between the early and late LGM is insufficient, so the effects of changing topography on glacier extent must be considered. The bed for the late LGM glaciation is calculated, once again using the methods of Section 3.2.3. Interestingly, without constraining it to be so, the majority of the late LGM bed is lower in elevation that the early LGM bed, as one would expect due to erosive processes. The early LGM equilibrium glacier thickness is then applied as an initial condition for the model simulation. The temperature signal required for a retreat to the late LGM position is a 


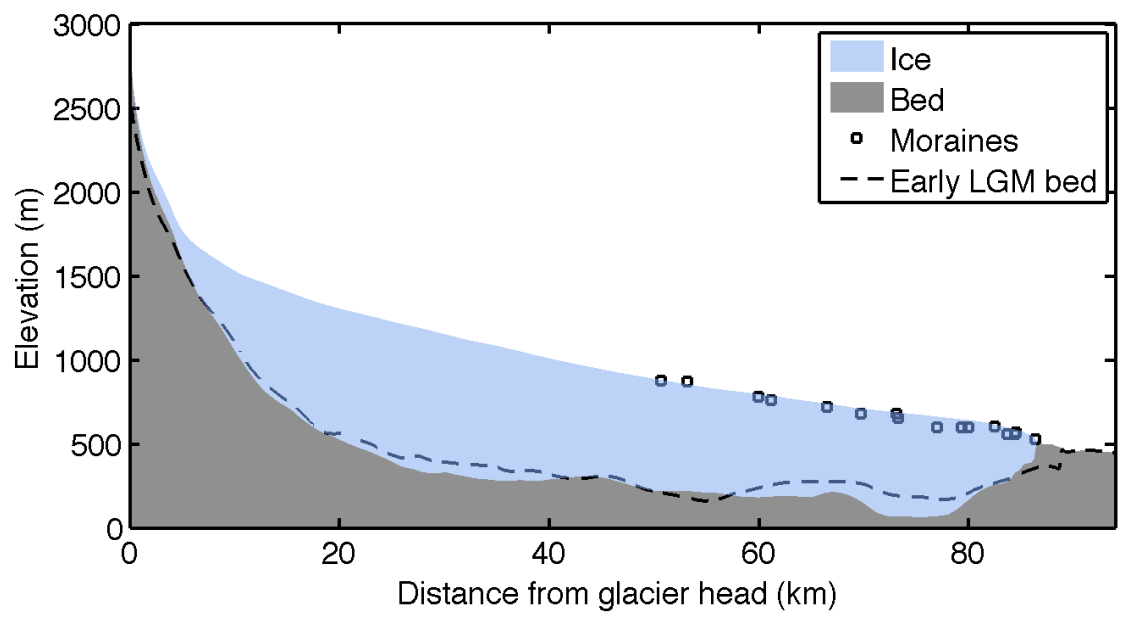

Figure 4.5: The equilibrium profile of the late LGM Tasman glacier, with moraine heights from Barrell et al. (2011). The dashed black line indicates the early LGM bed. Erosional processes, leading to a shift from the early to late LGM bed, combined with a small temperature signal, cause the reduction in glacier extent.

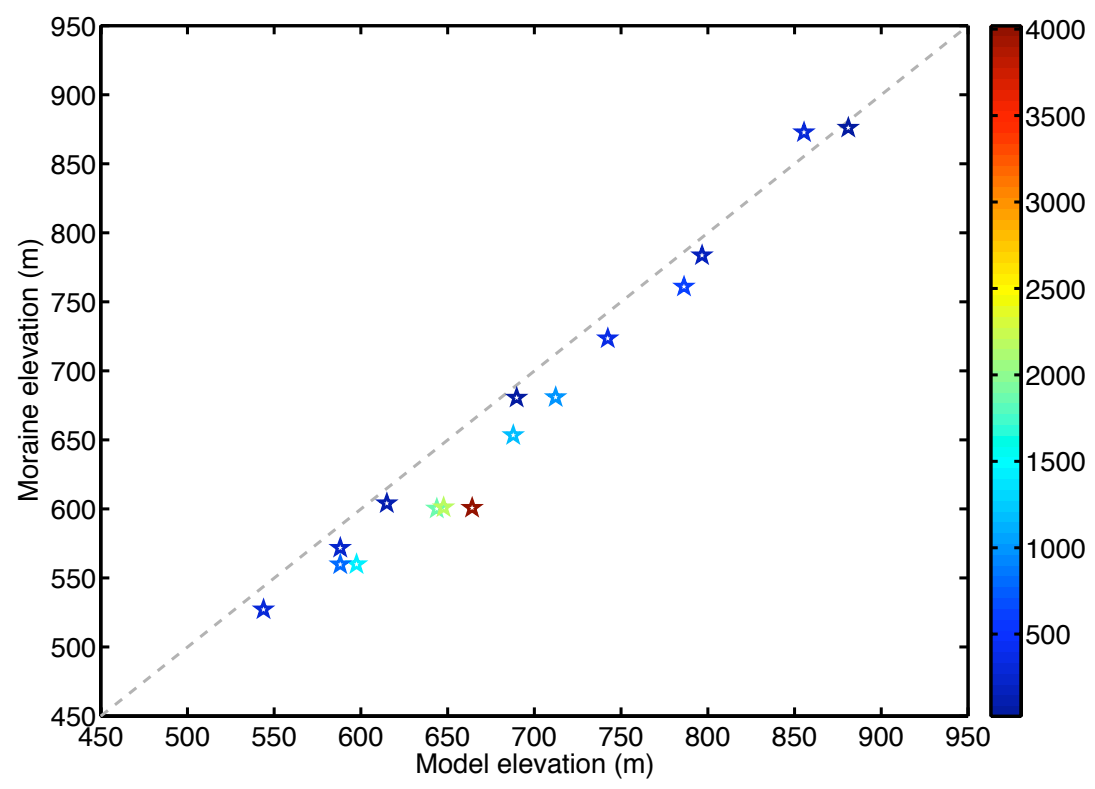

Figure 4.6: Modelled glacier profile elevation versus moraine ridge heights along the flowline for the late LGM. Moraine heights are from the outermost true left lateral moraine ridges, based on Barrell et al. (2011). Colour indicates cost. The dotted grey line indicates a one-to-one relationship. 
warming of $0.1^{\circ} \mathrm{C}$; the resulting glacier profile is shown in Figure 4.5.

The moraine and modelled elevations are again compared in Figure 4.6. Whereas the fit between the two is close to the one-to-one line, the modelled glacier profile is consistently at a slightly lower elevation than the moraine heights, which may once again reflect the convex glacier cross-sectional profile.

\subsection{Late-glacial}

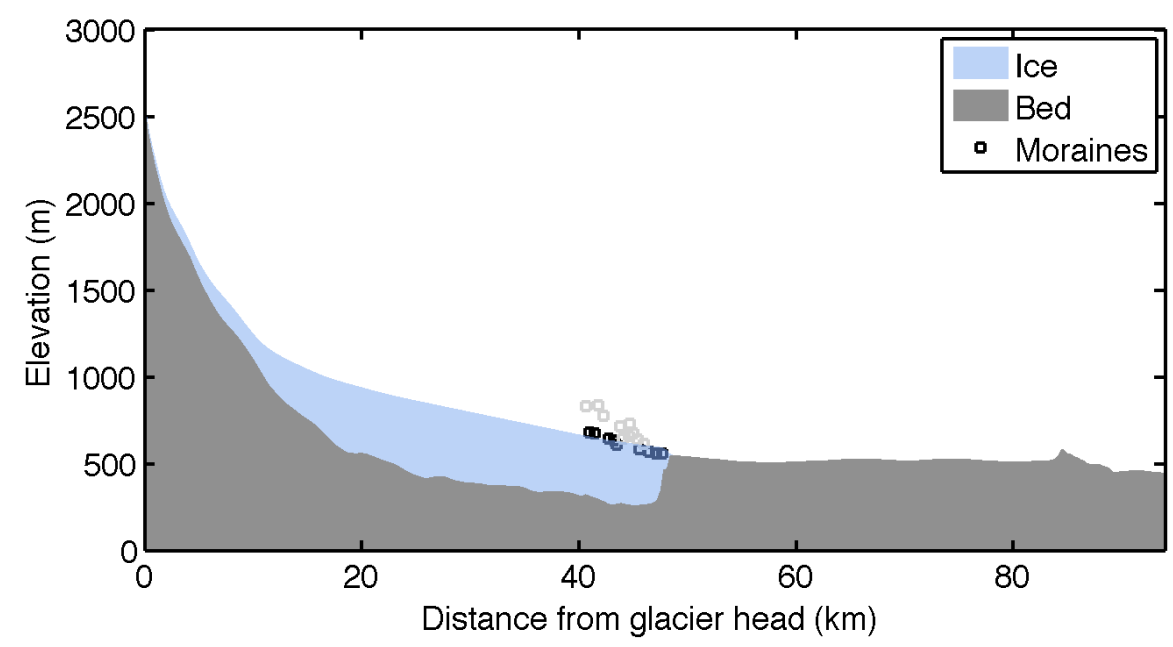

Figure 4.7: The equilibrium extent of the Tasman glacier, best matching the Lateglacial moraine record, due to a temperature depression of $2.2^{\circ} \mathrm{C}$ from the present. Moraine heights are from the true left lateral moraine ridge, based on Barrell et al. (2011). Heights used for modelling are in black, remaining heights are in grey.

The methods used for reconstructing the LGM Tasman glacier are applied to the Late-glacial. The Late-glacial moraine record provides a less clear longitudinal profile than the LGM record, even when only the true left moraine ridge is considered for consistency with the LGM. As can be seen in Figure 4.7, there are two different longitudinal profiles that could be chosen from the lateral moraines; the heights chosen for constraining the model are in 

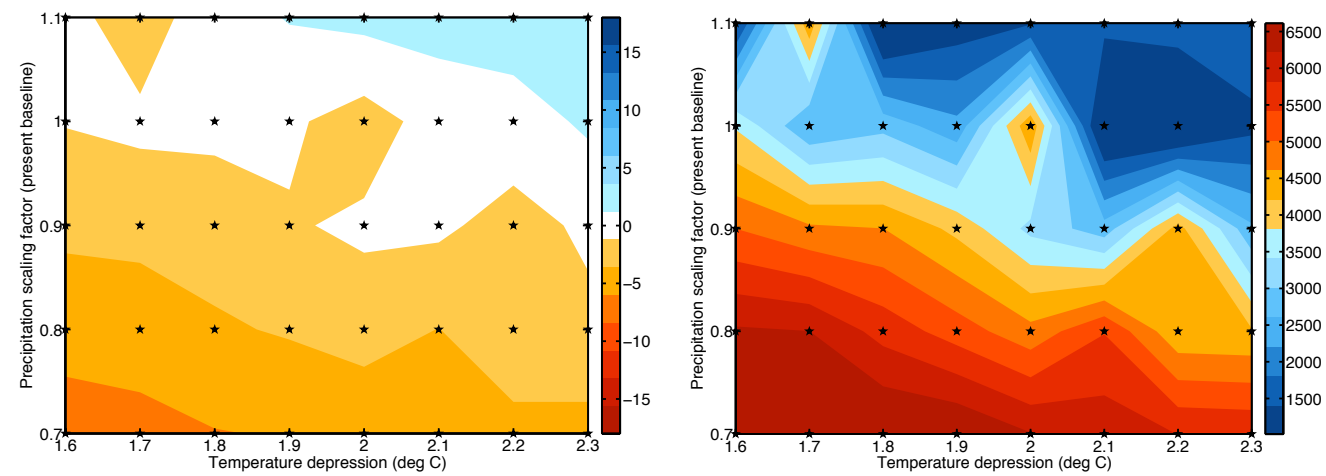

Figure 4.8: As in Figures 4.4(a) and 4.4(b), but for the Late-glacial reconstruction. Three different temperature/precipitation combinations allow for equivalent reproduction of the Late-glacial Tasman.

black, while the others are in grey. The opposite choice would require a less overdeepened bed and/or lower flow parameters, leading to a steeper profile. Because the calculated Late-glacial bed and associated flow parameters are consistent with those found for the LGM, the lower profile is chosen. ${ }^{1}$

The best fit result for current levels of precipitation is found with a temperature depression of $2.2^{\circ} \mathrm{C}$ from the present, and is shown in Figure 4.7. Temperature and precipitation sensitivity analysis shows that good fit is also produced with a temperature depression of $1.8^{\circ} \mathrm{C}$ if precipitation is increased by $10 \%$ (Figures $4.8(\mathrm{a})$ and $4.8(\mathrm{~b}))$. A 10\% decrease in precipitation requires a temperature depression of $2.4^{\circ} \mathrm{C}$. There is not a consistent linear relationship between the effects of temperature and precipitation changes.

\subsection{Erosional influence}

The magnitude of change between the glacier beds and the role of evolving bed topography in the transition from early to late LGM glacier extent

\footnotetext{
${ }^{1}$ The two profiles may also represent the evolution of the glacier profile during the Lateglacial. Analogous to the behaviour of the Tasman glacier today, the Late-glacial Tasman may have downwasted before retreating, leaving a record of both a more elevated and flatter profile.
} 
indicates that erosional and depositional processes are important to consider when modelling glaciers of the past in dynamic environments and that glacier size is sensitive to bed topography. The primary reason for this sensitivity is the height-mass balance feedback. For an atmospheric lapse rate of $-7.2^{\circ} \mathrm{C}$ per kilometre, as is used in this study, an increase in surface height of 140 metres closely corresponds to an effective cooling of $1^{\circ} \mathrm{C}$. Conversely, as a glacier erodes out its bed, the surface lowers, causing an effective warming, which will lead to retreat. The magnitude of this effect was shown through a general numeric model by Oerlemans (1984): a warm, maritime mountain glacier could retreat up valley 50 kilometres over 30,000 years due to erosion of its bed alone.

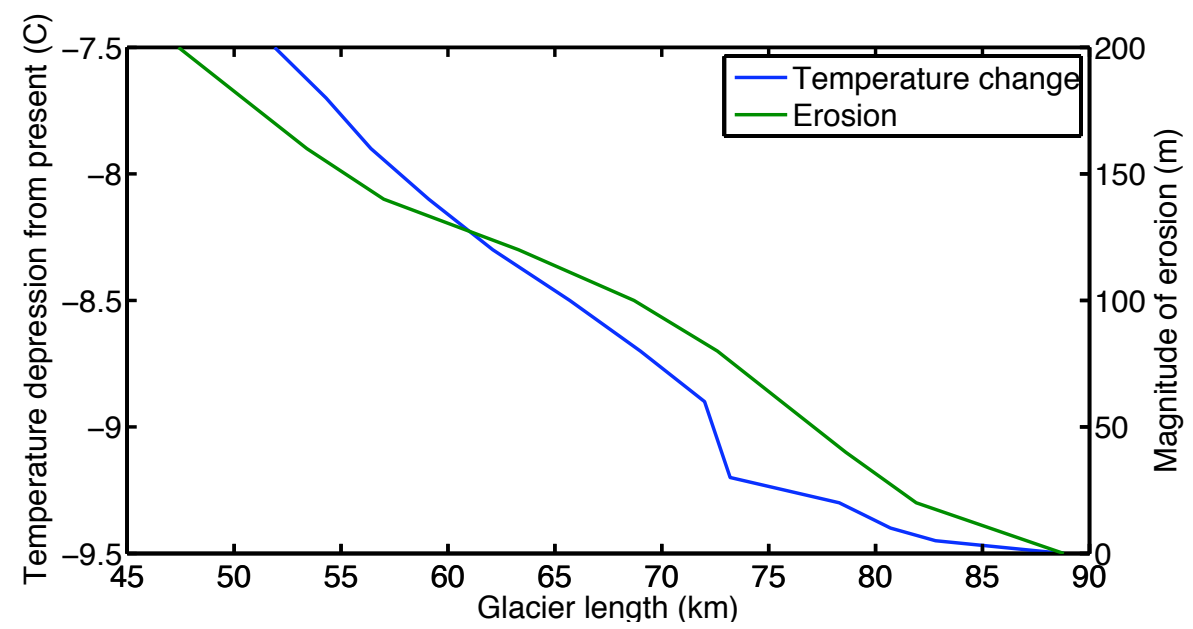

Figure 4.9: Glacier retreat due to change in temperature (blue line, left axis) and reduction in bed elevation due to erosion (green line, right axis). The two processes can have similar effects on glacier extent, and both should be considered when extracting a climate signal from a glacier record. Erosion is modelled as a decrease in bed elevation from the calculated early LGM bed. The magnitude of decrease in elevation varies along the flowline under the assumption that the glacier will have the greatest erosive force in locations that already exhibit the most erosion; the glacier extent in plotted against the maximum decrease in elevation along the flowline. 
In order to quantify this effect with respect to the Tasman glacier, an idealised experiment is performed. Beginning with the early LGM bed, a suite of new beds is created with different magnitudes of erosion, encapsulated in the lowering of the bed topography. The coupled model is then run with the early LGM equilibrium climate, until the glacier reaches a new equilibrium. The results are shown in Figure 4.9, with a comparison to the relative influence of temperature changes. The results of this experiment are largely instructive rather than physically-meaningful because the requisite depositional processes are not included. Regardless, the large influence of the process of glacier erosion on glacier extent is clear. Together with the results of Roe and O'Neal (2009) and those discussed in Section 4.3, this experiment implies that care must be taken when extracting a climate signal from a moraine record, especially one from a single mountain glacier when the magnitude of length change is relatively small. Dynamic glacier models and reasonable estimates of past bed topography, however, can assist in addressing these issues. 


\section{Chapter 5}

\section{Discussion and conclusions}

This work aimed to place constraints on the climate of the Late-glacial and early and late LGM through one-dimensional glacier modelling. The results show that a relatively large cooling is required to drive the Tasman Glacier to its LGM extent, and a significant warming $\left(\sim 5^{\circ} \mathrm{C}\right)$ between the LGM and Late-glacial. The application of glacier models to well-preserved and -mapped moraine sequences is a promising avenue for determination of past climate, but a careful consideration of changing bed topography is critical in a location with active uplift, erosion and sedimentation like the Southern Alps.

\subsection{Climates of the past}

Glacier extent is fundamentally controlled by mass balance; a positive perturbation from equilibrium will lead to advance, while retreat will occur in response to a negative one. Many aspects of climate affect mass balance, in addition to temperature and precipitation, such as cloudiness, windiness, relative humidity and lapse rate. Due to the unconstrained nature of the LGM and Late-glacial climate and encouraged by the success of simple melt factor models (e.g. Braithwaite and Olesen, 1989), this study focuses primarily on changes in temperature as a stand-in for climatic changes. Changes in pre- 
cipitation are also considered through sensitivity studies, but are less influential (Anderson and Mackintosh, 2006) and more unconstrained. The focus on temperature additionally allows for ease of comparison to other similar studies.

\subsubsection{The early Last Glacial Maximum}

The $7.0^{\circ} \mathrm{C}$ early LGM temperature depression found here is placed in the context of other studies in Table 5.1. Across the entire suite of studies considered, the temperature depression found here is among the largest. Among the SST temperature reconstructions, there is some evidence of a latitudinal gradient, with lager temperature depressions in the southernmost parts of New Zealand. If this gradient were to extend on to land, the temperature depression found in this study and those from North Island studies would not be at odds, but rather reflective of a spatially-coherent pattern. Outliers are found in the Shulmeister et al. (2001) and Rother and Shulmeister (2006) studies. The former found a large temperature depression near Auckland, North Island, while the latter found a small one in the Southern Alps, South Island. The Rother and Shulmeister (2006) study focused on a generalised region that the authors argued was broadly representative of the Southern Alps, so perhaps should not be spatially-anchored but rather viewed as a proof-of-concept. If these two studies are excluded, temperature depressions in the range of 4 to $5^{\circ} \mathrm{C}$ have been found on the North Island, while this study found $7.0^{\circ} \mathrm{C}$ on the South Island. More location-specific studies on LGM temperature depressions are clearly needed to flesh out this hypothesis.

ELA reconstructions, when translated into temperature changes using a lapse rate, show warmer conditions than those found here. For instance, ELA reconstruction at Boulder Lake indicates a $5-7^{\circ} \mathrm{C}$ temperature decrease for the LGM, taking into account the effects of changing precipitation (McCarthy et al., 2008), or $6.3^{\circ} \mathrm{C}$ if present-day precipitation is used (calculation based on 


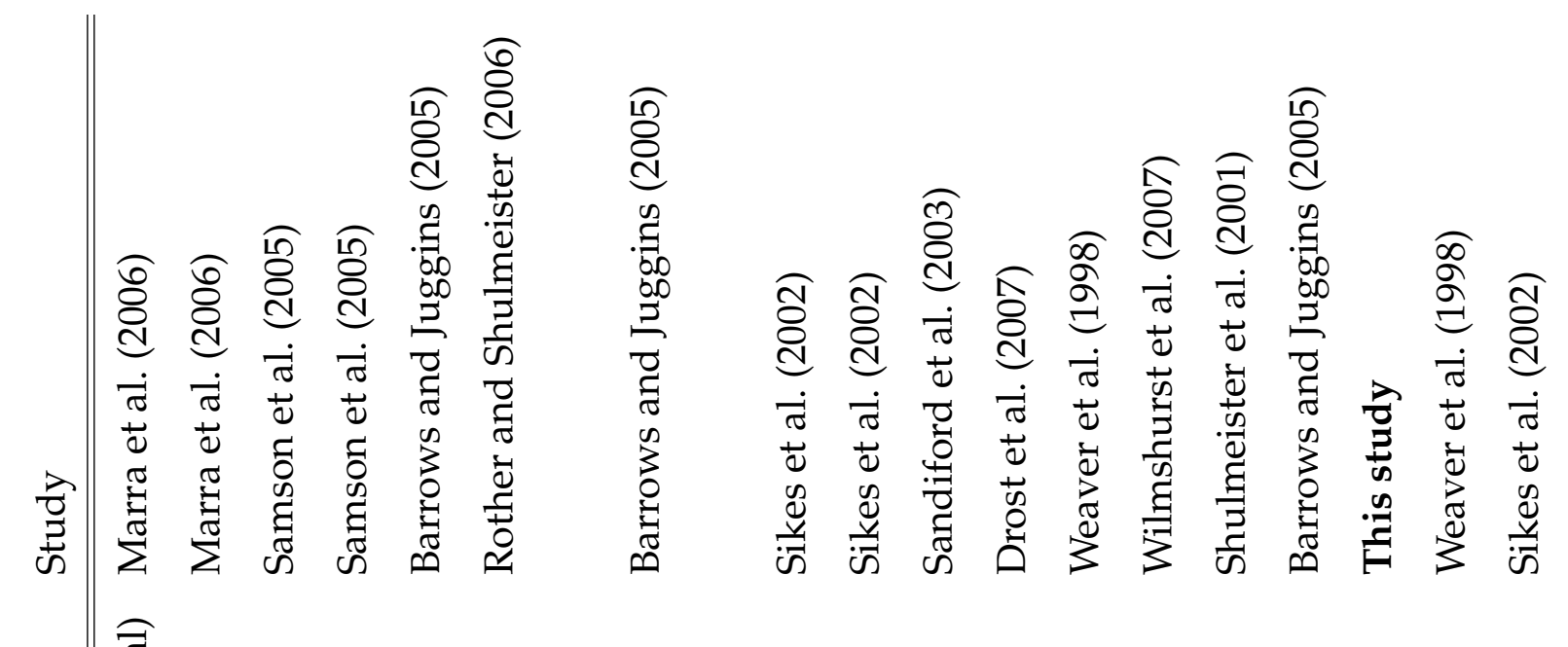

है

离

害

들

$\stackrel{9}{7}$

$\Xi$

క్

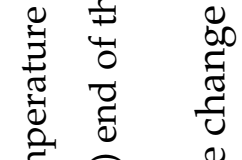
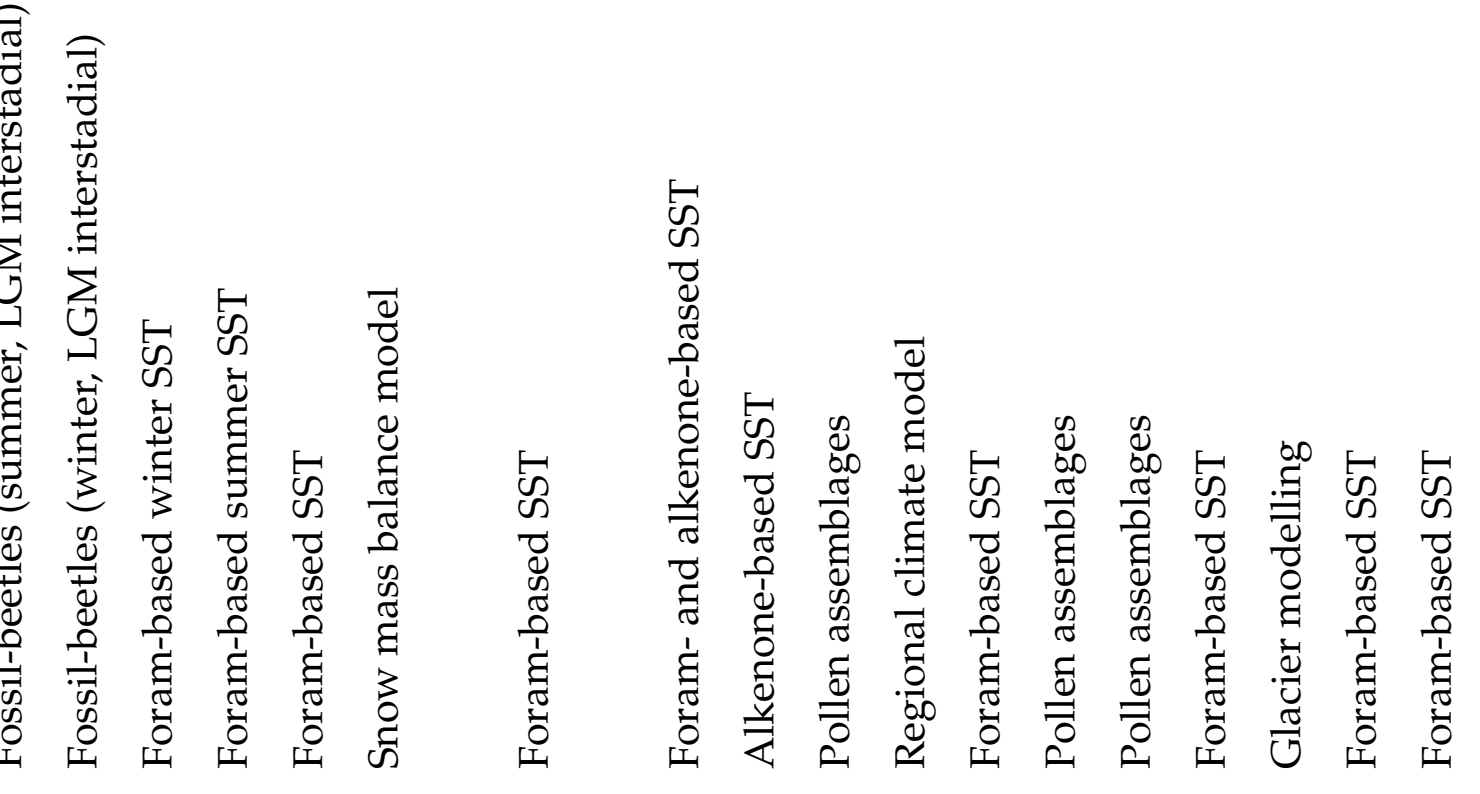

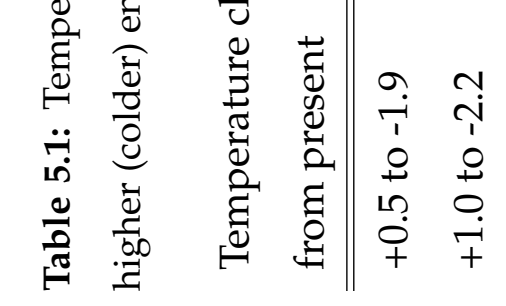

की

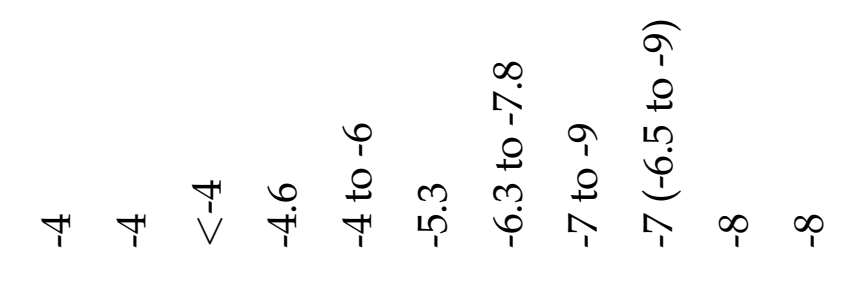


ELA depression and $-6.5^{\circ} \mathrm{C} / \mathrm{km}$ lapse rate). Similar results are found using other reconstructions in New Zealand (Porter, 1975; Bacon et al., 2001). Some of these differences may be due to assumptions about lapse rates and uncertain dating. More interestingly, this discrepancy may reflect the fact that a glacier can influence its own local climate. For a temperate glacier like the Tasman, the surface can be assumed to always be at the melting point, $0^{\circ} \mathrm{C}$. The 2 metre air temperature, solved for in modelling and usually measured in glacier studies, will reflect the combined influence of the "regional" temperature and the surface temperature (Greuell and Böhm, 1998). If the regional temperature is below freezing, the local ( 2 metre) temperature will be warmer; however, if the regional temperature is above freezing, the local temperature will be colder than the regional one, due to the influence of the ice surface temperature. Furthermore, these effects will not cancel out, because local temperatures above freezing affect melt, but local temperatures below freezing will have minimal effect on accumulation. By these arguments, the local temperature depression solved for via a glacier model like that used here may be cooler than the regional temperature. Assuming that the magnitude of this effect does not change across climate regimes, it will not affect temperature reconstructions found through ELA depressions, since all calculations are comparative, leading to a cancellation of absolute biases. Future quantification of this effect will assist in comparisons between the two methods of temperature reconstructions.

Downscaled climate models have the potential to provide paleotemperature estimates across New Zealand, although they require a number of initial and boundary conditions that may be unknown themselves, such as SST patterns for atmospheric models. Drost et al. (2007) found a mean temperature depression across all of New Zealand of $4.6^{\circ} \mathrm{C}$, but the change over the Southern Alps was substantially larger, between 6.5 and $9^{\circ} \mathrm{C}$. These values are largely a function of prescribed orography in the mountains, however, which was up to 1000 metres higher than present in some locations, so may 
be unrealistic. Temperature changes inferred from vegetation are larger than those shown in models, leading Drost et al. (2007) to suggest that increased seasonality would allow for both moderate temperature depressions and a climate harsh enough to support primarily grass- and shrub-lands. It is not unreasonable to assume that the strength of the seasonal cycle would have increased during the LGM due to lower sea levels, leading New Zealand to become more continental. Because glaciers tend to be more sensitive to warm summers than cool winters (Oerlemans and Reichert, 2000), increasing seasonality requires a colder mean temperature for the Tasman Glacier as modelled here.

\subsubsection{The late Last Glacial Maximum}

The LGM in New Zealand extended from $\sim 28 \mathrm{kyr}$ ago to $\sim 17 \mathrm{kyr}$ ago (Suggate and Almond, 2005; Schaefer et al., 2006; Newnham et al., 2007a). Was there a temperature trend during this period, leading up to the postLGM warming? Barrell et al. (2011) characterised the LGM Tasman Glacier moraines as belonging to the early or late LGM, with the latter being up to 3.5 kilometres shorter and 2 kilometres less wide than the former. This change in extent was interpreted by Porter (1975) to indicate an elevation of the ELA by 125 metres, which is related to an increase in temperature or a decrease in precipitation. However, changes in glacier extent should not immediately be interpreted as climatically-driven for two reasons. First, as has been shown by Roe and O'Neal (2009), glaciers can advance or retreat on the scale of 1-2 kilometres due to zero-trend natural variability (i.e. modes of variability like El Niño/Southern Oscillation), even if all other environmental variables are held constant. Due to the nonzero response time of a glacier, a temperature signal that has no persistence (i.e. white noise) will not lead to an analogous glacier response. Rather, the glacier serves as a filter that "sees" only the lower-frequency signals within the white noise, as shown in Figure 5.1. 


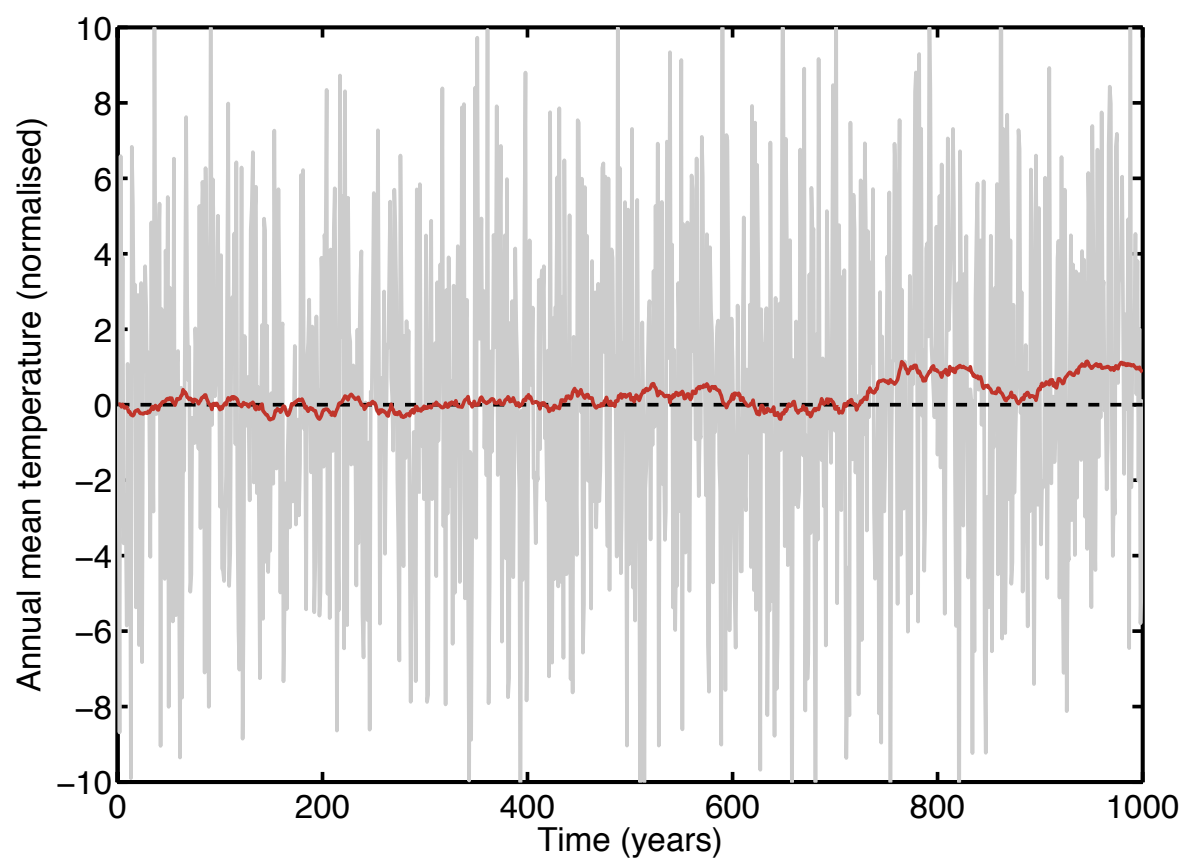

Figure 5.1: An illustrative example of the effect of a low-pass filter on white noise. The white noise (grey) is generated from a zero-mean normal distribution with a standard deviation of $4.3^{\circ} \mathrm{C}$, based on the standard deviation of the annual temperatures (1930-1999) at the Mt. Cook Hermitage (data from the NIWA Climate Database). A glacier acts to integrate a stochastic climate signal; here, a 50-year running mean is used as the low-pass filter, which can lead to an upwardly-trending temperature forcing on the glacier. In the example shown here, the upwardlytrending signal is concentrated in the last 300 years.

The resulting temperature time series is no longer trend-free noise; instead, it can induce long-term fluctuations in glacier length. Second, glaciers modify their own environments through erosion, deposition and transport. As was shown here and has been suggested more broadly by Kaplan et al. (2009), it appears that processes of bed erosion can lead to glacier retreat without a significant climate signal. Combing these two theories, the null hypothesis that the transition from the early to late LGM extents occurred within a stable climate cannot be eliminated. The $0.1^{\circ} \mathrm{C}$ temperature increase needed in the model to initiate the retreat falls within a range that could be ex- 
pected due to inter-decadal, zero-trend natural variability alone (Figure 5.1). A present-day example of this can be seen in Franz Josef glacier, which advanced over a kilometre between 1982 and 1999 due to changes in atmospheric circulation patterns and despite the anthropogenic warming trend. (Hooker and Fitzharris, 1999).

A minimal change in mean climate across the LGM as a whole is consistent with Southern Hemisphere temperature inferred from the EPICA Dome C core (Barbante et al., 2006). New Zealand land-based proxies seem to tell a similar story (see Figure 1.2 and Alloway et al. 2007), although the Okarito bog (Newnham et al., 2007b) and Northwest South Island speleothem (Williams et al., 2005) records indicate a small downward trend in temperature throughout the LGM. A purely geometric interpretation of the glacier moraine record around Lake Pukaki would lead one to disagree with these proxy records, and argue for a gradually warming LGM, whereas modelling reveals a consistency with other proxy records.

\subsubsection{The Late-glacial}

The Late-glacial reconstruction requires a temperature depression of $2.2^{\circ} \mathrm{C}$ from present, which is in the mid-range of estimates from other studies (Table 5.2). The question of greater interest is not, however, the absolute temperature during the Late-glacial but rather the temperature before the period began: does the Late-glacial represent an anomalous period of cooling amidst the warming trend between the LGM and the Holocene, or was it simply a stop on the way towards a warm Holocene, not indicative of a change in trend? The Northern Hemisphere shows evidence of the former, which has been termed the Younger Dryas, but the Southern Hemisphere record re-

mains inconclusive with respect to the existence and timing of the event, and its relationship to Northern Hemisphere cooling. For instance, the moraine record around Lake Pukaki on the east side of the Southern Alps 


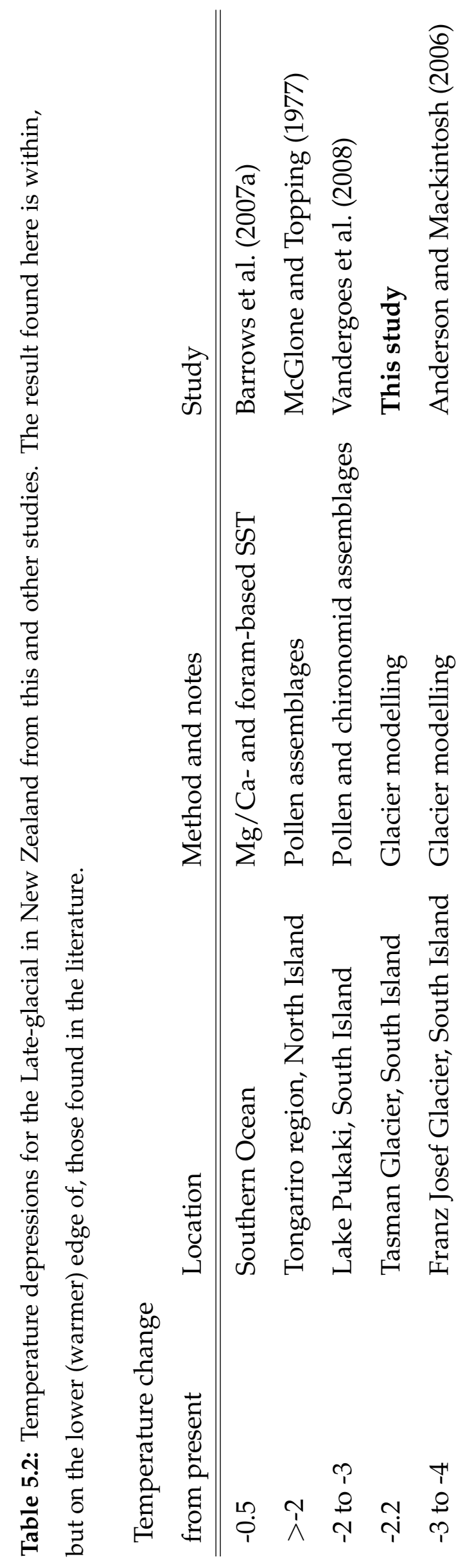


indicates glacier advance during the Antarctic Cold Reversal (Putnam et al., 2010) followed by retreat during the Younger Dryas (Kaplan et al., 2010). The speleothem $\partial^{18} \mathrm{O}$ record shows a New Zealand cold reversal, but it begins after the Antarctic Cold Reversal and continues to after the end of the Younger Dryas (Williams et al., 2005). Conversely, Barrows et al. (2007b) argue against a deviation from monotonic warming between the LGM and the Holocene based on SSTs near New Zealand and a new interpretation of the Waiho Loop moraine. While the consideration of equilibrium glacier states, as is done here, is not sufficient to provide answers to these questions, the application of a transient coupled glacier-erosion model may be helpful, and will be discussed below.

\subsubsection{Precipitation effects}

There is a limited trade-off between the effects of temperature and precipitation for both the Late-glacial and the LGM, although the effect is not consistent between the periods. For the LGM, a 10\% increase (decrease) in precipitation compensates for a $0.1^{\circ} \mathrm{C}$ increase (decrease) in temperature, although this effect does not hold for greater perturbations. The evidence for precipitation changes during the LGM is mixed, especially when focusing on the Southern Alps. All four of the PMIP2 models examined by Rojas et al. (2009) show that New Zealand was drier, independent of the movement of the storm tracks. For the Southern Alps, however, where most precipitation is of frontal origin and is enhanced by the high mountain peaks, the strength of the storm track may still be more important than a general drying of the atmosphere. Three out of four of the PMIP2 models show an increase in cyclone intensity during winter over the Southern Alps, which could cause local increases in precipitation over the Tasman glacier catchment. The dominance of orographic effects on precipitation in the region hinders solid conclusions about precipitation during the LGM, even if regional precipitation 
was known. The Late-glacial reconstruction exhibits more sensitivity to precipitation. A $10 \%$ increase in precipitation compensates for a $0.4^{\circ} \mathrm{C}$ increase in temperature, while a $10 \%$ decrease compensates for a $0.2^{\circ} \mathrm{C}$ decrease in temperature. The lower sensitivity during the LGM may be because of the larger amount of glacier surface area in the lower-precipitation zone farther from the Main Divide. Turney et al. (2003) interpreted pollen assemblages across New Zealand and has suggested that there was increased precipitation during the Late-glacial due to enhanced westerly circulation. Like the LGM, however, it may be necessary to consider precipitation over the Southern Alps distinct from New Zealand precipitation as a whole.

\subsubsection{Mass balance sensitivity}

The sensitivity of the model to each of the five parameters in the mass balance model was examined for the early LGM reconstruction. The model was most sensitive to the parameter scaling heat from shortwave solar radiation to melt. While all other LGM reconstructions required temperature depressions between 6.5 and $9^{\circ} \mathrm{C}$ colder than the present, the end member for the radiation parameter required a mean temperature $11.4^{\circ} \mathrm{C}$ less than present. This sensitivity may signify that the radiation term is not properly parameterised in the model. While the misfit between the model and the data with respect to the radiation parameter was not large across the entire range considered (see Figure 3.6), the smallest misfit was at the lowest values, at which the contribution from the insolation term is essentially negligible. This may in part be due to the use of a single parameter, rather than one for snow and one for ice, which does not take albedo effects into account. Because the magnitude of absorbed shortwave radiation scales directly with co-albedo, the model may be improved by using two parameters rather than one. Finally, while shortwave radiation contributes the second-most heat to melt (Ohmura, 2001), some work has shown that shortwave radiation does 
not correlate well with melt (Braithwaite and Olesen, 1984), so should not be used as a predictor. Additional misfit may occur because regional, rather than local, insolation is used here. Regional insolation does not take shading and aspect effects into account, which are influential in mountainous terrain (Hock, 1999; Arnold et al., 2006).

Two of the mass balance model parameters, $\mathrm{DDF}_{\text {snow }}$ and the snow/rain threshold, seem to exhibit non-linearities in the reconstructions with respect to their values. It would be informative to perform more model simulations using not only the end members of the parameters but also values between them to better determine patterns of model behaviour.

The $6.5-9.0^{\circ} \mathrm{C}$ range of temperature depressions for the early LGM is larger than is ideal for constraining past climate, and does not provide information about the relative likelihood of the values in the interval. Randomly varying all of the parameters within their reasonable ranges across a large number of model simulations would yield a probability distribution of temperatures. Placing prior distributions of the values of the model parameters would additionally improve the accuracy of the distribution.

\subsection{Glacier valley profiles}

The longitudinal profile of a glacier bed is difficult to determine for obvious reasons. Indirect methods, such as radar, gravity and seismic surveys, can be used to image the bed, but these can be expensive, time-consuming and/or logistically challenging for valley glaciers. As such, there is minimal research on the evolution of the glacier bed over time, or even at one point in time. It is thus challenging to model this process, due to the lack of data constraints. In this work, the glacier beds are instead calculated assuming a steady-state (zero net mass balance) as a function of the glacier surface profile, mass balance curve, and flow parameters (see Section 3.2.3). A feature that is evident in all of the profiles is a terminal overdeepening 
of the bed, a feature lacking in many theoretical models for bed evolution (Hooke, 1991; MacGregor et al., 2000; Anderson et al., 2006) but observed in the field by Alley et al. (2003) and proposed as a stabilising mechanism for glacier bed evolution. As previously mentioned, Alley et al. (2003) also suggested that the overdeepened bed should be $20-70 \%$ steeper than (and sloping in the opposite direction from) the overlying ice-air interface. This relationship is consistent with the LGM equilibrium surface profile. The calculated and present-day bed profiles support the conclusion that the beds of highly-erosive glaciers tend toward terminal overdeepenings.

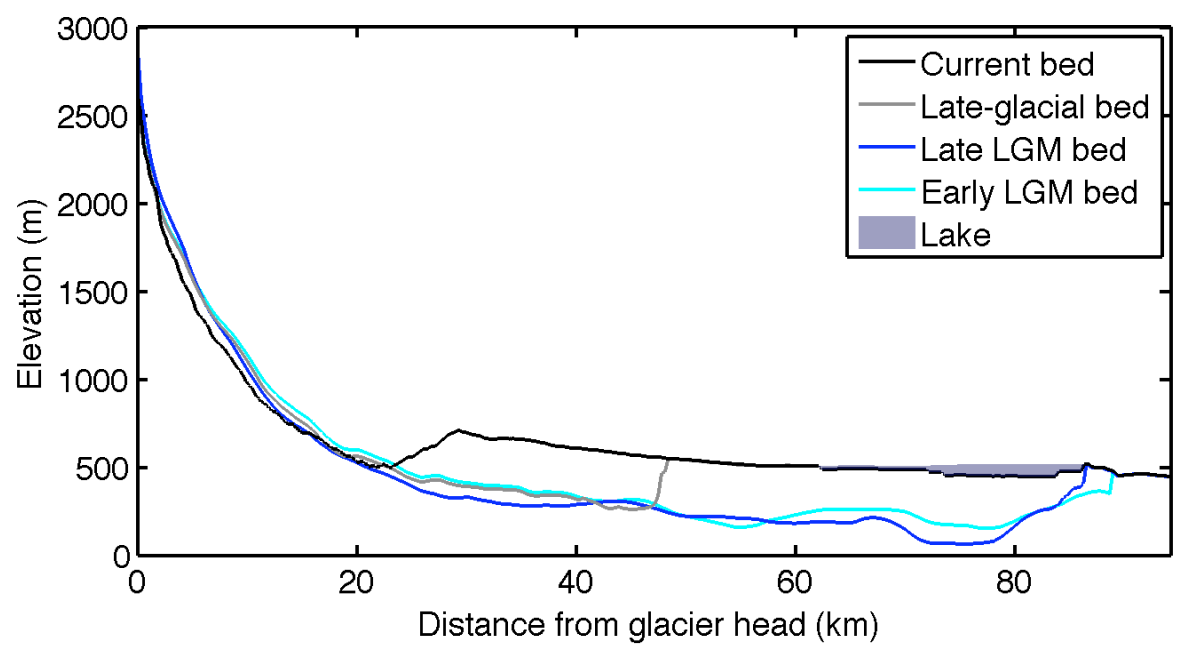

Figure 5.2: The bed profiles from the present-day, Late-glacial, early and late LGM. The first is interpolated based on data from Watson (1995), while the latter three are calculated using the method discussed in Section 3.2.3. It appears that the glacier has deposited large amount of sediment in the valley as it has retreated, and eroded terminal overdeepenings at each of its steady-states. Lake Pukaki is also shown.

While the bed reconstructions produced here cannot be objectively validated, they (1) are mathematically constrained by the flow equations governing glacier behaviour (Anderson et al., 2004), (2) are physically constrained by imaged bedrock (Kleffmann et al., 1998; Long et al., 2003), (3) produce features consistent with those seen on other highly erosive glaciers in the field 
(Alley et al., 2003), and (4) are consistent with other estimates of the magnitude of post-glacial sediment beneath Lake Pukaki (Shulmeister et al., 2010). For these reasons, it is reasonable to suggest that the bed profiles used in this study are reflective of the ones that existed during the Late-glacial and LGM steady-states. A comparison of all three bed profiles, as well as the estimate of the present-day profile, reveals the magnitude of change that a glacier valley system can accommodate (Figure 5.2). As the glacier retreated from its early LGM state, it deposited large amounts of sediment in the valley, filling in its previous trough. This is evident on the surface in the moraines between the early and late LGM maximum extents, and inferred for the subsurface based on the aforementioned factors. While periods of glacier advance are not considered here, it is plausible to imagine the system evolving in reverse time order, deepening its trough in the sediment layers as it advances.

Due to uncertainties about the exact elevation of the bedrock, simulations were performed where the bedrock was moved up and down 200 metres. Because the flow parameters change along with the bed profiles in the model employed, the temperature reconstruction was surprisingly robust to changes in the bed. Moving the bedrock lower in elevation resulted in the same temperature reconstruction as the original $7.0^{\circ} \mathrm{C}$ depression, while moving it up produced a $6.7^{\circ} \mathrm{C}$ depression. This does not, however, indicate that any bed may be used if appropriate flow parameters are chosen. The terminal overdeepening of the bed still appears to be necessary to produce the longitudinal profile of the glacier surface. It is encouraging that the model is minimally sensitive to the coupled flow parameter-bed profile boundary condition; this may indicate that a similar approach could be taken in other evacuated glacier valleys where there is no seismic data. 


\subsection{Future work}

A limitation in this work is the inability to model transient glacier behaviour due to the dependence on prescribed bed topography that changes between states. If not working in a hard bed system, a substantial avenue for future modelling work is the construction of a model with an interactive deformable sediment layer. Presently available data is likely insufficient to properly constrain a model such as this, however, so this approach would need to be coupled with field campaigns studying dynamic glaciers in sediment-rich basins. In the meantime, simpler approaches can be taken such as scaling erosion with ice velocity, calculating it from shear stresses, or modifying existing models (e.g. Braun et al., 1999; Pollard and DeConto, 2003) to better represent glacial processes over sediment surfaces.

The advantages of this approach are two-fold. First, the coupled model would allow for transient simulations of glacier extent, driven by a variety of climate reconstructions. The agreement or lack thereof between the model and the moraine record could help distinguish between the validity of different temperature reconstructions. Second, as discussed in Section 5.1.3, a coupled model could shed light on the path taken to get to a specific steadystate such as the Late-glacial. The bed profile, and thus the glacier profile, produced by a retreat followed by an advance would likely be distinct from that produced by a continuous retreat with a short stand-still. Since the lateral moraine record delineates the longitudinal profile of the glacier near the terminus, it is possible that only one of these paths would lead to the appropriate profile.

Application of the coupled model would also provide better constraints on the role of inter-annual, zero-trend variability in driving glacier length. The transition from the early to late LGM glacier extent modelled here offers a plausible null hypothesis that a climatic white noise could lead to glacier retreat; however, the argument is piece-wise because the white noise forcing 
could not actually be applied to an evolving glacier-sediment system. If the forcing was applied to the coupled system, better limits could be placed upon the magnitude of change that can occur due to this variability alone, and the dependence of that magnitude on variables such as the deformability of the sediment and ice velocity. Unfortunately, the introduction of this coupled model would necessarily lead to the loss of some of the advantages afforded by simple models, so the benefits of increasing complexity would need to be balanced against the drawbacks.

More generally, recent work has demonstrated that the cryosphere-solid earth system is closely coupled. Glaciers can be a dominating influence in modifying landscape on a large scale, by either limiting mountain range elevation (Egholm et al., 2009) or sheltering an active orogenic mountain belt from erosion, enhancing its elevation and extent (Thomson et al., 2010). Deglaciation may even lead to enhanced volcanism (Huybers and Langmuir, 2009), a powerful positive feedback cycle. Glaciers seem to offer a powerful connection between the atmosphere-ocean and solid earth systems.

\subsection{Concluding thoughts}

The moraine record for the Tasman glacier is used to constrain a coupled flowline-mass balance model in order to determine Late-glacial and LGM annual mean temperature. The model shows a $2.2^{\circ}$ temperature depression for the Late-glacial, and a $7.0^{\circ} \mathrm{C}$ temperature depression for the LGM, assuming present-day precipitation levels. The modelled Late-glacial Tasman Glacier is more sensitive to changes in precipitation than it is during the LGM, but changes in precipitation are less influential than changes in temperature in controlling glacier extent in the Late-glacial compared to the LGM. One-dimensional glacier modelling requires the bed profiles as a boundary condition, which are unknown but calculated here using established equations from the flowline model and glacier profiles based upon the moraine 
record. The bed profiles not only allow for better climate reconstructions but also illuminate the magnitude of erosion and deposition that may occur in a glacier valley on the geologically-short timescales of thousands of years.

The principles applied here can be applied to other glaciers in New Zealand in order to gain a more complete picture of the temporal and spatial variability of climate changes in New Zealand. This information will help fill in gaps in the knowledge regarding the last glacial cycle in the Southern Hemisphere, and its relationship to the Northern Hemisphere record. 


\section{Bibliography}

Allen, S.K., S. Gruber, and I.F. Owens (2009) "Exploring steep bedrock permafrost and its relationship with recent slope failures in the Southern Alps of New Zealand," Permafrost and Periglacial Processes, Vol. 20, No. 4, pp. 345-356.

Alley, R.B. (1992) "Flow-law hypotheses for ice-sheet modeling," Journal of Glaciology, Vol. 38, No. 129, pp. 245-256.

Alley, R.B., D.E. Lawson, G.J. Larson, E.B. Evenson, and G.S. Baker (2003) "Stabilizing feedbacks in glacier-bed erosion," Nature, Vol. 424, No. 6950, pp. $758-760$.

Alloway, B.V., D.J. Lowe, D.J.A. Barrell, R.M. Newnham, P.C. Almond, P.C. Augustinus, N.A.N. Bertler, L. Carter, N.J. Litchfield, M.S. McGlone et al. (2007) "Towards a climate event stratigraphy for New Zealand over the past 30000 years (NZ-INTIMATE project)," Journal of Quaternary Science, Vol. 22, No. 1, pp. 9-35.

Anderson, B.M., R.C.A. Hindmarsh, and W.J. Lawson (2004) "A modelling study of the response of Hatherton Glacier to Ross Ice Sheet grounding line retreat," Global and Planetary Change, Vol. 42, No. 1-4, pp. 143-153.

Anderson, B. and A. Mackintosh (2006) "Temperature change is the major driver of late-glacial and Holocene glacier fluctuations in New Zealand," Geology, Vol. 34, No. 2, p. 121. 
Anderson, R.S., P. Molnar, and M.A. Kessler (2006) “Features of glacial valley profiles simply explained," Journal of Geophysical Research, Vol. 111, No. F1, p. F01004.

Anderton, P.W., National Water, Soil Conservation Organisation (NZ), and N. Zealand (1975) Tasman Glacier 1971-73: Ministry of Works and Development for the National Water and Soil Conservation Organisation.

Arnold, N.S., W.G. Rees, A.J. Hodson, and J. Kohler (2006) “Topographic controls on the surface energy balance of a high Arctic valley glacier," Journal of geophysical research, Vol. 111, No. F2, p. F02011.

Bacon, S.N., T.J. Chinn, R.J. Van Dissen, S.F. Tillinghast, H.L. Goldstein, and R.M. Burke (2001) "Paleo-equilibrium line altitude estimates from late Quaternary glacial features in the Inland Kaikoura Range, South Island, New Zealand," New Zealand Journal of Geology and Geophysics, Vol. 44, No. 1, pp. 55-67.

Baral, D.R., K. Hutter, and R. Greve (2001) “Asymptotic theories of large-scale motion, temperature, and moisture distribution in land-based polythermal ice sheets: a critical review and new developments," Applied Mechanics Reviews, Vol. 54, p. 215.

Barbante, C., J.M. Barnola, S. Becagli, J. Beer, M. Bigler, C. Boutron, T. Blunier, E. Castellano, O. Cattani, J. Chappellaz et al. (2006) "One-to-one coupling of glacial climate variability in Greenland and Antarctica," Nature, Vol. 444, No. 7116, pp. 195-198.

Barrell, D.J.A., B.G. Andersen, and G.H Denton (2011) “Glacial geomorphology of the central South Island, New Zealand.," GNS Science monograph, Vol. 27.

Barringer, J.R.F. (1989) “A variable lapse rate snowline model for the Remark- 
ables, Central Otago, New Zealand.," Journal of Hydrology (NZ), Vol. 28, No. 1.

Barrows, T.T., S. Juggins, P. De Deckker, E. Calvo, and C. Pelejero (2007a) "Long-term sea surface temperature and climate change in the AustralianNew Zealand region," Paleoceanography, Vol. 22, No. 2, p. PA2215.

Barrows, T.T., S.J. Lehman, L.K. Fifield, and P. De Deckker (2007b) “Absence of cooling in New Zealand and the adjacent ocean during the Younger Dryas chronozone," Science, Vol. 318, No. 5847, p. 86.

Barrows, T.T. and S. Juggins (2005) "Sea-surface temperatures around the Australian margin and Indian Ocean during the Last Glacial Maximum," Quaternary Science Reviews, Vol. 24, No. 7-9, pp. 1017-1047.

Benn, D.I. and D.J.A. Evans (2010) “Glaciers and glaciation.," p. 73.

Berger, A. and M.F. Loutre (1991) "Insolation values for the climate of the last 10 million years," Quaternary Science Reviews, Vol. 10, No. 4, pp. 297-317.

Björnsson, H. (1996) "Scales and rates of glacial sediment removal: a $20 \mathrm{~km}$ long and $300 \mathrm{~m}$ deep trench created beneath Breiðamerkurjökull during the Little Ice Age," Annals of Glaciology, Vol. 22, pp. 141-146.

Boulton, G.S. (1978) "Processes of glacier erosion on different substrata," in Symposium on Glacier Beds: The Ice-Rock Interface, Proceedings of a Symposium held at Carleton University, Ottawa(Ontario) August 15-19, 1978. Journal of Glaciology, Vol. 23.

_ (1996) "Theory of glacial erosion, transport and deposition as a consequence of subglacial sediment deformation," Journal of Glaciology, Vol. 42, No. 140, pp. 43-62.

Boulton, GS, KE Dobbie, and S. Zatsepin (2001) "Sediment deformation beneath glaciers and its coupling to the subglacial hydraulic system," Quaternary International, Vol. 86, No. 1, pp. 3-28. 
Boulton, G.S. and R.C.A. Hindmarsh (1987) "Sediment deformation beneath glaciers: rheology and geological consequences," Journal of Geophysical Research, Vol. 92, No. B9, pp. 9059-9082.

Boulton, G.S. and A.S. Jones (1979) "Stability of temperate ice caps and ice sheets resting on beds of deformable sediment," Journal of Glaciology, Vol. 24, No. 90.

Braconnot, P., World Climate Research Programme, and P.G. Changes (2000) Paleoclimate Modelling Intercomparison Project (PMIP): Proceedings of the Third PMIP Workshop: La Huardière, Canada, 4-8 October 1999: World Climate Research Programme.

Braithwaite, R.J. (1995) “Positive degree-day factors for ablation on the Greenland ice sheet studied by energy-balance modelling," Journal of Glaciology, Vol. 41, No. 137, pp. 153-160.

Braithwaite, RJ and OB Olesen (1984) "Ice ablation in West Greenland in relation to air temperature and global radiation," Zeitschrift für Gletscherkunde und Glazialgeologie, Vol. 20, pp. 155-168.

Braithwaite, R.J. and O.B. Olesen (1989) “Calculation of glacier ablation from air temperature, west Greenland.," in Glacier fluctuations and climatic change: proceedings of the Symposium on Glacier Fluctuations and Climatic Change, held in Amsterdam, 1-5 June 1987, p. 219, Springer.

Brasseil, S.C., G. Eglinton, I.T. Marlowe, U. Pflaumann, and M. Sarnthein (1986) "Molecular stratigraphy: a new tool for climatic assessment," $\mathrm{Na}$ ture, Vol. 320, pp. 129-133.

Braun, J., D. Zwartz, and J.H. Tomkin (1999) “A new surface-processes model combining glacial and fluvial erosion," Annals of Glaciology, Vol. 28, No. 1, pp. 282-290. 
Broecker, W.S., G.H. Denton, R.L. Edwards, H. Cheng, R.B. Alley, and A.E. Putnam (2010) "Putting the Younger Dryas cold event into context," Quaternary Science Reviews, Vol. 29, No. 9-10, pp. 1078-1081.

Budd, W.F., P.L. Keage, and N.A. Blundy (1979) “Empirical studies of ice sliding," J. Glaciol, Vol. 23, No. 89, pp. 157-170.

Calov, R. and R. Greve (2005) "A semi-analytical solution for the positive degree-day model with stochastic temperature variations," Journal of Glaciology, Vol. 51, No. 172, pp. 173-175.

Carter, L. (2001) "Currents of change: the ocean flow in a changing world," Water \& Atmosphere 9 (4), pp. 15-17.

Chinn, T.J.H. (1994) "Snow and ice balance measurements from the Tasman Glacier, Waitaki Catchment, New Zealand,"Technical report, GNS Science.

Cox, S.C. and R.H. Findlay (1995) “The Main Divide Fault Zone and its role in formation of the Southern Alps, New Zealand," New Zealand journal of geology and geophysics, Vol. 38, No. 4, pp. 489-499.

Cutler, E.S. and B. Fitzharris (2005) “Observed surface snowmelt at high elevation in the Southern Alps of New Zealand," Annals of Glaciology, Vol. 40, No. 1, pp. 163-168.

Dieffenbacher-Krall, A.C., M.J. Vandergoes, and G.H. Denton (2007) “An inference model for mean summer air temperatures in the Southern Alps, New Zealand, using subfossil chironomids," Quaternary Science Reviews, Vol. 26, No. 19-21, pp. 2487-2504.

Drost, F., J. Renwick, B. Bhaskaran, H. Oliver, and J. McGregor (2007) “A simulation of New Zealand's climate during the Last Glacial Maximum," Quaternary Science Reviews, Vol. 26, No. 19-21, pp. 2505-2525. 
Dykes, R.C., M.S. Brook, C.M. Robertson, and I.C. Fuller (2011) “Twenty-First Century Calving Retreat of Tasman Glacier, Southern Alps, New Zealand," Arctic, Antarctic, and Alpine Research, Vol. 43, No. 1, pp. 1-10.

Egholm, D.L., S.B. Nielsen, V.K. Pedersen, and J.-E. Lesemann (2009) “Glacial effects limiting mountain height," Nature, Vol. 460, pp. 884-888.

Egholm, D.L., M.F. Knudsen, C.D. Clark, and J.E. Lesemann (2011) “Modeling the flow of glaciers in steep terrains: The integrated second-order shallow ice approximation (iSOSIA)," Journal of Geophysical Research, Vol. 116, No. F2, p. F02012.

Fitzharris, B.B., T.J. Chinn, and G.N. Lamont (1997) “Glacier balance fluctuations and atmospheric circulation patterns over the Southern Alps, New Zealand," International journal of climatology, Vol. 17, No. 7, pp. 745-763.

Fitzharris, B.B., G.R. Clare, and J. Renwick (2007) “Teleconnections between Andean and New Zealand glaciers," Global and Planetary Change, Vol. 59, No. 1-4, pp. 159-174.

Gage, M. and R.P. Suggate (1958) "Glacial chronology of the New Zealand Pleistocene," Geological Society of America Bulletin, Vol. 69, No. 5, p. 589.

Glen, J.W. (1955) “The creep of polycrystalline ice," Proceedings of the Royal Society of London. Series A. Mathematical and Physical Sciences, Vol. 228, No. 1175 , p. 519.

(1958) "The flow law of ice: A discussion of the assumptions made in glacier theory, their experimental foundations and consequences," IASH Publ, Vol. 47, pp. 171-183.

Greuell, W. and R. Böhm (1998) “2 m temperatures along melting midlatitude glaciers, and implications for the sensitivity of the mass balance to variations in temperature," Journal of Glaciology, Vol. 44, No. 146, pp. 9-20. 
Hales, T.C. and J.J. Roering (2009) "A frost"buzzsaw" mechanism for erosion of the eastern Southern Alps, New Zealand," Geomorphology, Vol. 107, No. 3-4, pp. 241-253.

Hallet, B., L. Hunter, and J. Bogen (1996) “Rates of erosion and sediment evacuation by glaciers: A review of field data and their implications," Global and Planetary Change, Vol. 12, No. 1-4, pp. 213-235.

Harrison, W.D. (1972) “Temperature of a temperate glacier," J. Glaciol, Vol. 11, No. 61, pp. 15-29.

Hart, J.K. (1996) "Proglacial glaciotectonic deformation associated with glaciolacustrine sedimentation, Lake Pukaki, New Zealand," Journal of Quaternary Science, Vol. 11, No. 2, pp. 149-160.

Hawkins, F.F. (1985) “Equilibrium-line altitudes and paleoenvironment in the Merchants Bay area, Baffin Island, NWT, Canada," Journal of Glaciology, Vol. 31, No. 109, pp. 205-213.

Hellstrom, J., M. McCulloch, and J. Stone (1998) “A Detailed 31,000-Year Record of Climate and Vegetation Change, from the Isotope Geochemistry of Two New Zealand Speleothems," Quaternary Research, Vol. 50, No. 2, pp. $167-178$.

Henderson, R.D. and S.M. Thompson (1999) “Extreme rainfalls in the Southern Alps of New Zealand," Journal of Hydrology (NZ), Vol. 38, No. 2, pp. 309-330.

Hindmarsh, R.C.A. (2001) “Notes on basic glaciological computational methods and algorithms," Continuum Mechanics and Applications in Geophysics and the Environment, pp. 222-249.

_ (2006) "Stress gradient damping of thermoviscous ice flow instabilities," Journal of geophysical research, Vol. 111, No. B12, p. B12409. 
Hochstein, M.P., D. Claridge, S.A. Henrys, A. Pyne, D.C. Nobes, and S.F. Leary (1995) "Downwasting of the Tasman Glacier, South Island, New Zealand: changes in the terminus region between 1971 and 1993," New Zealand journal of geology and geophysics, Vol. 38, No. 1, pp. 1-16.

Hock, R. (1999) “A distributed temperature-index ice-and snowmelt model including potential direct solar radiation," Journal of Glaciology, Vol. 45, No. 149, pp. 101-111.

__ (2003) "Temperature index melt modelling in mountain areas," Journal of Hydrology, Vol. 282, No. 1-4, pp. 104-115.

_ (2005) "Glacier melt: a review of processes and their modelling," Progress in physical geography, Vol. 29, No. 3, p. 362.

Hooke, R.L.E.B. (1991) "Positive feedbacks associated with erosion of glacial cirques and overdeepenings," Bulletin of the Geological Society of America, Vol. 103, No. 8, p. 1104.

Hooker, BL and BB Fitzharris (1999) "The correlation between climatic parameters and the retreat and advance of Franz Josef Glacier, New Zealand," Global and Planetary Change, Vol. 22, No. 1-4, pp. 39-48.

Hutter, K. (1983) Theoretical glaciology: Reidel.

Huybers, P. (2006) "Early Pleistocene glacial cycles and the integrated summer insolation forcing," Science, Vol. 313, No. 5786, p. 508.

Huybers, P. and C. Langmuir (2009) "Feedback between deglaciation, volcanism, and atmospheric CO2," Earth and Planetary Science Letters, Vol. 286, No. 3-4, pp. 479-491.

Ivy-Ochs, S., C. Schlüchter, P.W. Kubik, and G.H. Denton (1999) “Moraine exposure dates imply synchronous Younger Dryas glacier advances in the 
European Alps and in the Southern Alps of New Zealand," Geografiska Annaler: Series A, Physical Geography, Vol. 81, No. 2, pp. 313-323.

Jouzel, J., V. Masson, O. Cattani, S. Falourd, M. Stievenard, B. Stenni, A. Longinelli, S.J. Johnsen, J.P. Steffenssen, J.R. Petit et al. (2001) “A new 27 ky high resolution East Antarctic climate record," Geophysical Research Letters, Vol. 28, No. 16, pp. 3199-3202.

Kamb, B. and K. Echelmeyer (1986) "Stress-gradient coupling in glacier flow. I: Longitudinal averaging of the influence of ice thickness and surface slope," Journal of Glaciology, Vol. 32, No. 111, pp. 267-284.

Kaplan, M.R., A.S. Hein, A. Hubbard, and S.M. Lax (2009) "Can glacial erosion limit the extent of glaciation?" Geomorphology, Vol. 103, No. 2, pp. 172-179.

Kaplan, M.R., J.M. Schaefer, G.H. Denton, D.J.A. Barrell, T.J.H. Chinn, A.E. Putnam, B.G. Andersen, R.C. Finkel, R. Schwartz, and A.M. Doughty (2010) "Glacier retreat in New Zealand during the Younger Dryas stadial," Nature, Vol. 467, No. 7312, pp. 194-197.

Kerr, T.R. (2005) "Snow storage modelling in the Lake Pukaki catchment, New Zealand: an investigation of enhancements to the snowsim model."

Kienzle, S.W. (2008) "A new temperature based method to separate rain and snow," Hydrological Processes, Vol. 22, No. 26, pp. 5067-5085.

Kirkbride, M. (1989) "The influence of sediment budget on geomorphic activity of the Tasman Glacier, Mount Cook National Park, New Zealand."

Kirkbride, M.P. (1995) "Relationships between temperature and ablation on the Tasman Glacier, Mount Cook National Park, New Zealand," New Zealand Journal of Geology and Geophysics, Vol. 38, No. 1, pp. 17-27. 
Kirkbride, M.P. and C.R. Warren (1999) “Tasman Glacier, New Zealand: 20th-century thinning and predicted calving retreat," Global and Planetary Change, Vol. 22, No. 1-4, pp. 11-28.

Kleffmann, S., F. Davey, A. Melhuish, D. Okaya, and T. Stern (1998) “Crustal structure in the central South Island, New Zealand, from the Lake Pukaki seismic experiment," New Zealand Journal of Geology and Geophysics, Vol. 41, No. 1, pp. 39-49.

Koppes, M.N. and D.R. Montgomery (2009) "The relative efficacy of fluvial and glacial erosion over modern to orogenic timescales," Nature Geoscience, Vol. 2, No. 9, pp. 644-647.

Le Meur, E., O. Gagliardini, T. Zwinger, and J. Ruokolainen (2004) "Glacier flow modelling: a comparison of the Shallow Ice Approximation and the full-Stokes solution," Comptes Rendus Physique, Vol. 5, No. 7, pp. 709-722.

Long, D.T., S.C. Cox, S. Bannister, M.C. Gerstenberger, and D. Okaya (2003) "Upper crustal structure beneath the eastern Southern Alps and the Mackenzie Basin, New Zealand, derived from seismic reflection data," New Zealand Journal of Geology and Geophysics, Vol. 46, No. 1, pp. 21-40.

MacGregor, K.R., R.S. Anderson, S.P. Anderson, and E.D. Waddington (2000) "Numerical simulations of glacial-valley longitudinal profile evolution," Geology, Vol. 28, No. 11, p. 1031.

Mager, S. and S. Fitzsimons (2007) "Formation of glaciolacustrine Late Pleistocene end moraines in the Tasman Valley, New Zealand," Quaternary Science Reviews, Vol. 26, No. 5-6, pp. 743-758.

Marra, M.J., J. Shulmeister, and E.G.C. Smith (2006) “Reconstructing temperature during the Last Glacial Maximum from Lyndon Stream, South Island, New Zealand using beetle fossils and maximum likelihood envelopes," Quaternary Science Reviews, Vol. 25, No. 15-16, pp. 1841-1849. 
McCarthy, A., A. Mackintosh, U. Rieser, and D. Fink (2008) "Mountain Glacier Chronology from Boulder Lake, New Zealand, Indicates MIS 4 and MIS 2 Ice Advances of Similar Extent," Arctic, Antarctic, and Alpine Research, Vol. 40, No. 4, pp. 695-708.

McCrea, J.M. (1950) “On the isotopic chemistry of carbonates and a paleotemperature scale," The Journal of Chemical Physics, Vol. 18, p. 849.

McGlone, M.S. and W.W. Topping (1977) "Aranuian (post-glacial) pollen diagrams from the Tongariro region, North Island, New Zealand," New Zealand journal of botany, Vol. 15, pp. 749-760.

Meier, M.F. and A.S. Post (1962) "Recent variations in mass net budgets of glaciers in western North America," in Symposium of Obergurgl, pp. 63-77.

Mullan, B. (1996) "Effects of ENSO on New Zealand and the south Pacific," Prospects and needs for climate forecasting. Miscellaneous Series, Vol. 34, pp. 23-27.

Newnham, R.M., D.J. Lowe, T. Giles, and B.V. Alloway (2007a) “Vegetation and climate of Auckland, New Zealand, since ca. 32000 cal. yr ago: support for an extended LGM," Journal of Quaternary Science, Vol. 22, No. 5, pp. 517534.

Newnham, R.M., M.J. Vandergoes, C.H. Hendy, D.J. Lowe, and F. Preusser (2007b) "A terrestrial palynological record for the last two glacial cycles from southwestern New Zealand," Quaternary Science Reviews, Vol. 26, No. 3-4, pp. 517-535.

Newnham, R.M. and D.J. Lowe (2000) “Fine-resolution pollen record of lateglacial climate reversal from New Zealand," Geology, Vol. 28, No. 8, p. 759.

Oerlemans, J. (1984) “Numerical experiments on glacial erosion," Zeitschrift für Gletscherkunde und Glazialgeologie, Vol. 20, pp. 107-126. 
_ (1986) "An attempt to simulate historic front variations of Nigardsbreen, Norway," Theoretical and applied climatology, Vol. 37, No. 3, pp. 126135.

_ (1989) "On the response of valley glaciers to climatic change."

_ (1997) "Climate sensitivity of Franz Josef Glacier, New Zealand, as revealed by numerical modeling," Arctic and Alpine Research, Vol. 29, No. 2, pp. 233-239.

_ (2001) Glaciers and climate change: Taylor \& Francis.

_ (2002) "On glacial inception and orography," Quaternary International, Vol. 95, pp. 5-10.

(2005) “Extracting a climate signal from 169 glacier records," Science, Vol. 308, No. 5722, p. 675.

Oerlemans, J., B. Anderson, A. Hubbard, P. Huybrechts, T. Johannesson, W.H. Knap, M. Schmeits, A.P. Stroeven, R.S.W. Van de Wal, J. Wallinga et al. (1998) "Modelling the response of glaciers to climate warming," Climate Dynamics, Vol. 14, No. 4, pp. 267-274.

Oerlemans, J. and B.K. Reichert (2000) “Relating glacier mass balance to meteorological data by using a seasonal sensitivity characteristic," Journal of Glaciology, Vol. 46, No. 152, pp. 1-6.

Oerlemans, J. and CJ Van der Veen (1984) Ice sheets and Climate: Reidel.

Ohmura, A. (2001) "Physical basis for the temperature-based melt-index method," Journal of Applied Meteorology, Vol. 40, No. 4, pp. 753-761.

Paterson, W.S.B. (1994) The physics of glaciers: Pergamon, New York.

Pelletier, J.D. (2008) “Glacial erosion and mountain building," Geology, Vol. 36, No. 7, p. 591. 
Pollard, D. and R.M. DeConto (2003) "Antarctic ice and sediment flux in the Oligocene simulated by a climate-ice sheet-sediment model," Palaeogeography, Palaeoclimatology, Palaeoecology, Vol. 198, pp. 53-67.

Porter, S.C. (1975) “Equilibrium-line altitudes of late Quaternary glaciers in the Southern Alps, New Zealand," Quaternary research, Vol. 5, No. 1, pp. $27-47$.

Purdie, H., B. Anderson, W. Lawson, and A. Mackintosh (2010) “Controls on spatial variability in snow accumulation on glaciers in the Southern Alps, New Zealand; as revealed by crevasse stratigraphy," Hydrological Processes.

Purdie, J. and B. Fitzharris (1999) "Processes and rates of ice loss at the terminus of Tasman Glacier, New Zealand," Global and Planetary Change, Vol. 22, No. 1-4, pp. 79-91.

Putnam, A.E., G.H. Denton, J.M. Schaefer, D.J.A. Barrell, B.G. Andersen, R.C. Finkel, R. Schwartz, A.M. Doughty, M.R. Kaplan, and C. Schlüchter (2010) "Glacier advance in southern middle-latitudes during the Antarctic Cold Reversal," Nature Geoscience, Vol. 3, No. 10, pp. 700-704.

Roe, G.H. and M.A. O'Neal (2009) "The response of glaciers to intrinsic climate variability: observations and models of late-Holocene variations in the Pacific Northwest," Journal of Glaciology, Vol. 55, No. 193, pp. 839-854.

Rojas, M., P. Moreno, M. Kageyama, M. Crucifix, C. Hewitt, A. Abe-Ouchi, R. Ohgaito, E.C. Brady, and P. Hope (2009) “The Southern Westerlies during the last glacial maximum in PMIP2 simulations," Climate Dynamics, Vol. 32, No. 4, pp. 525-548.

Rother, H. and J. Shulmeister (2006) "Synoptic climate change as a driver of late Quaternary glaciations in the mid-latitudes of the Southern Hemisphere," Climate of the Past, Vol. 2, No. 1, pp. 11-19. 
Ruddell, A.R. (1995) "Recent glacier and climate change in the New Zealand Alps. Unpub," Ph.D. dissertation, Ph. D. thesis, School of Earth Sciences, University of Melbourne, Melbourne.

Samson, C.R., E.L. Sikes, and W.R. Howard (2005) “Deglacial paleoceanographic history of the Bay of Plenty, New Zealand," Paleoceanography, Vol. 20, No. 4, p. PA4017.

Sandiford, A., R. Newnham, B. Alloway, and J. Ogden (2003) “A 28 000$7600 \mathrm{cal}$ yr BP pollen record of vegetation and climate change from Pukaki Crater, northern New Zealand," Palaeogeography, Palaeoclimatology, Palaeoecology, Vol. 201, No. 3-4, pp. 235-247.

Schaefer, J.M., G.H. Denton, D.J.A. Barrell, S. Ivy-Ochs, P.W. Kubik, B.G. Andersen, F.M. Phillips, T.V. Lowell, and C. Schlüchter (2006) "Nearsynchronous interhemispheric termination of the last glacial maximum in mid-latitudes," Science, Vol. 312, No. 5779, p. 1510.

Schaefer, J.M., G.H. Denton, M. Kaplan, A. Putnam, R.C. Finkel, D.J.A. Barrell, B.G. Andersen, R. Schwartz, A. Mackintosh, T. Chinn et al. (2009) "High-frequency Holocene glacier fluctuations in New Zealand differ from the northern signature," science, Vol. 324, No. 5927, p. 622.

Shulmeister, J., P. Shane, O.B. Lian, M. Okuda, J.A. Carter, M. Harper, W. Dickinson, P. Augustinus, and H. Heijnis (2001) "A long lateQuaternary record from Lake Poukawa, Hawke's Bay, New Zealand," Palaeogeography, Palaeoclimatology, Palaeoecology, Vol. 176, No. 1-4, pp. 81107.

Shulmeister, J., D. Fink, O.M. Hyatt, G.D. Thackray, and H. Rother (2010) "Cosmogenic 10Be and 26Al exposure ages of moraines in the Rakaia Valley, New Zealand and the nature of the last termination in New Zealand glacial systems," Earth and Planetary Science Letters. 
Sikes, E.L., W.R. Howard, H.L. Neil, and J.K. Volkman (2002) “Glacialinterglacial sea surface temperature changes across the subtropical front east of New Zealand based on alkenone unsaturation ratios and foraminiferal assemblages," Paleoceanography, Vol. 17, No. 2, p. 1012.

Spall, J.C. (2003) Introduction to stochastic search and optimization: estimation, simulation, and control: John Wiley and Sons.

Stuart, S.J. (2011) “Observations and Modelling of Precipitation in the Southern Alps of New Zealand," Master's thesis, Victoria University of Wellington.

Sugden, D.E. and B.S. John (1985) Glaciers and landscape: Arnold.

Suggate, R.P. and P.C. Almond (2005) "The last glacial maximum (LGM) in western South Island, New Zealand: implications for the global LGM and MIS 2," Quaternary Science Reviews, Vol. 24, No. 16-17, pp. 1923-1940.

Thomson, S.N., M.T. Brandon, J.H. Tomkin, P.W. Reiners, C. Vásquez, and N.J. Wilson (2010) “Glaciation as a destructive and constructive control on mountain building," Nature, Vol. 467, No. 7313, pp. 313-317.

Truffer, M., K.A. Echelmeyer, and W.D. Harrison (2001) "Implications of till deformation on glacier dynamics," Journal of Glaciology, Vol. 47, No. 156, pp. 123-134.

Turney, C.S.M., M.S. McGlone, and J.M. Wilmshurst (2003) “Asynchronous climate change between New Zealand and the North Atlantic during the last deglaciation," Geology, Vol. 31, No. 3, p. 223.

Urey, H.C. (1948) "Oxygen isotopes in nature and in the laboratory," Science, Vol. 108, No. 2810, pp. 489-496.

Vandergoes, M.J., A.C. Dieffenbacher-Krall, R.M. Newnham, G.H. Denton, and M. Blaauw (2008) "Cooling and changing seasonality in the Southern 
Alps, New Zealand during the Antarctic Cold Reversal," Quaternary Science Reviews, Vol. 27, No. 5-6, pp. 589-601.

Vandergoes, M.J. and S.J. Fitzsimons (2003) “The Last Glacial-Interglacial transition (LGIT) in south Westland, New Zealand: paleoecological insight into mid-latitude Southern Hemisphere climate change," Quaternary science reviews, Vol. 22, No. 14, pp. 1461-1476.

Van der Veen, C.J. (1999) "Evaluating the performance of cryospheric models," Polar Geography, Vol. 23, No. 2, pp. 83-96.

Watson, M.I. (1995) "Geophysical and glaciological studies of the Tasman and Mueller Glaciers," Ph.D. dissertation, Applied Geology-University of Auckland.

Weaver, P.P.E., L. Carter, and H.L. Neil (1998) "Response of surface water masses and circulation to late Quaternary climate change east of New Zealand," Paleoceanography, Vol. 13, No. 1, pp. 70-83.

Weertman, J. (1964) "The theory of glacier sliding," Journal of Glaciology, Vol. 5, pp. 287-303. (1973) “Creep of ice," Physics and chemistry of ice, pp. 320-337.

Williams, P.W., D.N.T. King, J.X. Zhao, and K.D. Collerson (2005) “Late Pleistocene to Holocene composite speleothem $18 \mathrm{O}$ and $13 \mathrm{C}$ chronologies from South Island, New Zealand-did a global Younger Dryas really exist?" Earth and Planetary Science Letters, Vol. 230, No. 3-4, pp. 301-317.

Williams, P.W., H.L. Neil, and J.X. Zhao (2010) “Age frequency distribution and revised stable isotope curves for New Zealand speleothems: palaeoclimatic implications," International Journal of Speleology, Vol. 39, No. 2, pp. $99-112$. 
Wilmshurst, J.M., M.S. McGlone, J.R. Leathwick, and R.M. Newnham (2007) "A pre-deforestation pollen-climate calibration model for New Zealand and quantitative temperature reconstructions for the past 18000 years BP," Journal of Quaternary Science, Vol. 22, No. 5, pp. 535-547.

Yang, Z.L., R.E. Dickinson, A. Robock, and K.Y. Vinnikov (1997) “Validation of the snow submodel of the Biosphere-Atmosphere Transfer Scheme with Russian snow cover and meteorological observational data," Journal of Climate, Vol. 10, No. 2, pp. 353-373. 